\title{
Die phyletische Entfaltung der Sinnesorgane der Säugetierzunge.
}

\author{
Von
}

B. Haller.

Hierzu Tafel XIX-XXI und 36 Textfiguren.

'Trotz der zahlreichen Errungenschaften über den Bau der Sinnesorgane des Geschmackes der Saugetiere, die seit der Entdeckung der Geschmacksknospen an den Wall- und Pilzpapillen durch Loven und G. Schwalbe erzielt wurden, bleiben manche Fragen bezüglich der Phylogenese unbeantwortet. Es- ist festgestellt worden, dass die pilzformigen Papillen gleich von Anfang an an der Saugetierzunge in grosser Zahl sich finden und besonders durch die vorletzte Veröffentlichung Oppels (18) steht es ausser Zweifel, dass sich die Wallpapillen überall, bei allen Abteilungen sich vorfinden, und dass auch die Papillae foliatae, deren Gesamtheit das Randorgan darstellt, bereits bei den Monotremen auftreten. Es ist somit die Saugetierzunge, so wie sie sich diesbezüglich bei den Monotremen findet, schon etwas bis zu einem gewissen Grade fertiges und die beginnenden Zustande finden sich unter den rezenten Säugetieren nicht mehr.

Jene Fragen, die ich zurzeit für unbeantwortet bezeichne, beziehen sich somit zum Teil auf die Weitergestaltung aus Monotremenzustanden, an die der Anschluss bei anderen höher stehenden, aber immerhin noch niederen Saugetieren bekannt ist. Es sind dies die Fragen nach der Gruppierung der Pilzpapillen, spăter die Entstehung der Wallpapillen und die Vergrösserung beziehentlich Verminderung des Randorganes bei den verschiedenen $\mathrm{Ab}$ teilungen. Mit der Beantwortung dieser Fragen ist aber die Phylogenese der Zungenoberflache geklart und wirft sich dann die andere Frage, die nach den vorsăugetierlichen Zustanden, auf.

Sind auch bezüglich des Entstehens neuer Wallpapillen aus anderen Papillen Vermutungen schon öfter ausgesprochen worden, so ist es doch die Errungenschaft der neuesten Zeit und das 
Verdienst J. Beckers (2), diese Erklärungen bestimmter gefasst zu haben. Er fasst seine Anschauung wie folgt zusammen: „Die Papillae vallatae haben sich aus den praexistierenden Zungenpapillen, in erster Linie aus den Papillae fungiformes durch das Hinzutreten von Geschmacksdrüsen gebildet. Ihrer Zusammensetzung nach kann man sie in drei Ordnungen einteilen: Eine Wallpapille I. Ordnung ist hervorgegangen aus einer einfachen Papilla fungiformis, eine Wallpapille II. Ordnung ist hervorgegangen aus drei oder mehreren Papillae fungiformes, eine Wallpapille III. Ordnung ist hervorgegangen aus der Vereinigung von Papillae filiformes oder fungiformes. Eine Papille der dritten Ordnung kann auch als ein durch einen tiefen Graben abgesetztes Teil der Zungenschleimhaut angesehen werden. Übergangsformen von den Papillae fungiformes $\mathrm{zu}$ den Papillae vallatae kommen vor.

Die serösen Drüsen sind ureigene Gebilde und entstehen nicht in Abhangigkeit oder als ein Produkt von Papillen. Sie vereinigen sich aber mit solchen aus $Z$ weckmasssigkeitsgründen.

Das Randorgan (Papilla foliata) ist, soweit es sich um die hier untersuchten Tiere handelt, nicht aus der Papilla vallata hervorgegangen, auch nicht aus der Papilla fungiformis, sondern dieses Organ stellt ausschliesslich einen unter dem Einfluss der zugehörigen serösen Drüsen veränderten Schleimhautteil der Zunge dar. Die Leisten sind keine veränderten Pilz- oder Wallpapillen, sondern entsprechen dem Wall der Wallpapillen ... Die Furchen entstehen zunăchst durch zapfenförmige Tiefenwucherung des Oberflichenepithels, durch welches das Drüsensekret, einen Sekretkanal bildend, nach aussen sich Bahn bricht. Durch Verschmelzung dieser Sekretkanale entstehen dann Sekretbehälter in Form von Gräben und Furchen. In der Wand der Sekretkanäle, nicht in der der Ausführgänge, die ja an ersteren ihr Ende erreichen, entstehen Geschmacksknospen.

Das Vorkommen von Randorganen, die aus mehr oder weniger verănderten Pilzpapillen hervorgegangen sind und eine den Wallpapillen mehr oder weniger abnliche Form zeigen, ist nicht ausgeschlossen, und es ist anzunehmen, dass in diesen Făllen bezw. bei den betreffenden Tierfamilien zur Zeit der Entstehung der serösen Drüsen an der Stelle des Randorgans noch gut erhaltene Pilzpapillen vorhanden waren" (1. c. pag. 614-615). 
Wie weit es Becker gelungen ist, seine Auffassung zu stützen oder zu erharten, möge am Schluss besprochen werden, nachdem das, was mir an Einzelbeobachtungen festzustellen gelang, mitgeteilt ward.

Es sollen die diesbezüglichen Verhältnisse getrennt für die einzelnen Abteilungen behandelt werden, bei denen die Bearbeitung insofern ungleich ausfiel, als ich nicht von allen Abteilungen schnittfăhiges Material besass. ${ }^{1}$ )

Das frische Material wurde in $10 \%$ Formalinlösung gehärtet und entweder mit Eosin-Hämatoxylin oder mit Methylenblatz gefärbt. Letzteres wurde zum Schlusse ausschliesslich verwendet, da Methylenblau die Schleimdrüsen tiefblau, die serösen Drüsen aber nur ganz hellblau (meergrün) fărbt und so eine Doppelfärbung völlig ersetzt. Bevor die Schnitte in Methylenblau gebracht wurden, wurden sie zuvor in eine Alaunlösung (3-4 gr Alaun in $100 \mathrm{ccm}$ Wasser) gebracht, dann ausgewaschen.

\section{A. Monotremen.}

Bezüglich der Monotremen fehlen mir eigene Beobachtungen und sollen hier hauptsăchlich die Ergebnisse Poultons (21) und Oppels (1. c.) wiedergegeben werden.

Zuerst möchte ich hier die Zustände der Zunge von Ornithorhynchus besprechen, da meiner Meinung nach sich hier in mancher Beziehung ursprünglichere Zustande zeigen als bei Echidna. Bekanntlich zerfällt die Ornithorhynchuszunge in einen vorderen und einen hinteren Abschnitt. Der hintere muskulösere, von oben gesehen runde Abschnitt endigt nach vorne zu mit zwei Hornpapillen und ist ausserdem der Träger der Geschmacksorgane. Der vordere Abschnitt ist dagegen, besonders der Spitze $\mathrm{zu}$, weniger muskulös, und nach 0 ppel mehr von drüsigem $\mathrm{Bau}$, indem Schleimdrüsen ihn hauptsăchlich ausfüllen.

Die Geschmacksorgane bestehen je ans einer grossen Papilla vallata auf jeder Seite, die gleich hinter dem vorderen Ende des hinteren Abschnittes, nahe beieinander hinter den Hornpapillen, gelegen sind. Die hinteren Sinnesorgane sind die Randorgane (Papillae foliatae) und liegen auf jeder Seite $n$ am hintersten Teil

1) Für die makroskopische Untersuchung standen mir die Präparate der hiesigen anatomischen Sammlung zur Verfïgung, wofür ich hier bestens danken möchte! 
der Zunge, dort, wo sich die Schleimhaut der Zunge auf die des Gaumens umschlägt".

Über die beiden Wallpapillen, die tief versenkt sind, keinen erhabenen Wall aufweisen und an ihrer Dorsalfache keine Geschmacksknospen tragen, sagt $O p p e 1$, der diesbezüglich in das Wesen der Gebilde tiefer eindrang als Poulton: „Es ist richtiger, die die Geschmacksknospen tragenden Organe als Kämme oder Leisten, denn als Papillen zu bezeichnen, da es sich um mehr in der Längsrichtung als in der Breite ausgedehnte, am Anfang und Ende weniger als in der Mitte emporragende Erhebungen handelt. Doch erscheinen dieselben bei Ornithorhynchus einheitlicher, also weniger stark gelappt als bei Echidna".

Bezüglich der viel kleineren Papillen des Randorganes, deren Zahl bei Ornithorhynchus jederseits eins, bei Echidna aber jederseits $3-5$ betrăgt, ist 0 p pels Ergebnis, dass sie ihrer For'm nach kleine versenkte, den Wallpapillen anderer Sauger ganz ähnliche, seitwärts (Echidna) oder "auf ihrer Oberfläche ${ }^{\text {" }}$ (Ornithorhynchus) mit Geschmacksknospen versehene Gebilde sind.

Die serösen Drüsen der Schnabeltierzunge gruppieren sich entsprechend den ihnen zugehörigen Sinnesorganen in drei Gruppen. Eine mittlere Gruppe umgibt die beiden grossen Wallpapillen, je eine kleinere oberflächlichere Gruppe das Randorgan. Eigenartig und in ihrer Art einzig bei Saugetieren ware nach Oppel das Verbalten der Schleimdrüsen. - wodurch Ornithorhynchus auch von Echidna sich stark entfernen würde -, denn sie bestehen „aus zwei Gruppen, einer hinteren und einer vorderen, welche miteinander nicht in Verbindung stehen". Die hintere Gruppe ist die Fortsetzung der Drüsen des Pharynx und ist erheblich geringer als die vordere Schleimdrüsengruppe. Ihre Lage ist somit zwischen den Gruppen der serösen Drüsen in ganz rückwärtiger Stellung. Die vordere gleichfalls unpaare Schleimdrüsengruppe „erfüllt nahezu den ganzen Raum des vorderen Teiles der Zunge". "Dabei liegen die Drüsen so dicht, dass für die übrigen Gewebsteile, so anch für die Muskulatur, nur wenig Raum bleibt." Die Schleimdrüsen münden sowohl an der dorsalen als auch an der lateralen Seite der Zunge auf der ganzen Ausdehnung des Drüsenbezirkes und somit auch an der Zungenspitze.

Die Oberfläche des vorderen Zungenteiles ist, wie von jeher bekannt, im hinteren Abschnitte durch haarähnliche Papillen, am 
vorderen durch breitere Papillen überdeckt. Im bindegewebigere Teil dieser Papillen an der Zungenspitze hat nun Poulton eigenartige, subepitheliale Nervenendigungen beschrieben, die sonst in der Saugetierzunge nirgends bekannt sind, denn sicher sonst. nirgends vorkommen, und die sich am ehesten mit den Tastorganen der Zunge und Schnabelspitze in der Wachshaut gewisser Vögel vergleichen liessen.

Der Ornithorhyncluus-Zunge gegenüber zeigt die EchidnaZunge bekanntlich grosse Modifikationen, was ja zum Teil aus der Verlängerung des Kieferapparates nach vorne erklarlich ist. Der lange wurmförmige vordere Zungenabschnitt verbreitert sich hinten zu einem kurzen dicken Abschnitt. An diesem sitzen an dessen breitem Rande medianst die beiden versenkten grossen Wallpapillen, an den seitlichen Teilen jederseits die Reihe der Papillae foliatae. Die Oberflache dieses verdickten hinteren Abschnittes wird von grösseren stachelförmig auslaufenden Papillen bedeckt, deren Reihen von innen und hinten nach aussen und vorn verlaufen und somit die Reihen der beiden Seiten miteinander einen nach vorne zu offenen Winkel bilden. Allmahlich aber gehen sie in querverlaufende Reihen über und die Papillen nehmen damit an Grösse ab. Auch diese Anordnung verliert sich aber allmahlich, wodurch dann der grössere Teil der Zungenoberflache von dicht gestellten, kleinen und stachelförmigen Papillen bedeckt wird.

Auffallig ist, dass weder Poulton nocl Oppel, die doch mit moderner Technik untersuchten, von Sinnesknospen oder pilzförmigen Sinnespapillen etwas erwăhnen, und doch lässt sich vermuten, dass jene abgerundeten, an der Zungenspitze beim Schnabeltier sich findenden, durch Poulton auf einem Langsschnitt abgebildeten, angeblich kontraktilen Papillen Papillae fungiformes sind. Nachdem solche Papillen bei den Săugetieren durchgehends vorkommen, so ware es auch geradezu unverstandlich, warum sie bei Monotremen fehlen sollten und werden wohl zukünftige Untersuchungen darauf zu achten haben.

Was die Verteilung der Zungenoberflächendrüsen betrifft, so bilden nach 0 ppel die serösen um die beiden Wallpapillen mit den Randorganen ein ganz einheitliches Feld, demgegenüber die Schleimdrüsen sehr in den Hintergrund treten sollen. Immerhin war es Oppel wegen dem Fehlen jenes Schleimhautteiles 
seiner Prăparate, welcher $z$ wischen hinterem Zungenende und Pharynx gelegen ist, nicht möglich, die Ausdehnung des Schleimhautgebietes festzustellen und es dürfte aus seinen Angaben nur so viel feststehen, dass die Schleimhautdrüsen sich bloss auf dieses Gebiet beschränken, dem gesamten vor den Sinnesorganen gelegenen Zungengebiet aber fehlen.

\section{B. Marsupialier.}

Über die Zunge der Marsupialier liegt eine umfangreichere Literatur vor und auch ich war in der Lage, Beutelföten von Hypsiprimnus (spec. ?) und eine leider zu mikroskopischen Zwecken nicht geeignete Zunge einer erwachsenen Didelphys virginiana und eines Halmaturus zu untersuchen.

Vor allem möchte ich hier die schon durch Oppel hervorgehobene Tatsache betonen, dass die Dreizahl der Wallpapillen bei Marsupialiern als bewiesen erachtet werden kann, wodurch eine Zunahme in Rücksicht auf die Monotremen feststeht. Ferner geht aus den Angaben samtlicher Autoren hervor, dass das Randorgan in reduziertem beziehentlich beginnendem Zustande sowohl, als auch in höherer Entfaltung vorkommt. Fehlen soll es nach W. Thompson (29) bei Tarsipes, gering entfaltet ist es nach Tuckerman (28), Poulton (21) und Gmelin (8) bei Halmaturus, bei Petrogale nach Parsons (19). Besser entwickelt ist es indessen bei Macropus, Phascolarctus, Phalangista, Belideus, Acrobatus und Didelphys nach Tackerman und Poulton. Oppel konnte bei Dasyurus bloss eine geringe Anlage sehen und gering ist es nach ihm auch bei Petaurus und Phascolarctus, bedeutender bei Phalangista.

Papillae fungiformes mit oft bis sechs Sinnesknospen wurden von allen diesen Autoren gesehen, ebenso verhornte Zăhnchenund Kronenpapillen an der dorsalen Zungenoberflache.

Dies wăren die wichtigsten uns hier interessierenden Ergebnisse und indem ich darum für die übrige Literatur auf Oppels Werk verweisen will, möchte ich hier vor der Schilderung meiner Erfahrungen noch die hier für diese Arbeit wichtige Tatsache erwăhnen, dass 0 ppel bei Dasyurus ballucatus sogar auf der einen Seite zwei vordere paarige Wallpapillen gesehen hat. 
Und nun will ich hier versuchen, durch die eigenen Beobachtungen das bereits Bekannte ergånzend, zu einem Allgemeinbild der Marsupialierzunge zu gelangen.

Auf einer Långsschnittserie eines Beutelfötus von Hypsiprimnus (spec.?) konnte festgestellt werden, dass die Zunge der Länge nach in mehrere Abschnitte bezüglich der Schleimhaut sich einteilen lăsst. Der hinterste Abschnitt (Textfig. 1, III) begann am Pharynx und reichte bis zu den beiden paarigen Wallpapillen (pv.). Ausgezeichnet war er durch die zablreichen Mündungen der noch gering entfalteten Schleimdrüsen. Von den



Fig. 1 .

Hypsiprimnus. Beutelfötus. Längsschnitt durch die Zunge. Schwache Vergrösserung. I, II, III = erstes, zweites und drittes Zungengebiet. pv. = paarige Wallpapille; pf. = Pilzpapillen; pp. = Zungenspitze; uz. = Unterzunge; sld. = Sublingualdrüse; sd. = seitliche Schleimdrüsen.

paarigen Wallpapillen an ist ein grösseres Gebiet (II), das bis zum Gebiet der Zähnchenpapillen (I) reicht. Hier hatten, jetzt wenigstens, die Papillen runde Oberflache ohne Hornaufsatz und fanden sich bereits einzelne. Pilzpapillen mit Sinnesknospenanlagen (pf.) vor. Das vorderste Gebiet zerfiel in einen hinteren und einen vorderen kleineren Abschnitt. Der hintere dieses hatte Zăhnchenpapillen bereits mit eingestreuten Pilzpapillen zwischen ibnen; der vordere, die Zungenspitze umfassende Teil (pp.) bestand aus grossen, runden Papillenanlagen mit zum Teil bereits deutlichen Sinnesknospen. 
Wallpapillen waren drei, eine mittlere und zwei seitliche weiter vorne liegende vorhanden, das Randorgan bestand aus einer Epitheleinsenkung.

Die serösen Drüsen umgaben diese Sinnesorgane, doch ob in einer zusammenhängenden Lage, wie Oppel für Petaurus, Sminthopsis, Phalangista, Plascolarctus und Aegyprimnus angibt, wüsste ich nicht zu sagen. Dafür konnte ich für die Schleimdrüsenlage feststellen, dass sie hinten vor dem Kehlkopf beginnend, jederseits nach vorne zieht, dann das Gebiet der drei Wallpapillen umgreift und dann lateralst bis zur Gegend der Sublingualis (sld.) gelangt (sd.), dort aufhörend. Es reicht somit das Schleimdrüsengebiet bei Hypsiprimnus etwa so weit nach vorne wie bei Phalangista nach 0 ppel und erreicht nicht fast die Zungenspitze, wie demselben Autor nach bei Phascolarctus.

Dieses aus einem Lăngsschnitt gewonnene Bild ergänzt ein Totalpräparat von Didelphys virginiana. Die Zunge hat hier eine anfangs gleich breite (Fig. 9), dann sich allmäblich verjüngende Form, die an der Spitze sich plötzlich wieder verbreitert. Das hinterste Feld (III) beginnt am Pharynx und reicht bis etwa vor die beiden paarigen Wallpapillen. Es ist auf der Zunge durch Längsfalten gekennzeichnet, welche mit dem Gebiete nach vorne zu enden. In der Mitte des Feldes liegt hinten die unpaare Wallpapille, von ovoider Form mit nach sagittal gestellter Lăngsachse; im vorderen T'eil liegen die beiden paarigen Wallpapillen, von denen die linke eine Doppelpapille ist, d. h. der ansehnliche Wall umfasst zwei getrennte, eine grössere und eine kleinere Papille. An der lateralen Seite des Feldes lag jede1seits das Randorgan. Dieses dürfte wohl das grösste sein, das bisher bei den Marsupialiern beschrieben ward. Auf der rechten Seite waren es sechs, auf der linken acht Grübchen, die je in eine sog. Papilla foliata (ro.) führten. Wie ich weiter unten noch ausführlicher begründen will, fasse ich jedes solche Grübchen als ein „Element“ des Randorganes auf und somit möchte ich jetzt schon der Kürze halber von sechs bis acht Elementen des Randorganes sprechen. Es fiel somit die Ausdebnung des Randorganes auf jenes Feld, welches ich als das dritte oder letzte der Zunge bezeichnete und in welchem auch die drei Wallpapillen gelegen sind. 
Das nach vorne zu năchstfolgende Feld (II) bestand zu Beginn aus Fadenpapillen, die allmahlich grösser werdend, in Zahnchenpapillen übergingen, mit welchen das erste und grösste Feld der Zunge (I) überzogen ist. Diese verhornten Zähnchenpapillen sind in Querreihen angeordnet, ohne dass in der Mitte der Zunge, wie Oppel meint, die allen Marsupialiern eigene Längsfurche vorhanden gewesen ware. Doch war in der Mitte des Feldes eine etwa rhombenförmige Vertiefung (v.), in der dann die Zăhnchenpapillen am kräftigsten waren.

Auf diesem ganzen grossen ersten Felde der Zunge sind pilzförmige, ansebnlich grosse Papillen vorhanden und zwar in ziemlich gleichmăssiger Anordnung, ohne dass dabei eine reihenförmige Stellung so recht zum Ausdruck gelangen würde. Es erstrecken sich diese Papillen auf das zweite Feld nicht, auch bei Halmaturus nicht. An dem vorderen Zungenende, der verbreiterten Zungenspitze, sind die Papillae fungiformes zwar etwas kleiner, doch zahlreicher, und somit stehen sie viel dichter beisammen.

Was das Randorgan von Halmaturus betrifft, so fand ich dasselbe genau so vor, wie $\mathrm{Gmelin}$ es beschreibt und abbildet (l. c. Fig. 5). Es waren fünf bis sechs punktförmige Öffnungen vorhanden, womit noch keine allzu grosse Reduktion angedeutet ist. Kleine punktförmige Öffnungen seitwărts vom Randorgane sind zweifellos Mündungen von Schleimdrüsen, wie sie sich auch bei anderen Säugetieren vorfinden. Solche Mündungen finden sich zwischen den Epithelfalten des ersten Feldes der Zunge nicht nur, sondern reichen solche bis zum Pharynx, dann finden sie sich in den Seitenwänden der Mundhöhle bis hinauf zur 'Tonsille (t), überall durchaus gleichmåssig verteilt. Wie weit indessen die Schleimdrüsen seitlich in der Zunge nach vorne zu reichen, konnte obne Schnittserien selbstverstandlich nicht festgestellt werden.

Es kann somit über die Zunge der Beuteltiere heute soviel mit Sicherheit festgestellt werden, dass die Zungenschleimhaut sich auf der dorsalen Zungenflache in drei hintereinander gelegene Felder gliedert, von denen das hinterste Feld vom Pharynx an und bis zu den Tonsillen hinauf die Mündungen der Schleimdrüsen trăgt, dass aber ein Teil dieser an der lateralen Seite der Zunge bis zur Unterzunge (Textfig. 1) sich nach aussen 
öffnet. Dass ferner die Wallpapillen in der Dreizahl vorhanden sind, wobei ich freilich auf die Doppelpapille links bei Didelphys schon jetzt einiges Gewicht legen möchte, wie denn dieser Zustand bei Dasyurus hallucatus nach Oppel (18, pag. 128) sogar zu einer vollstăndigen Verdoppelung der Papille führen kann, und, dass das Randorgan bei den einzelnen Formen, in Erinnerung an die Verbăltnisse bei Monotremen, in sehr ursprünglicher geringer Entfaltung sich zeigt, bei anderen wieder und in extremster Weise wobl bei Didelphys eine Entfaltung erreicht, welche schon konvergenterweise an manche Nagetiere und höhere Simier erinnert, und somit aus vielen grossen Elementen besteht. Die Pilzpapillen mit dorsalstandigen Sinnesknospen haben bei den Marsupialiern eine grosse Verbreitung, doch ob auch immer der Fall besteht wie bei Didelphys, wo sie sich auf das erste Zungenfeld beschränken, wäre schon darum unwalrscheinlich, weil sie bei Hypsiprimnus auch weiter nach hinten $z \mathbf{u}$ finden sind gerade so wie bei Halmaturus.

\section{Edentaten.}

Die untersuchte Zunge von Myrmecophaga jubata, die leider sich zur mikroskopischen Untersuchung nicht mehr eignete, wies einige wesentliche Verschiedenheiten von dem über die Edentatenzunge Bekannten auf. Allgemein werden für die xenarthren Edentaten zwei Wallpapillen angegeben, so für Tamandra di- und tridactyla, Chlamydophorus truncatus, Dasypus villosus und peba von Tuckerman (27), der bei Chlamydophorus und Dasypus auch zwei Randorgan-Elemente beschreibt.

Demgegenüber hat die Nomarthre Manis javanica, deren Zunge auch formell viel Ähnlichkeit mit der Zunge von Myrmecophaga jubata hat, nach Oppel drei in nach vorne zu offenes Dreieck gestellte Vallatae. Diese laufen dorsalwarts spitz aus und sind umwallt. Sie liegen etwa in der Mitte der langen, wurmförmigen Zunge, genauestens vor einer medianen Längsrinne, die in der bekannten knopfförmigen Verdickung der Zungenspitze endet. Es beschrănken sich nach Oppel die Schleimdrüsen auf das hintere Zungenende vor dem Pharynx. Seröse Drüsen liegen nur um die drei Wallpapillen herum und da von anderen solchen der Autor nichts erwahnt, so ist wohl anzunehmen, dass er keine Randorgane bei Manis gefunden hat. 
Die von mir untersuchte, viel längere Zunge von Vyrmecophaga besitzt gleichfalls die bei Manis beschriebene Scheide (Textfigur 2, A, s.) am hinteren Zungenende. Hier öffnen sich auch die Schleimdrüsen, aber nur eine Gruppe von ihnen noch am hinteren Zungenende vor dem Pharynx; die anderen (sdm.) sind in drei Quergruppen angeordnet, von denen die kleinere vor der Tonsille,

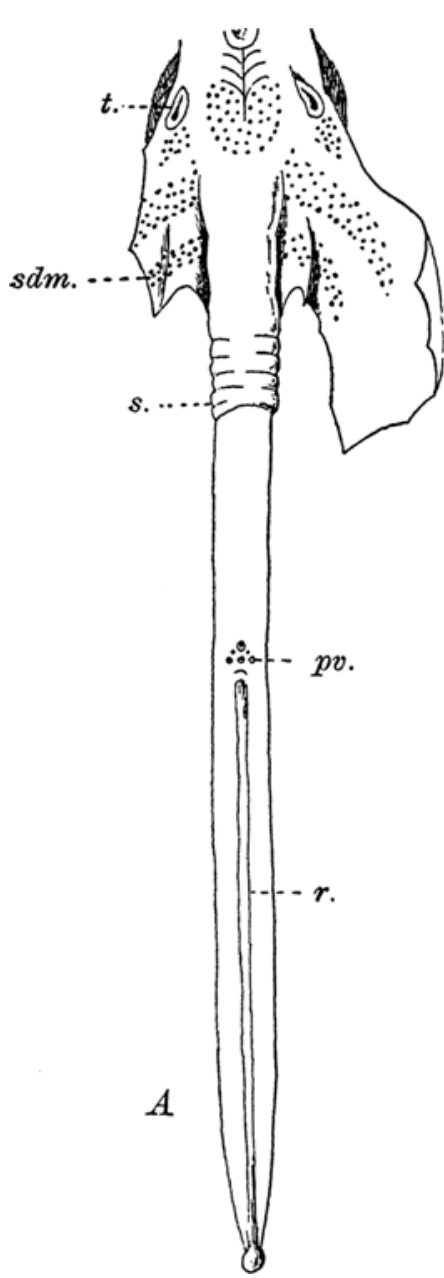
die zwei grossen seitwärts von der Zunge in die Mundwand sich ergiessen. Die ganze Zunge, der das Randorgan fehlt, ist glatt bis auf die Wallpapillen. Die Wallpapillen liegen wie bei Manis und anderen myrmecophagen Formen in der Zungenmitte (pv.), von wo aus eine Langsrinne zum knopfförmig verdickten vorderen Zungenende führt.

Ich fand sechs ungleichgrosse Wallpapillen vor. Alle lagen in einem weiten Ringgraben und besassen den durch Oppel für Manis festgestellten dorsalen Fortsatz, ohne dass ein Wall erkenntlich gewesen ware. Ohne Oppels Er-

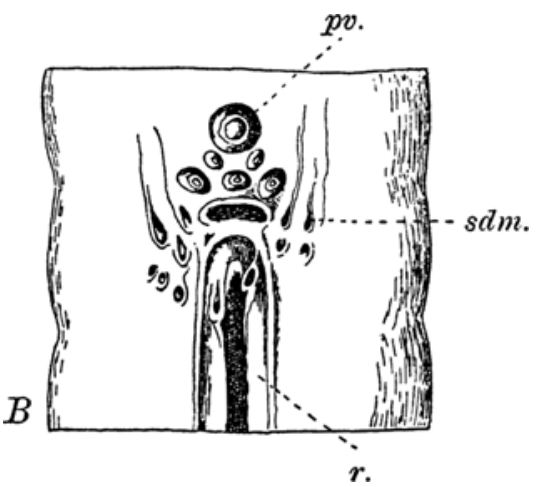

Fig. 2.

Myrmecophaga jubata. A die ganze Zunge von oben, B das Gebiet der Wallpapillen bei Lupenvergrösserung. $\mathrm{t}$. = Tonsille; sdm. = Schleimdrüsenmündungen; $\mathbf{s}$. = Zungenscheide; pv. $=$ Wallpapillen; r. $=$ Rinne zum Knopfe der Zungenspitze. 
fahrung hătte man irrtümlich Doppelgräben vermuten können. Die hinterste Wallpapille lag mittelstanndig und ist sehr gross (B, pv.), vor ihr lag jederseits eine kleine Wallpapille, dann vor dieser wieder eine unpaare etwas grössere, worauf seitlich von dieser je eine noch grössere Wallpapille sich befand. Die Stellung der Papillen war also jener anderer Edentaten gleich, d.h. dreieckige. An der nach vorne zu gekehrten Basis des gleichschenkligen Dreieckes befand sich eine quergestellte, bewallte Grube und neben dieser auf jeder Seite zu Beginn der Medianrinne (r.) befanden sich eine Zahl ansehnlicher Gruben (sdm.) vor. Rechts waren sechs ungleich grosse, links vier fast gleich grosse vorhanden. Zwei solche Öffnungen lagen ausserdem, je eine auf jeder Seite, in der Laingsrinne selbst. Gewiss gibt es keine Papillen innerhalb dieser Gruben und sie können nur die Yündungen jener Drüsen sein, die ihr Sekret ergiessend, die Zungenoberflăche klebrig machen zur Festhaltung der Ameisen. Dass diese Drüsen der mechanisch und nicht taktil wirkenden Zunge von Schleimdrüsen sich ableiter lassen, ist wohl anzunehmen, wobei eine Veränderung des Sekretes als Voraussetzung gilt. Liegen doch an gleicher Stelle neben den Wallpapillen auch bei anderen Formen von Săugetieren Mündungen von Schleimdrüsen.

Sicher wăre somit, dass bei Myrmecophaga jubata eine Vermehrung der sonst bei Edentaten nur in geringer Zahl sich findenden Wallpapillen sich einstellte.

\section{Chiropteren.}

Von Chiropteren untersuchte ich die einheimischen Formen, halte mich indessen bei der Beschreibung an Vesperugo noctua und an reifer, dem Austragen nahestehende Föten-Zungen von Pteropus edulis. Es steht nach allen Autoren fest, dass die Makrochiropteren, die Frugivoren drei Wallpapillen besitzen, die in der $Y$-Form am hinteren Ende der Zunge liegen. Demgegenüber fehlt nach allen Beobachtern die unpaare Zentralpapille bei den insectivoren Formen, den Mikrochiropteren. Randorgane von geringerer Entfaltung werden bei den Mikrochiropteren wenigstens auch vielfach festgestellt.

Es zeigt die Zunge von Vesperugo noctua (Fig. 10) von oben betrachtet zwei Felder, nămlich ein hinteres (II), das vorne 
durch eine nach vorne $z$ lkonvexe Rinne begrenzt, als Tuberculum von ovoider Gestalt sich erhebt und vom Pharynx an bis zu seinem vordersten Drittel durch eine mediane Langsfurche geteilt ist, und ein vorderes Feld. Von jener Querrinne an wird auch das vordere Feld durch eine mediane Längsfurche durchzogen, welche jedoch nicht bis in die gut abgesetzte Zungenspitze hineinreicht. Diese zwei Felder sind voneinander auch dadurch unterschieden, dass das vordere mit ungemein dicht stehenden verhoruten baarförnig nach hinten zu gerichteten Papillen besăt ist (Textfig. 3, A, I), indessen das hintere Feld verhornte Koronalpapillen (II) triggt. Wahrend dann an Totalpraparaten, mit der Lupe betrachtet, kein weiterer Unterschied zu machen ist, zeigt der vergrösserte Lanngsschnitt, dass die Koronalpapillen nur bis zu den Wallpapillen reichen, von da bis zum Pharynx aber weiche Schleimpapillen die Zungenoberflăche bedecken (III). Somit sind auch hier die drei Felder an der Zunge deutlich. Ausserdem ist die Zungenspitze von dem anderen Teil des ersten Feldes dadurch verschieden, dass die Zähnchenpapillen, d. i. ihr verhorntes Oberende, sich in viele Stacheln zersplittert (Textfig. 3, A und 11, A, z.).

Demgegenüber zeigt die Zunge von Pteropus eigenartige Modifikationen.

Das zweite Feld (Fig. 11, II) ist hier dem ersten gegenüber zwar durch keine Randfurche abgegrenzt wie bei den einheimischen Formen und gelangt es auch zu keiner Tuberkelbildung am $z$ weiten Felde, doch ist die Grenze zwischen erstem und zweitem Feld durch die Schleimhautbildung gegeben. Das zweite Feld wird durch hohe, beim Fötus noch nicht völlig fertige Papillen gebildet, die noch kein Hornzahn besitzen und über die die später abzustreifende embryonale Epithellage hinwegzieht (Textfig. 3, $\mathrm{B}, \mathrm{II})$. Demgegenüber ist das erste Feld von Anlagen kleinster Zahnpapillen überzogen, die nur in der Mitte des Feldes völlig entwickelt und sehr grosse, nach hinten zu gerichtete Zahnpapillen sind (I). Es ist da in der Mitte des Feldes eine etwas rhombisch längliche Mulde vorhanden, die nicht bis zur Zungenspitze reicht und von grossen Zahnpapillen überzogen wird (Fig. 11). Eine seitliche Reihe runder und flacher Randpapillen umstumt das erste Feld und jede dieser zeigt die auf der dorsalen Flache gelegene Anlage je zweier Geschmacksknospen. Zum Teil ragen diese Papillen noch gar nicht hervor, da nur der bindegewebige 



Fig. 3.

Laterale Längsschnitte durch die Zunge: A von Vesperugo noctua, B von Pteropus edalis. I, II, III = erstes bis drittes Feld. m. srd. = mittleres, s. srd. $=$ seitliches, seröses Drüsengebiet $; \mathbf{m}$. sdr. $=$ mittleres, s. srd. $=$ seitliches Schleimdrïsengebiet; sdr $^{\prime}$, sdr $^{\prime \prime}, \mathbf{s d r}^{\prime \prime \prime}=$ die am Pharynx mündenden grossen Drïsen des mittleren Schleimdrüsengebietes; u. sdr. $=$ unterster, vorderster-Teil des seitlichen Schleimdrüsengebietes; sl. = Sublingualdrüse; ar. = Arterie; ve, = Vene; $\mathrm{n} .=$ Nerv. 
Teil sich vorwölbt, das Epithel aber glatt darüber hinwegzieht. An der Spitze der Zunge (Textfig. 3, B, I') sind dann die bindegewebigen Teile dieser Papillen noch höher und die mit Sinnesknospenanlage versehenen Papillen stehen viel dichter, ja sie finden sich sogar in zwei Reihen an der unteren Zungenspitzenflăche. Die Sinnesknospenanlagen reichen noch nicht bis zur Oberfăche des Epithels.

Das dritte Feld der Zunge ist auf Längsschnitten dadurch deutlich (III), dass die Papillen hier schon entwickelt sind.

Bei unseren einheimischen Formen sind zwar nur zwei Wallpapillen, doch in ansehnlicher Entfaltung, vorhanden. Sie sind von oben betrachtet ovoid und liegen an dem hinteren Zungenende in gleicher Querebene mit den Randorganen. Sie sind mit ihrer Langsachse so gestellt, dass sie einen nach vorne $z u$ offenen Winkel bilden und werden allseitig von Papillen umgeben. Anders sind die Zustande bei Pteropus, denn bei diesem sind drei Wallpapillen (Fig. 11, po.) vorhanden, wie dies aus einer $\mathrm{Ab}$ bildung I udwig Ferdinands Prinzen von Bayern (14) schon bekannt war, von denen zwei ziemlich fest beisammen liegen (Fig. 3 pv.), eine dritte unpaare aber hinter ihnen lagert und zum Teil zwischen sie eingeschoben ist. Vor den drei Wallpapillen liegt ein kleines, nach vorne zu sich zuspitzendes papillenfreies Gebiet und hinten folgt das hintere Ende des dritten Feldes (III). Dieses ist durch Langsfalten ausgezeichnet, welche sich dann nach hinten auf das Frenulum pharyngis festsetzen, die mittelste Falte aber in den Wall der mittleren Wallpapille übergeht. Während die gut entfalteten Walle bei Vesperugo ganz glatt sind, sind jene von Pteropus vielfach eingekerbt.

Vor den Wallpapillen findet sich bei Vesperugo jederseits eine mit je zwei Sinnesknospen versehene Pilzpapille (Fig. 10 schwarz). Anders bei Pteropus. Hier finden sich solche, aber noch nicht völlig entfaltete Pilzpapillen, fünf an der Zahl, seitwarts von den Wallpapillen, umgeben von den anderen Papillen (Fig. 3 pf.).

Die Verteilung der übrigen Pilzpapillen bei Vesperugo wurde an Schnittserien festgestellt und dann erst schwarz in das fertige Bild eingetragen. Es liegen da in der Rinne zwischen dem zweiten und ersten Feld in ziemlich gleichmăssigen Abstănden voneinander eine Reihe von Pilzpapillen ('Textfig. 4 pf.) und über 
der Reihe auf dem zweiten Felde finden sich auch noch solche in gleicher Anordnung. Dann zieht eine unregelmåssige Doppelreihe jederseits entlang der Sagittalrinne des ersten Feldes nicht ganz bis zur Zungenspitze. Eine regelmässige Doppelreihe umsăumt das erste Feld, wobei Zähnchenpapillen auch auf die seitliche Zungenflache noch gelangen. Die beiden lateralen Doppelreihen treffen sich an der Zungenspitze und vereinigen sich hier zu einem dichten Pilzpapillenbesatz, der sich selbst auf die Ventralseite noch umschlägt, gleich wie bei Pteropus.

Bemerkenswert ist es, dass während die hinteren Pilzpapillen nur je eine allerdings sehr grosse Sinnesknospe führen (Textfig. 4,

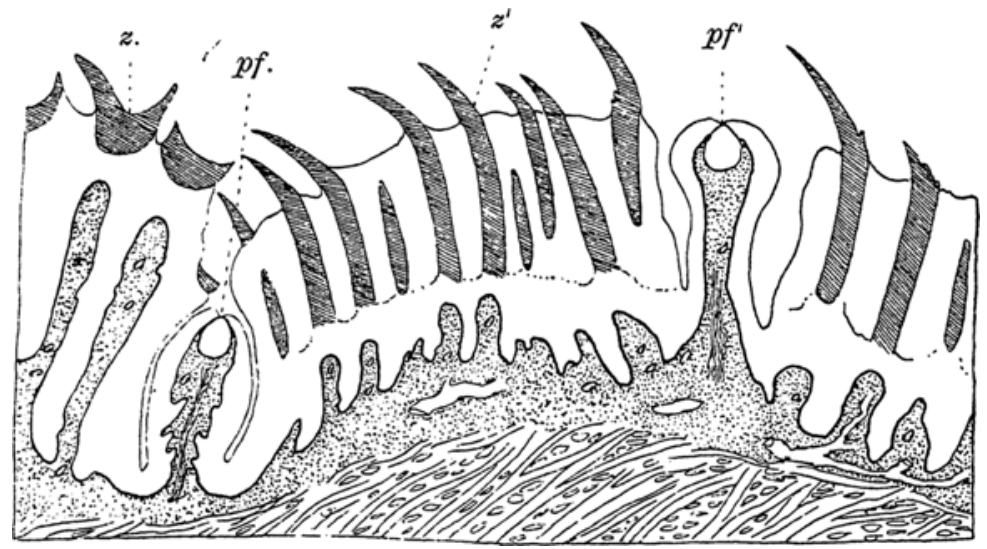

Fig. 4.

Vesperugo noctua. Längsschnitt durch die Zunge zwischen erstem und zweitem Feld. pf. $=$ Pilzpapille in der Rinne; pf $^{\prime}=$ solche im ersten Feld; z. = Koronalpapille; $z^{\prime}=$ Zähnchenpapille.

pf., pf'), die mit ihrem unteren Teil weit in den bindegewebigen Teil der Papille einragt, die vorderen Papillen und besonders die auf der Zungenspitze gelegenen, immer zwei Sinnesknospen haben (Textfig. 11, A, pf.). Diese Beobachtung steht mit den Angaben Tuckermans (25) bezïglich Vespertilio tabulatus insofern in Einklang, als er auch Pilzpapillen mit nur einer Knospe gesehen hat, aber gerade an dem breiten Teil des Zungenrückens solche antraf, die sogar drei Knospen aufwiesen und die er geradezu darum als Übergånge zu Wallpapillen auffasst.

Von diesen grossen Sinnesknospen möchte ich hier bemerken, dass sie nicht gleich anderen Sinnesknospen im allgemeinen, mit 
ihrer Mündung von der Epitheloberfläche weit entfernt und durch den Toldtschen Gang an der Oberflache sich öffnen, sondern nur etwas eingesenkt unter der Epitheloberfläche gelegen sind. Es mag dieser Zustand wohl dadurch bedingt sein, dass die
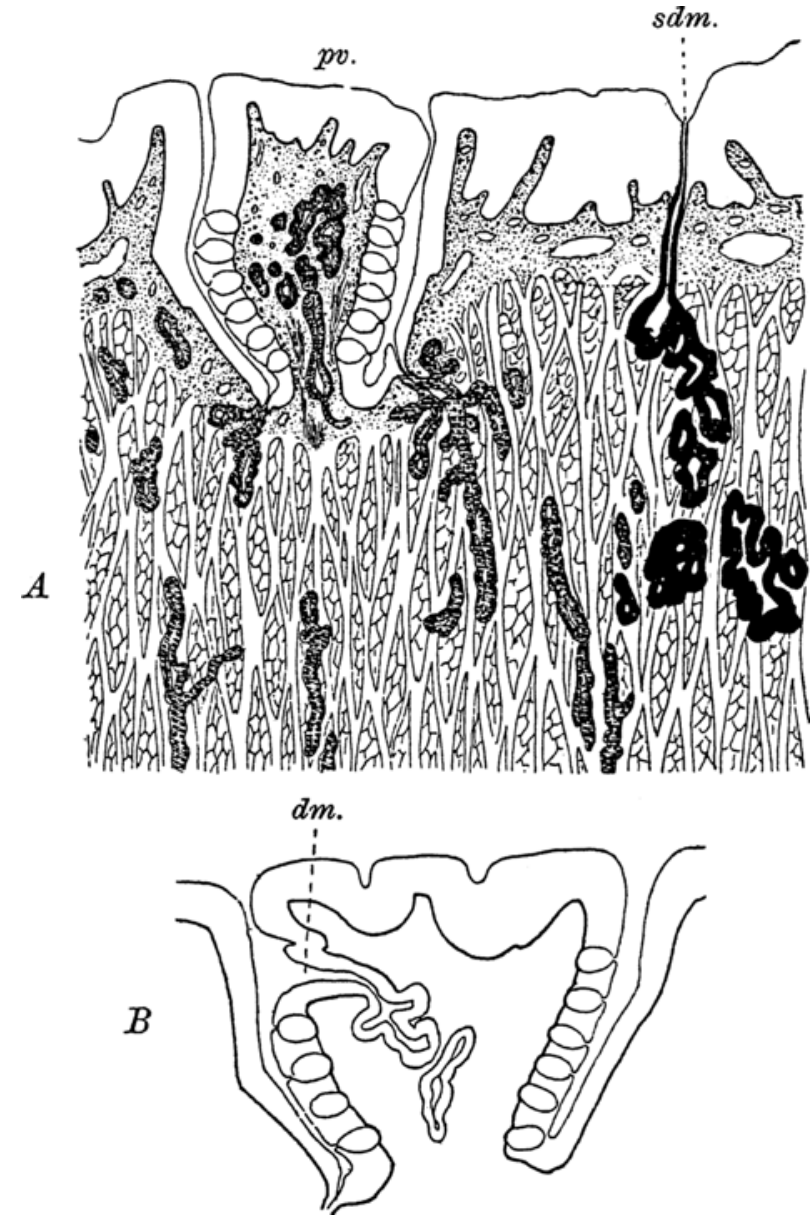

Fig. 5.

Vesperugo noctua. Querschnitte durch eine Wallpapille. pv. = Wallpapille; $\mathrm{dm} .=$ Mündung einer in der Papille gelegenen serösen Drüse; sdm. $=$ eine Schleimdrüse.

Papille möglicherweise kontraktil ist, wie dies Poulton von jenen der Monotremen schon behauptete. Dadurch nun, dass bei diesem Prozesse die Knospen in die Bindegewebspapille sich tiefer versenken mit ibren Basalenden, dürfte ihnen nach der Oberfläche 
zu ein gewisser Schutz geboten sein. Ich will darauf noch bei der Maus zurückkommen. Da die Höbe dieser grossen Sinnesknospen jene der Epithellage übersteigt, ragen sie naturgemäss in die Bindegewebspapille betrăchtlich vor. Ein anderer Umstand, den ich hier gleichfalls erledigen möchte, besteht darin, dass jeder Sinnesknospe ein ovales Ganglion unten anliegt (gl.). Ob freilich in allen Pilzpapillen sich solche Ganglien vorfinden, oder die Ganglienzellen wie für gewöhnlich diffus dem Nerven anliegen, möchte ich unentschieden lassen. Bekanntlich kann es zu solchen Ganglienkonzentrierungen, wenn auch nur ausnahmsweise, in den Wallpapillen kommen, wo Poulton bei dem Marsupialier Perameles ein solches beschrieben und abgebildet hat.

Was nun die Wallpapillen betrifft, so zeigen sich bezüglich des Vorkommens der Geschmacksknospen unter den beiden hier behandelten Chiropteren Unterschiede von phyletischer Bedeutung.

Die Wallpapillen von Vesperugo (Textfig. 5) sind hoch, ziemlich schlank und oben flach, im Gegensatz zu den runden von Vespertilio tabulatus (nach Tuckerman [25]) und Vespertilio murinus (nach oppel [17]), wobei sie in gleicher Höhe mit dem Walle enden. Geringe Einkerbungen ihrer dorsalen Oberfläche zeigen sich zwar (B), ohne dass es zu fortsatzartigen Bildungen kommen würde. Die Sinnesknospen liegen um die Seiten der Knospe und finden sich solche in der Seite des Walles nie. Es erreichen die Knospen nach oben nie die obere Fläche, sondern hören eine gute Strecke früher schon auf. Die meisten serösen Drüsen münden unten im Boden des Wallgrabens und liegen rings um die Papille. Allein es finden sich seröse Drüsen auch in der bindegewebigen Papille selbst, ein Verhalten, das ziemlich vereinzelt dasteht, denn in der Literatur finde ich ăhnliche Befunde ausser einer Angabe 0 ppels ${ }^{1}$ ) nicht und auch mir ist ein solches Verhalten sonst nicht bekannt geworden. Auch diese Drüsen münden zum Teil unten im Boden des Wallgrabens (Textfig. 5, A), doch sind unter ibnen auch solche vorhanden, die oberbalb des durch die Geschmacksknospen besetzten Wandringes,

1) Oppel (17) hat diese Drüsen gesehen, doch nur in einem Falle, und da er keine Serie besass, blieb er über sie im Unklaren. Mündungen erkannte er darum nicht und am ehesten möchte er sie für Ausführgänge von serösen Drüsen halten, wie ja solche auch an der dorsalen Fläche der Papille ausnahmsweise beim Menschen münden können. 
gleich unterhalb der dorsalen Oberflache der Wallpapille, sich in den Graben öffnen (Textfig. 5, B, dm.). Immerhin ist diese Art der Mündung nicht die Regel, vielmehr bloss die Ausnahme.

Diesem Verhalten gegenüber ist das der bei den untersuchten Föten von Pteropus völlig entfalteten Wallpapillen ein ursprünglicheres. Die unpaare Wallpapille (Textfig. 6, A) ist niedrig und umfangreich und zeigt eine Langsfurche auf ihrer dorsalen Flache (lf.). Die Geschmacksknospen finden sich nicht



Fig. 6 .

Pteropus edulis. Querschnitte. A durch die unpaare, $B$ durch eine der paarigen Wallpapillen.

nur an den Seiten der Papille, sondern auch an der dorsalen Oberfläche. Auch finden sich an den Grabenseiten der Walle in von oben nach unten ziehenden Strejfen Geschmacksknospen, wie das ja auch schon bei manchen anderen Saugetieren bekannt ist (w.), doch bleiben $z$ wischen diesen Streifen im niederen Epithel Stellen frei (w') von Sinnes$\mathrm{knospen}$. In der Papille finden sich weder in den unpaaren 
noch in den paarigen Wallpapillen seröse Drüsen wie bei Vesperugo. Bezüglich der Lagerung der serösen Drüsen um und unter der Papille möchte ich bemerken, dass diese in eine rechte und eine linke Gruppe zerfallen und dass unter der Papille die Muskellage frei von Drüsen ist (Textfig. 10, A), ein Umstand, der möglicherweise mit dem Verwachsen zweier Wallpapillen zu einer unpaaren in Zusammenhang $\mathrm{zu}$ bringen ist, und wohl die Verfolgung der Ontogenese solch einer Papille (z. B. bei der Hausmaus) darüber Klarheit schaffen könnte.

Die paarigen Walipapillen sind auf ihrer dorsalen Oberfläche uneben, doch fehlt die Längsfurche (Textfig. 6, B); bezüglich der Anordnung der Geschmacksknospen herrscht indessen keine Verschiedenheit, denn auch die paarigen Wallpapillen sind allseitig und somit auch an der dorsalen Fläche von ihnen überzogen. oppel berichtet von dorsal den Wallpapillen aufsitzenden Geschmacksknospen bei dem Beuteltiere Aepyprymnus, und Geschmacksknospen in der der Grabenseite zugekehrten Wallwand sah er bei Sminthopsis. Diese Stellen führen auch an den paarigen Wallpapillen von Pteropus Geschmacksknospen (w), doch in gleicher Weise wie in der unpaaren Wallpapille. Fie finden sich seröse Drüsen auch in den paarigen Wallpapillen in der Papille.

Jedenfalls ist das Vorhandensein von Geschmacksknospen auf der dorsalen Flăche einer Wallpapille von grosser phyletischer Bedeutung, wie ich darauf noch weiter hinten zurückzukommen gedenke, sollte auch der Zustand von Pteropus nur ein vorübergehender sein und sich herausstellen, dass bei dem völlig entwickelten Tiere jene dorsalständigen Knospen fehlen, denn auch dann würde damit festgestellt sein, dass einstens Knospen auch dorsalwärts lagen, ăhnlich wie heute noch bei den Pilzpapillen es der Fall ist. Damit wird aber eine gewisse genetische Beziehung dieser beiden Sinnespapillenarten $\mathrm{zu}$ einander festgestellt, wie es denn durch F. Hermann (10) bewiesen ist und seither glaube ich auch u. a. durch Stöhr erkannt wurde, dass in der ontogenetischen Anlage der Wallpapillen Knospen an der dorsalen Fläche vorkommen.

Die Randorgane der untersuchten Chiropteren sind ungleich entfaltet, denn wăhrend jene von Pteropus aus sechs Elementen bestehen, werden jene von Vesperugo von nur ein bis zwei Elementen gebildet. Trotzdem ist bei Vesperugo damit kein 
physiologischer Rückschritt erzielt, denn was an Elementenzahl verloren geht, wird an Machtigkeit der einzelnen Elemente ein-

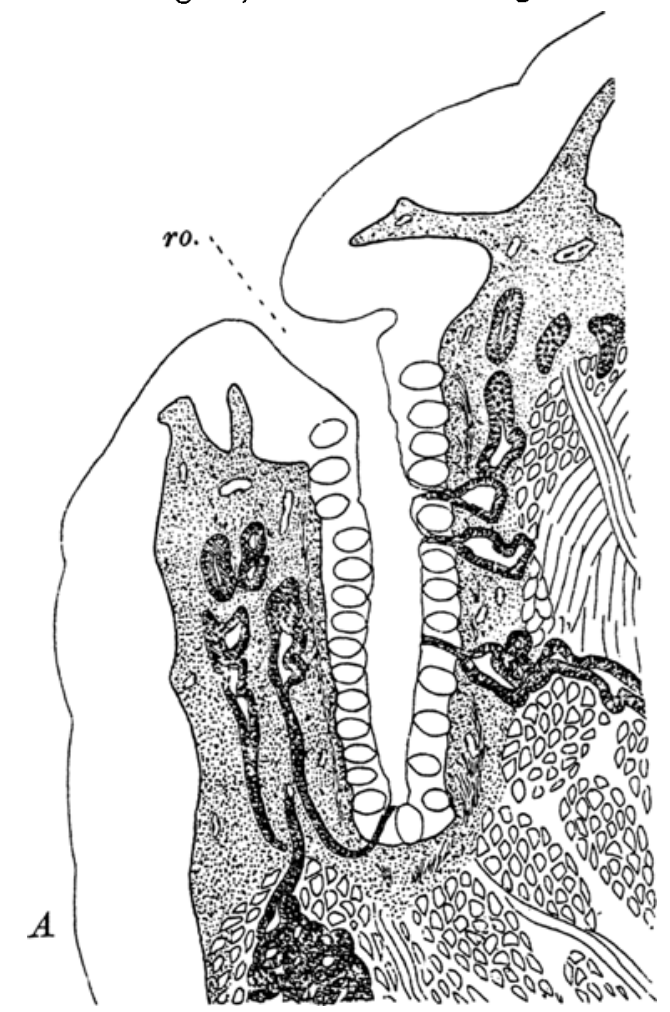
geholt. Entsprechend der Măchtigkeit der Elemente Letzterens sind die Mündungen ansehnlicher wie bei Pteropus. Es liegen die Querschlitze so weit am Zungenrande, dass seitwärts von ihnen keine Schleimdrüsen mehr zur Mündung gelangen (Textfig. 7, A), Es besteht jedes Element aus einer tiefen und längeren Epitheleinsenkung, deren Wănde ganz glatt sind. Sind zwei Elemente vorhanden, so liegen sie etwas weiter auseinander als bei Pteropus. Auf einem Zungenquerschnitte lassen sich im ganzen

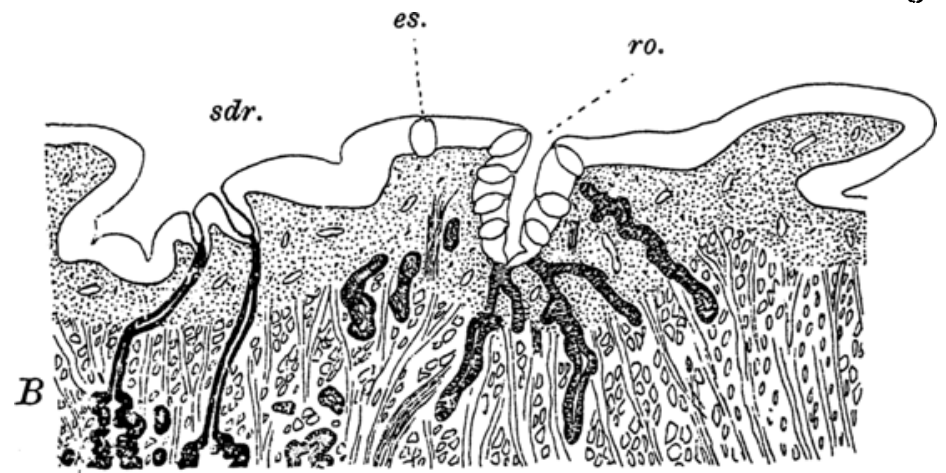

Fig. 7.

Querschnitte durch je ein Randorganelement. A von Vesperugo noctua, $B$ von Pteropus edulis. ro. = Mündung der Grube; sdr. = zwei Schleimdrüsen; es. = eine einzelne Sinnesknospe ausserhalb des Randorgans. 
27 bis 30 Geschmacksknospen feststellen, die dicht übereinander gelagert und auch den Boden der Einsenkung einnehmend, nicht ganz bis zu der Mündung hinaufreichen. Diese, mit dickerem Epithel überzogen, ist somit frei von Knospen (ro.). Es lagern die serösen Drüsen um die ganze Spalte herum und münden nicht nur an dem Boden der Spalte, sondern auch entlang der ganzen inneren Seite zwischen den Sinnesknospen und darüber bis weit hinauf.

Demgegenüber liegt die Elementenreihe des Randorganes bei Pteropus etwas weiter nach innen, so, dass Schleimdrüsen auch lateral von der Grubenreihe noch zur Mündung gelangen (Textfig. 7, B, sdr.).

Die einzelnen Elemente des Randorganes sind hier ganz kleine Gruben (ro.), obgleich es keinem Zweifel unterliegen kann, dass die Ontogenese des Randorganes abgeschlossen ist. Eine weitere Entfaltung könnte schliesslich nur darin liegen, dass sich noch weitere Teile des Randes mit einstülpen würden, wodurch die Grube sich noch etwas vertiefen würde und was an der Sache wenig ändern würde. Zwei Umstände sprechen allerdings für diese Möglichkeit. Erstens dei Umstand, dass die Geschmacksknospen bis zur Mündung hinaufreichen und dann jener, dass nach seitwarits $\mathrm{zu}$ eine einzige Geschmacksknospe (es.) ausserhalb der Grube gelegen ist. Doch könnte letzterer Umstand vielleicht auch ein bleibendes Verhalten darstellen in Berücksichtigung jener Tatsache, dass Gmelin (l. c. pag. 548) bei dem völlig entwickelten Pferde einmal noch eine seröse Drüse ausserhalb des Randorganelementes zwischen zwei Elementen münden sah.

Die Randorganelemente von Pteropus besitzen auf Schnitten nicht mehr als 7 bis 10 Geschmacksknospen. Zumeist am Boden der Grube, aber auch weiter aufwärts, bis an der Grubenmündung münden die serösen Drüsen.

Wir gelangen somit bei den Chiropteren zu dem Ergebnis, dass hier eine Verminderung der Zahl der Randorganelemente, wie sich bei Vesperugo zeigt, durch eine Vergrösserung der einzelnen Elemente physiologisch kompensiert wird.

Es ist eine längstbekannte Tatsache, dass einzelne Sinnesknospen, erinnernd noch an ursprüngliche rezent nicht mehr vorhandene Zustände, sich auch einzeln in der Schleimhaut der Mund- 
höhle vorfinden können, ähnlich wie bei den Amphibien. Bei den Säugetieren liegen sie an der vorderen Epiglottiswand, an der solche einzelne Sinnesknospen von $\mathrm{H}$. Rabl (23) sogar bei dem Menschen gefunden wurden. Merkel (15) hat aber solche auch an der hinteren Wand entdeckt. Bei den Chiropteren verhält sich dies etwas anders. Jederseits lateralwärts an der vorderen Epiglottiswand, vor den Mündungen der Epiglottisschleimdrüsen (Textfig. 8 , sdr ${ }^{\prime \prime}$, sdr ${ }^{\prime \prime \prime}$ ), welche noch dem mittleren Schleimdrüsengebiet der Zunge, als deren hintere Fortsetzung angehören (Textfigur 3, A), befindet sich ein Streifen höheren Epithels, der'

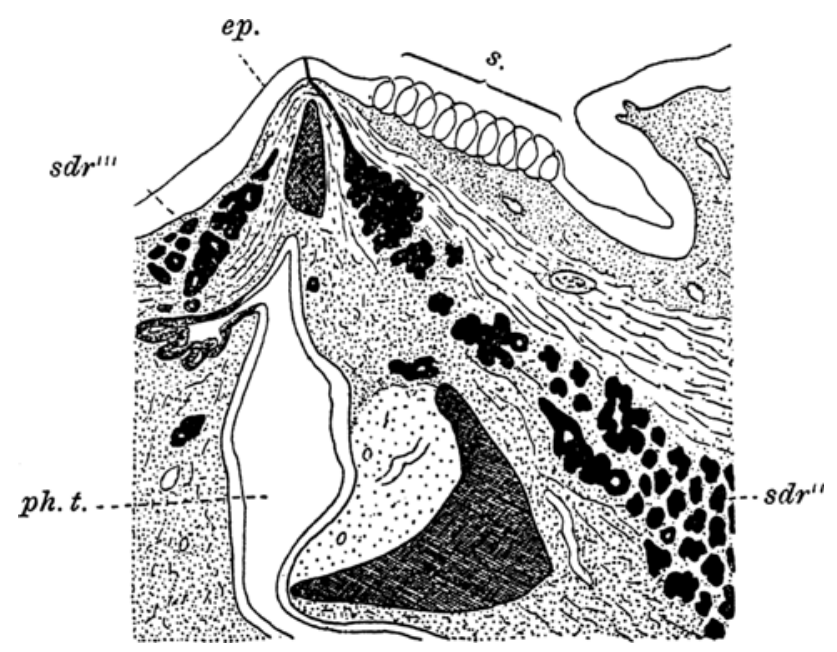

Fig. 8.

Vesperugo noctua. Latero-sagittaler Längsschnitt durch den Kehlkopf. s. $=$ Geschmacksknospenreihe; ep. = Epiglottis; $s d \mathbf{r}^{\prime \prime}=$ vordere, sdr $^{\prime \prime \prime}=$ hintere Schleimdrüsen der Epiglottis; ph. t. = Pharingealtasche.

durch eigenartige Zellgruppenreihen im Epithel mir schon beim Pteropusfötus auffiel. Bei Vesperugo fand ich dann, dass dieser hohe Epithelstreifen durch nebeneinander verlaufende Sinnesknospenreihen (Textfig. 8, s.) gebildet wird. Jeder Reihe gehören neun fest beisammen liegende Geschmacksknospen an, die völlig im Epithel gelegen sind und einen deutlichen Toldtschen Gang nach der Oberfläche zu aufweisen. Bei Pteropus waren sie noch im Werden begriffen und dürfte ihre Zahl dort vielleicht noch etwas grösser sein. Seröse Drüsen finden sich hier aber 
keine, so dass die Knospen gleich wie die auf den Pilzpapillen ohne jener funktionieren.

Damit wären wir angelangt bei der topographischen Verteilung der Zungendrüsen. Was die Schleimdrüsen betrifft, so lassen sich bei Vesperugo jederseits zwei Gebiete unterscheiden. ${ }^{1}$ ) Das seitliche Gebiet zieht von der lateralen Epiglottiswand zwischen dem Frenulum und der Tonsille nach vorne auf die Zunge (Textfigur 9, A, s. sd.), liegt hier laterodorsal, wird dann am Randorgan ganz schmal, um nachher in lateraler Lage wieder mächtiger $\mathrm{zu}$ werden (B, s. sd). Bis zu dieser Stelle münden die einzelnen Drüsen an der dorsalen Zungenfläche auf Schleimpapillen oder zwischen diesen. Dabei schlägt sich die Epithellage des oft langen Ausführungsganges auf die Keimlage des Epithels über, indessen der dünne Mündungsgang durch ein Plattenepithel in der dicken Schleimhautepithellage gebildet wird, welches die direkte Fortsetzung der äussersten Zellschichte ist und mit Beginn des Drüsenganges aufhört. Vor dem Randorgan aber ändert sich die Sache und die einzelnen Drüsen münden übereinander in der lateralen Wand der Zunge bis tief hinunter zur Anwachsungsstelle der Zunge (C, s. sd'). In dieser Weise erreicht das seitliche Schleimdrüsengebiet die Gegend der Sublingualdrüse und hört hier auf (Textfig. 9, s., sdr.). Auf Figur 10 habe ich dies Verhalten mit Blau eingetragen, wobei die unterbrochene blaue Linie jenen Teil der Schleimdrüsen darstellt, die lateralwärts münden.

Das mittlere Schleimdrüsengebiet zieht von der vorderen Wand der Epiglottis, mit dem der anderen Seite sich berührend (Textfig. 9, A, m. sd.) und zuvor die Epiglottisdrüsen bildend (Textfig. 3, A), etwas bis hinter die Wallpapillen und wird dann hier ganz schmal (Textfig. 9, B, m., sd.). Dies geht dann vor den Wallpapillen soweit, dass nur noch je eine Drüse das Mittelgebiet darstellt (C, m., sd). Damit hört dann, wie aus Fig.10 ersichtlich, dieses Gebiet vor dem mittleren Gebiet der serösen Drüsen auf. Alle Schleimdrüsen münden auf Schleimpapillen oder zwischen solchen.

Wesentliche Modifikationen erfuhr das Schleimdrüsengebiet bei Pteropus, denn hier fehlt das mittlere Drüsengebiet, dafür ist das

1) Das Verhalten der Schleimdrüsengebiete bei Plecotus auritus würde nach Oppels Beobachtungen (17) mehr mit den Verhältnissen bei Vesperugo stimmen, als mit denen von Pteropus, was ja zu erwarten war. 




m.srd. m.sd. s.srd.

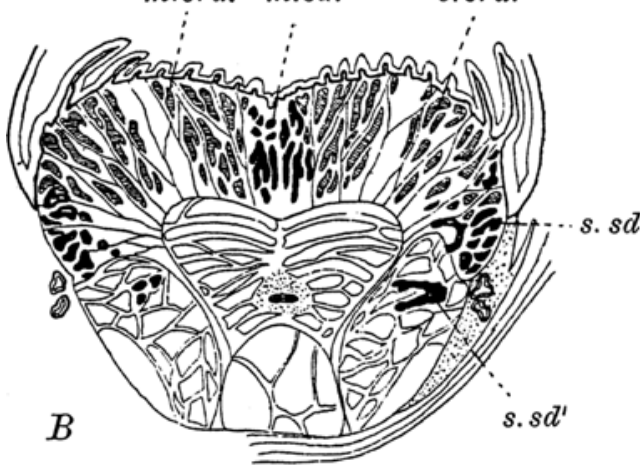

m. sd. m. srd.

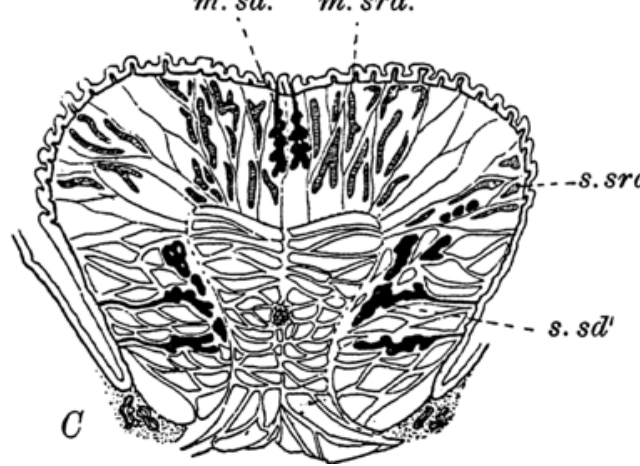

Fig. 9.

Vesperugo noctua. Drei Querschnitte durch die Zunge. A hinter den serösen Drüsenfeldern, B hinter den Wallpapillen, $C$ vor den Wallpapillen. m. sd. = mittleres, s. sd. = seitliches Schleimdrüsengebiet; m. srd. = mittleres, s. srd. = seitliches Gebiet der serösen Drüsen. seitliche um so mächtiger. Es beginnt das Schleimdrüsengebiet auf der ganzen lateralen Seite des Pharynx (Fig. 11 mit blau) zieht dann, das Frenulum völlig freilassend, lateralwärts, erreicht so das Randorgan, schlägt sich hier auf die ventrale Halfte der Zunge um (Textfig. 10 schwarz, Fig. 11 mit unterbrochener blauer Linie) und erreicht so in mächtiger Lage (Textfig. 10, B, schwarz und Textfig. $3, \mathrm{~B}$, sdr.) die Gegend der Sublingualis (sl.) um hier zu enden. Vom Randorgan an münden nur noch wenig Schleimdrüsen aber an der dorsalen Zungenfläche ('Textfigur $10, A$, sdr.), von da an nur noch an der lateralen, wie bei Vesperugo. Es sind diese Drüsen hier nichts anderes, als die Homologa der sogen. Sublinguales minores der höheren Säugetiere.

Allein auch diesbezüglich zeigt Pteropus Vesperugo gegenüber fortschrittliche Modifikationen. Anfangs sieht man nämlich zwar noch 
einzelne Drüsen für sich münden, dann aber nicht mehr. Vielmehr vereinigen sich mehrere Ausführungsgange zu einheitlichen Găngen (Textfig. 10, g.), die dann eine Strecke als Lăngsgänge nach vorwärts ziehen, um dann nach aussen biegend zu münden. So verringert sich die Zahl der Mündungen und werden Verhältnisse geschaffen, die an jene höherer Săugetiere erinnern.
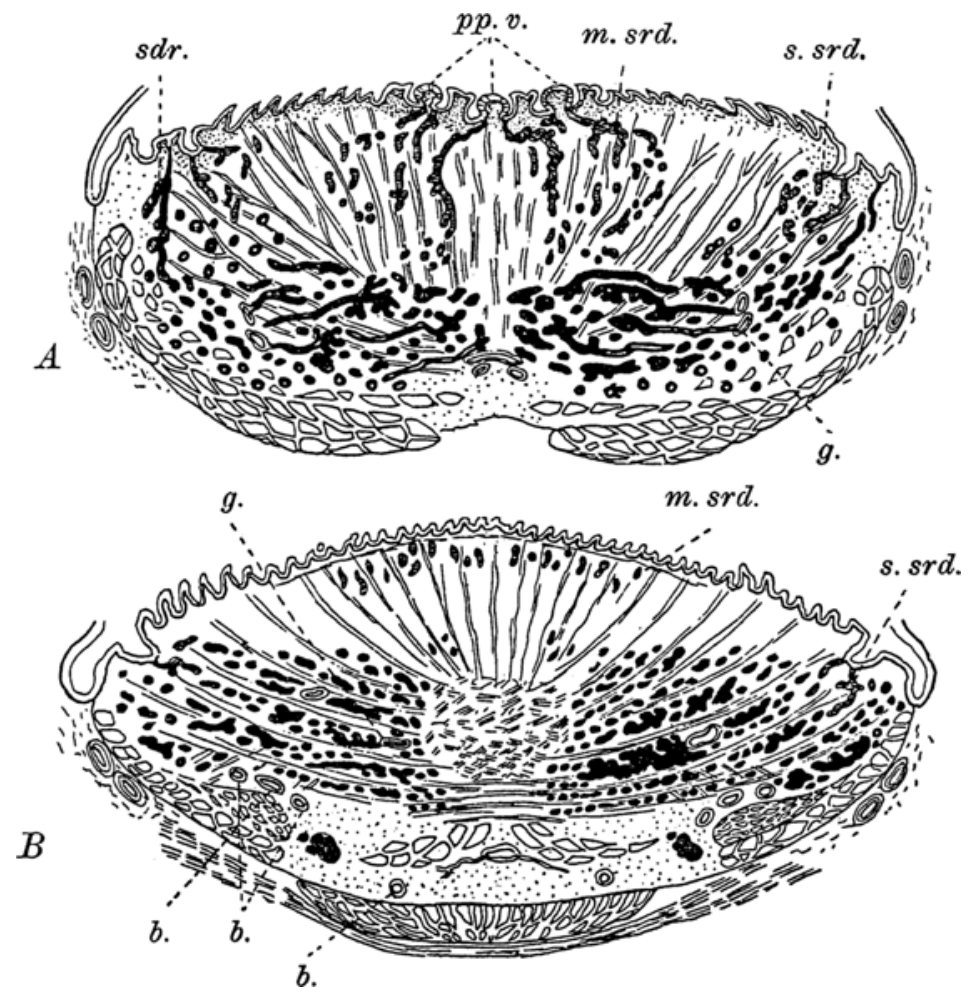

Fig. 10.

Pteropus edulis. Zwei Querschnitte durch die Zunge. A durch die Gegend der Wallpapillen, B vor derselben. Bezeichnungen wie zuvor.

$$
\text { g. = Drüsengänge; } b .=\text { Blutgefässe. }
$$

Die erste Drüse liegt sogar der Sublingualis an, seitwärts von der (Textfig. 3, B, sl.) dort mündend (u., sdr.).

Entsprechend den Sinnesorganen, in deren Diensten sie stehen, gruppieren sich folgerichtig die serösen Drüsen. Bei Vesperugo sind die beiden Gebiete der Wallpapillen (Fig. 10, rot) durch die mittleren Schleimfelder voneinander getrennt (Textfigur 9, m., srd.) und berühren nirgends die seitlichen Gebiete der 
serösen Drüsen (s., srd.). Beide Grebiete umgeben ihre Sinnesorgane. Anders bei Pteropus, denn da bei diesem das mittlere Schleimdrüsengebiet fehlt, liegen die beiden mittleren serösen Gebiete fest aneinander, mit Ausnahme unter der unpaaren Wallpapille, wo die Drüsen dieser sich auf jeder Seite den angrenzenden serösen Drüsen anschliessen, wodurch inmitten ein
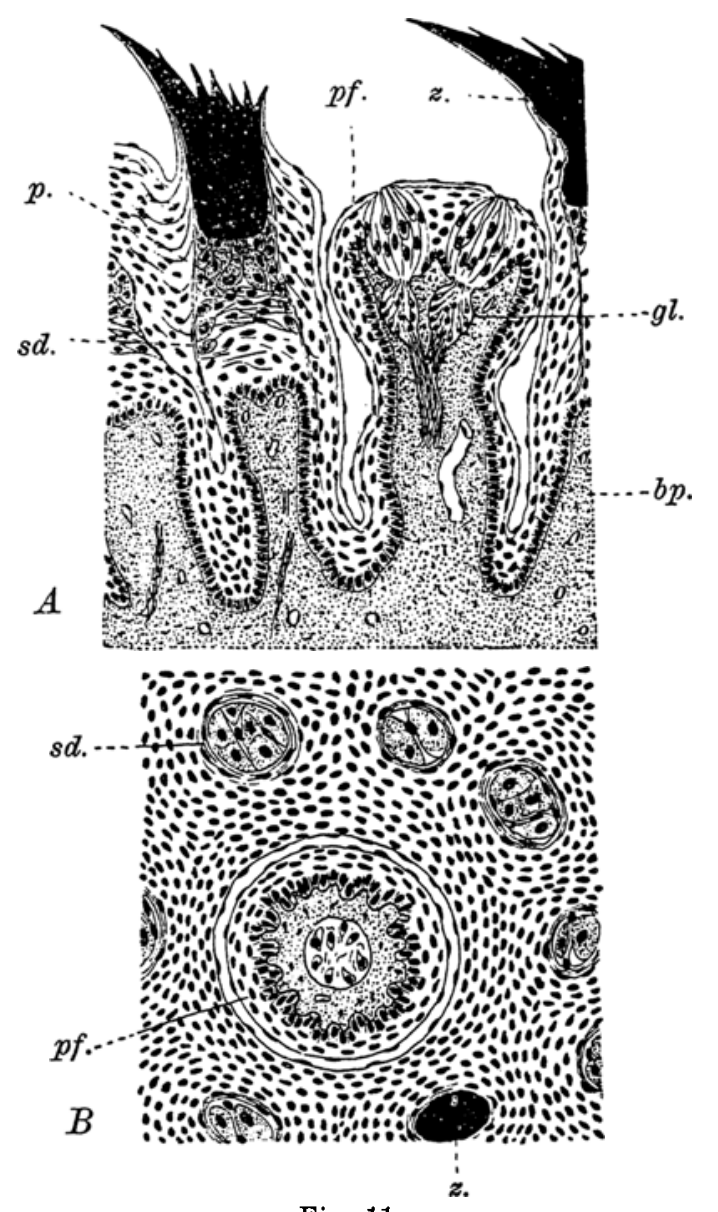

Fig. 11.

Vesperugo noctua. A Längsschnitt aus der Zungenspitze, B Horizontalschnitt etwas weiter hinten. pf. $=$ Pilzpapille; z. $=$ horniger Teil der Zähnchenpapille; p. = Papillenpolster; sd. = Papillenscheide; bp. = Bindegewebspapille; gl. = Ganglien. drüsenfr'eies Gebiet entsteht (Textfig. 10, A). Auch hier treffen sich die beiden Gebiete der gleichen Seitenhälfte nicht.

Hier möchte ich noch die Struktur der mechanischen Zungenpapillen besprechen. Ich halte mich aus leicht begreiflichen Gründen an die Zustände bei Vesperugo. Wie wir schon gesehen haben, ist das vordere Zungenfeld mitZăhnchenpapillen überzogen, deren Hornteil nach hinten gebogen ist, und wurde auch erwähnt, dass sie dort auf der Zungenspitze ausgefranst sind.

Das zweite Feld wird überzogen durch verhornte Koronalpapillen und endlich das dritte Feld durch unverhornteSchleimpapillen, von denen die lateralsten in der 
hinteren Zungenhälfte enorm gross sind und manchmal gelbbraun pigmentiert erscheinen. Im wesentlichen unterscheiden sich diese Hornzähne nur darin von den anderen auf dem ersten Zungenfelde, so dass ihre Struktur gemeinsam behandelt werden kann. Dass indessen im wesentlichen die Zähnchenpapillen von denen anderer Säugetiere sich nicht unterscheiden, und dass besonders die $\mathrm{Zu}$ stände, wie sie Poulton (20) für Marsupialier beschrieben hat, mit denen der Chiropteren übereinstimmen, brauche ich kaum zu versichern, wie denn auch die Nager, wie weiter unten gezeigt werden soll, gleiches aufweisen. Wenn ich mich hier trotzdem auf die ausschliessliche Berücksichtigung der Chiropteren beschrănke, so geschieht dies, da weiter unten doch die Resultate verknüpft werden sollen. Es liegen die Papillen sehr fest nebeneinander, wobei sie nur mit ihren scharfen Enden aus dem Epithel herausragen, was am besten ein bei schwacher Vergrösserung betrachteter Längsschnitt vergegenwärtigt (Textfig. 4). An der eigentlichen Papille lassen sich drei Teile unterscheiden, der bindegewebige (Textfig. 11, A, bp.), der darüber gelegene epitheliale (p., sd.) und der aus dem den epithelialen Teil in sich bergenden Epithel hervorragende hornige (z). Es kann der bindegewebige Papillenteil abgerundet oder oben eingekerbt sein, je nach der Măchtigkeit des ihm aufsitzenden epithelialen Teils. Die Papille ist hier sehr nervenreich und Gefăssschlingen treten in sie. An dem epithelialen Papillenteil lassen sich drei Lagen unterscheiden: erstens die Keimschichte, dann eine darüber liegende indifferente Schichte, und dann eine darauffolgende Lage, der der hornige Teil anfsitzt. Diese Epithellage sitzt der anderen etwa kuppelförmig auf und ihre Form richtet sich je nach der des hornigen Teiles. Es ist dies jene Lage, die Poulton bei Marsupialiern als dicke, mit Pikrokarmin sich nicht färbende und stark granulierte beschreibt und abbildet. Sie umgreift dann gewissermassen schalenförmig den hornigen Teil und obgleich die lateralsten Zellen ihre Rander nach oben biegen, konnte ich doch nie den Findruck einer zwiebelschalenförmigen Lage gewinnen. Tatsache aber ist es, dass die ausseren Zellen unter ihnen mit ihrem äusseren Rande, besonders die obersten, nach oben biegen, so die Papillenscheide (sd.) mitbilden helfend. Diese Zellen sind stark granuliert, grösser als die anderen darunter liegenden Epithelien und unterscheiden sich von diesen noch dadurch, dass ihre 
Kerne sich, wie seit Poulton für Pikrokarmin bekannt, mit Karminen und Metbylenblau weniger tief färben. Der Zellkörper macbt am ehesten den Eindruck von Drüsenzellen, was sie aber nicht sind. Ich glaube, der Name Papillenpolster passt am besten auf diese Zellkuppel.

Oben, unter dem hornigen Teil der Papille, bilden diese Zellen das Polster allein, unten aber schieben sich zwischen sie andere Epithelien ein, was auf Papillenquerschnitten (Textfig. 11, B) am besten $\mathrm{zu}$ beobachten ist. Sowohl die lateralsten dieser Zellen, als auch die lateralsten der darunter liegenden, mit Ausnahme der der Keimschichte, besitzen lateralst schalenförmig nach oben gerichtete Fortsătze, wie dies auch Poult on für die Marsupialier gesehen, und indem sich dann diese Fortsătze aneinander legen und durch solche die der Papille anliegenden Epithelien noch vermehrt werden, entsteht um die epitheliale Papille eine Papillenscheide (sd.), die dann auch noch an dem hornigen Papillenteil zu erkennen ist. Diese Scheide reicht hinunter bis zwischen zwei Papillen und oft genug hat man den Eindruck, als wenn sie hier auf die der angrenzenden Papille umböge. In der Papillenscheide lassen sich die Fortsătze einzelner Zellen nicht erkennen, sondern bloss der Eindruck ineinander gelagerter Ringe ist es, den man erbalt.

Das Papillenpolster kann nicht drüsig sein, denn der hornige Teil der Papille ist aus verhornten Zelllagen des Epithels herrorgegangen und diese ist somit keine kutikulare Bildung, ausserdem kommt ja dieses Polster auch dort vor, wo die Papillenoberenden nicht verbornt sind, wie unter anderem bei den Musteliden, wie wir das weiter unten sehen werden. Seine physiologische Bedeutung muss somit eine andere sein. Meines Dafür-

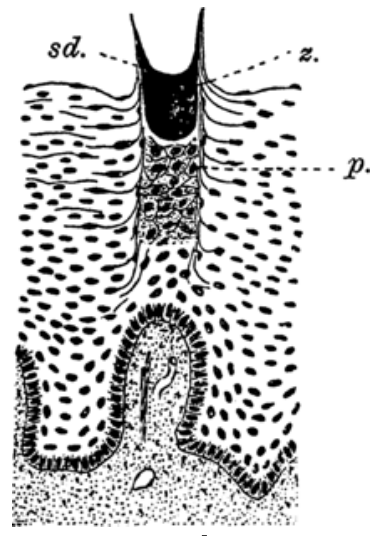

Fig. 12.

Vesperugo noctua. Querschnitt durch das zweite Zungenfeld. $\mathbf{z}=$ horniger Teil der Papille; p. = Papillenpolster; sd. $=$ Papillenscheide. baltens nach dürfte seine Bedeutung wohl darin liegen, den durch den Bissen auf die Hornzähnchen ausgeübten Druck zu mildern. 
Die Koronalpapillen des zweiten Drüsenfeldes sind nur bezüglich der Form des verhornten Endes modifizierte Zähnchenpapillen und zeigen infolgedessen auch denselben Bau. Ihr Zähnchen kann zwei- oder dreizackig sein, ist aber nie ausgefranst wie jene der Zungenspitze. Es lässt sich an ihm das Papillenpolster (Textfig. 12, p.) als auch die Papillenscheide (sd.) gut erkennen.

Mit der Năherung an das dritte Feld sind die Hornzăhnchen immer weniger verstreut, runden sich allmählich $a b$ und hören damit als solche auf. Hand in Hand damit wird das Papillenpolster immer geringer und an den völlig abgerundeten Schleimpapillen sind sie nicht mehr vorhanden. Doch gibt es da allmähliche Übergănge. Dann gibt es auch noch rundumwölbte Schleimpapillen, besonders aber spitz zulaufende, deren Kuppel oder Spitze noch einen geringen Grad einer Verhornung zeigt, wie besonders die schon erwähnten Randpapillen vor dem Randorgane.

Fassen wir nun das zusammen, was bisher über dieChiropterenzunge bekannt ist und vergleichen es mit den Zustănden der Marsupialier, so gelangen wir zu folgendem Ergebnis:

Eine Vermehrung der Wallpapillen hat nicht stattgefunden, ja nicht einmal die Tendenz zu einer solchen, die doch bei manchen Marsupialiern schon gegeben ist (Didelphys virginiana, Dasyurus hallucatus), ist nicht vorhanden. Eherzeigt sich eine Verminderung, indem bei Vesperugou. a. die unpaare Wallpapille fehlt. Bezüglich des Randorganes ist aber auch der gleiche Zustand wie bei den Marsupialiernerhalten, kein primarster, wie auch dort nicht mehr, sondern es gibt Randorgane mit vielen Elementen oder solche mit wenigen, wobei aber die funktionelle Energie kompensiert wird, erhöht wird durch machtigere Entfaltung. Bezüglich der Filzpapillen ist nur darin eine Änderung zu erblicken, dass dieselben eine reihenweise Anordnung sich errangen.

Das erste Zungenfeld gewinnt zwar dadurch mehr an sensibler Bedeutung, hat an Ausdebnung aber zugunsten des zweiten Feldes verloren, das nun besser zur Geltung gelangt. Die Mitte des 
ersten Feldes zeigt sich auch hier zu mechanischen Funktionen geeignet und können sich auch an ihm Hornzăhnchen kräftiger entfalten, wie eben bej Pteropus. Die Zungenspitze behalt ihren früheren hohen sensiblen Charakter.

\section{Insektivoren.}

Die Zunge von Erinaceus europaeus zeigt Verbăltnisse, die sie an die der Marsupialierzunge anreihen. Die kräftige Zunge verschmälert sich allmăhlich an ibrer Spitze (Fig. 12), um dann spitz zu enden. Eine Grenze zwischen einem ersten und zweiten Feld gibt es nicht, beide bilden zusammen die Zungenoberfläche vor den bekannten drei Wallpapillen, die selır weit nach hinten liegen (pv.) und hinter denen sich das Schleimdrüsengebiet durch seinen Oberflächenüberzug abhebt. Die Grenze des dritten Feldes beginnt somit mit den Wallpapillen.

Jene ganze grosse Zungenoberfläche wird durch ausserst zarte Zahnpapillen bedeckt, die im hintersten Gebiet mehrzackig sind. Es greift der Papillenbesatz auf die untere Zungenflache nicht über.

Die Pilzpapillen ordnen sich in ganz bestimmter Weise an. Vor den Wallpapillen besetzen sie auch die Mitte der Zungenoberfläche, von dieser Gruppe an aber ist die ganze mittlere Zungenoberflache bis auf die Zungenspitze von Pilzpapillen völlig fleei.

An den Seitenteilen der Zunge stehen die Pilzpapillen in Längsreihen. $\mathrm{Zu}$ äusserst am Rande befindet sich eine Reihe, die in der Mitte der Randorganslänge beginnt und hier hinten die grössten Pilzpapillen aufweist (pf.). So diese Reihe nach vorne zieht, werden die Pilzpapillen immer kleiner, bis sie an der Zungenspitze in den dicksten Pilzpapillenbesatz übergehen, der aber von sehr kleinen Papillen gebildet wird. Eine zweite $\left(\mathrm{pf}^{\prime \prime}\right)$ und dritte ( $\left.\mathrm{pf}^{\prime \prime \prime}\right)$ Reihe zieht parallel zur ausseren Zungenspitze und hängt mit der vorderen Gruppe zusammen, aus mittelgrossen Papillen bestehend.

Die drei sehr grossen Wallpapillen (pv.) stehen in nach vorne zu offenem Winkel und ist die unpaare Zentralpapille nur ein wenig grösser als die paarigen Wallpapillen. Ihre dorsale Oberfläche ist quergerunzelt wie die der zwei bei Talpa. Obgleich diese Papillen tief 
versenkt sind, gelangt doch kein Wall zur Entfaltung. Das Randorgan (ro.) besteht nur aus einem unvollkommenen Element, ein er halb en, in Form einer lăngsovalen, zur sagittalen Achse der Zunge quergestellten grossen Papille, die auf der vorderen Seite von einem Graben begrenzt wird. Die Papille (Textfig. 13) hat oben eine unterbrochene Längsfurche (f.) und der hintere Graben ist nur noch angedeutet $\left(\mathrm{g}^{\prime}\right)$, aber auch nicht überall so gut entwickelt. Unter ibm sieht man noch einige, in der Rückbildung begriffene Drüsenacini (punktiert), die jedoch keinen Ausführungsgang mehr besitzen

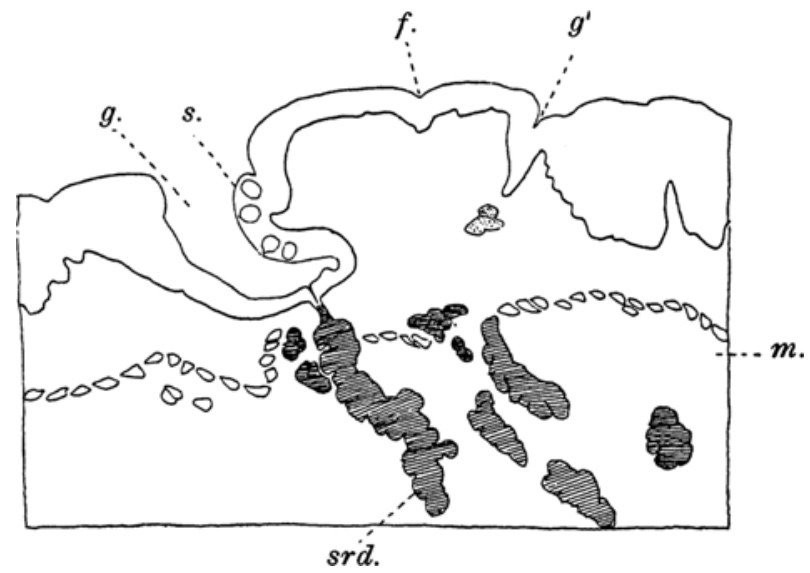

Fig. 13.

Erinaceus europaeus. Quergeschnittenes Randorgan. $\mathrm{g} .=$ erhaltene, $\mathbf{g}^{t}=$ rudimentäre Spalte; $\mathbf{s}$. $=$ Sinnesknospen; m. = Muskulatur; srd. = seröse Drüsen.

und sich viel heller färben als jene der mündenden serösen Drüsen (sdr.). Der Graben umgibt somit die Papille nur von vorne und um die beiden Enden. Eines dieser Enden hatte Oppel auf dem Schnitte getroffen, an dem dann die Geschmacksknospen die Papille umringeln, sonst aber nur an der dem Graben zugekehrten Seite in drei oder vier Lagen sich finden (s.). Die Papille selbst ist somit nur teilweise versenkt. In den Boden des Grabens münden die Drüsen. Grmelins Befund ist ăhnlich.

E. Simier.

Unter den Simiern zeigen sich bei den niedersten Formen Zustände, die eher bei den Halbaffen vermutet werden konnten, Archiv f. mikrosk. Anet. Bd. 74 . 
und welche Zustände nur zu lebhaft an die niedrigen Zustände der Zunge der Insektivoren erinnern. Von diesen Zustanden der Zungenoberfläche bis zu jenen des Menschen ist ein so schöner Übergang selbst durch die wenigen Formen, die ich zu untersuchen Gelegenheit hatte feststellbar, wie sonst in keiner höheren Säugetierabteilung, wie den bei den Simiern mit den Prosomiern beginnend, die doch an Insektivoren anschliessen, auch in anderen anatomischen Beziehungen die Deszendenz sich ja sehr lebhaft ausprägt. Dabei zeigen, wie wir sehen werden, manche Lemuriden ${ }^{1}$ ) Zustănde an der Zungenoberflache, die wohl bezüglich des Phyletischen besser zwischen niederste Simier und Cercopitheciden hineinpassen würden, allein wir dürfen nicht vergessen, dass bei der phyletischen Entfaltung nicht alle Organe gleichen Schritt einhalten. Ich beginne somit mit der Zunge von Hapale penicillata.

Die wie bei allen Affen abgestutzt beginnende Zunge lässt die drei Felder von der Oberfläche aus betrachtet nicht erkennen und nur das dritte Feld (Fig. 22, III) ist dem grossen vorderen Felde gegenüber gut bezeichnet, indem mit ersterem beginnend, die Zähnchenpapillen aufhören und dann das dritte Feld grosse, breite, abgeflachte, zum Teil miteinander verwachsene Schleimpapillen führt. Immerhin ist an dem vorderen Feld dadurch ein hinteres kleineres Stïck abgegrenzt, dass in diesem sich gar keine Pilzpapillen finden. In diesem Gebiet hätten wir es dann doch mit einem zweiten Felde niederer Săugetiere zu tun. In dem ersten Felde sind zwischen den Zähnchenpapillen eine grosse Zahl verschieden grosser Pilzpapillen eingestreut, ohne dass eine bestimmte Anordnung dieser erkennbar wăe. Sie stehen recht dicht beisammen. Eine Verdichtung an der Zungenspitze ist mir nicht' aufgefallen.

Genaustens an der Grenze zwischen dem dritten und zweiten Feld liegt in der Zungenmitte die einzige überaus grosse, ãusserlich als solche erkennbare Wallpapille, deren Wall nach hinten zu in zwei Wülste auslăuft, von denen der rechte ganz kurz, der linke aber ansehnlich lang ist und bis zum Frenulum reicht, wo er mit einer der mittelgrossen Schleimpapillen verschmilzt. Dieser Wulst (w.) hat, wie wir sehen werden, eine gewisse phy-

1) Die richtige Bestimmung der Formen in der hiesigen anatomischen Sammlung vorausgesetzt. 
letische Bedeutung und möge er jetzt schon der Sagittalwulst genannt werden.

Bei genauer Betrachtung fällt es auf, dass zwei grosse Papillen am hinteren Ende des ersten Feldes, die grössten unter såmtlichen Pilzpapillen, zwar keinen Wall besitzen, doch deutlich mit einem Ringgraben umsäumt sind. Nachdem dies festgestellt
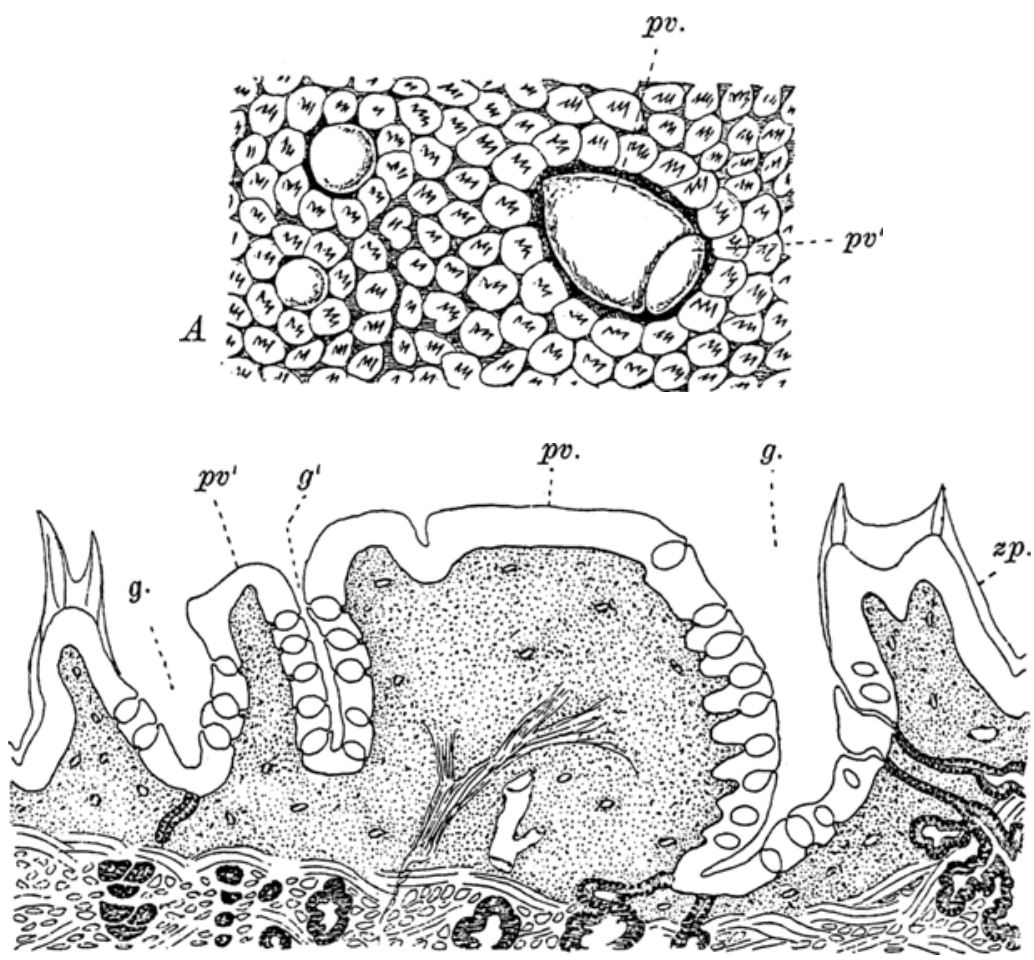

$B$

Fig. 14.

Hapale penicillata. A die auf Fig. 22 sich bei p. findende eine Papille bei starker Lupenvergrösserung. B ein Querschnitt dadurch. pv. = Haupt-, $\mathrm{pv}^{\prime}=$ Tochterpapille; $\mathrm{g} .=$ Grabenwall $; \mathrm{g}^{\prime}=-$ Teilungswall.

wurde, konnte an der rechtsseitigen mit starker Lupenvergrösserung auch beobachtet werden (Textfig. 14, A), dass er durch eine Querfurche in eine innere kleinere (pv.') und eine aussere grössere Hälfte (pv.) abgeteilt ist. Dabei ist wie gesagt diese ganze Papille nur von den gewöhnlichen Zăhnchenpapillen umgeben, die allerdings zu einem Ringe sich verdichteten. Ähnliches zeigte sich auch 
an den beiden seitwärts liegenden kleinere Papillen, was sonst an den anderen Papillen dieser Art nicht der Fall ist.

Zum Glück war diese Zunge noch geeignet zum Schneiden und das Epithel erhalten. Ich machte also Querschnitte durch diese Papille. Da ergab sich dann folgendes wichtige Verhalten. Der grosse Teil der Papille zeigt neben der Grenzfurche (Textfig. 14, B, g) zwischen ihm (pv.) und dem kleinen Abschnitt (pv.') noch eine ganz kurze seichte Furche. Es teilt die tiefe Grenzfurche $\left(g^{\prime}\right)$, die bis auf die Bodenhöhe des Wallgrabens (g.) reicht, die zwei Abschnitte der Papille vollstandig voneinander. Die Seitenwände der gesamten Papille wie der Tochterpapille tragen Geschmacksknospen, die weit hinauf bis an die dorsale Papillenfläche reichen, ohne, dass an derselben sich solche befinden würden. Auch die Grabenseiten der angrenzenden Zähnchenpapillen (zp.) führen Geschmacksknospen. Die beiderseitigen grossen Papillen sind zwar nicht sehr dicht, wie wir das gewöhnt sind, doch immerhin genügentlich mit serösen Drüsen umgeben, und diese münden in den Boden des Wallgrabens (g), zum geringen Teil aber auch weiter oben an der Wallseite der angrenzenden Zăhnchenpapillen, hier zwischen den Geschmacksknospen. In der Furche zwischen den beiden Teilen der Papille $\left(\mathrm{g}^{\prime}\right)$ münden keine Drüsen, nur dort, wo diese Furche sich mit dem Wallgraben vereinigt, also an diesen $z$ wei Stellen.

Die beiden kleinen Pilzpapillen auswärts von der oben beschriebenen grossen Papille (Textfig. 14, A) sind wie gesagt gleichfalls mit einem noch seichten Wallgraben umgeben, doch fehlten seröse Drüsen vollstăndig. Die Geschmacksknospen liegen in ansehnlicher Zahl auf der dorsalen Fläche der Papille, so dass sie noch auf den Rand der Seitenwănde übergreifen, ohne diese besetzt zu haben.

Aus diesem Befund lässt sich die Schlussfolgerung ziehen, dass die beiden seitlichen kleinen Papillen zwar noch Pilzpapillen, da ohne seröse Drüsen, von den anderen sich dadurch unterscheiden, dass die Zahl ihrer Geschmacksknospen zugenommen und infolgedessen auf die Seitenwände der Papille sich fortzusetzen beginnt und dass ein Wallgraben im Beginne der Bildung sich befindet. Demgegenüber sind die grossen Papillen schon zu einer ausgesprochenen Wallpapille geworden, deren Wall allerdings noch aus getrennten Zähnchenpapillen besteht. Von diesen möchte 
ich aber noch mitteilen, dass nicht überall in der Schnittserie Geschmacksknospen an ibren Grabenseiten sich befinden und dass somit nur einige von diesen wallbildenden Papillen an der genannten Stelle Sinnesknospen führen, was wieder annehmen lăsst, dass diese letzteren ursprünglich Pilzpapillen waren und nur nach ihrer zum Wall erforderten Umbildung Zalunchenaufsatz erwarben. So liegt denn die Genese einer Wallpapille hier vor uns. Sie ist aus einer Pilzpapille geworden, dafür sprechen $u$. a. noch die Übergänge an den kleinen seitlich gelegenen Papillen; sie erwarben die serösen Drüsen spontan - wofür bei den Ungulaten der-direkte Nachweis erbracht werden soll - wobei dann sowohl zufällig angrenzende Pilz-als Zăhnchenpapillen das Material zu einem $\mathrm{zuk}$ ü $\mathrm{ftigen} W$ all lief ern. Damit erringen diese ersteren den Forderungen entsprechend andere Bedeutung.

Diesem indirekten Entstehen von Wallpapillen gegenüber zeigt vorliegender Fall aber auch das Entstehen einer Wallpapille durch Teilung, also direkt, denn die Nebenwallpapille $\left(\mathrm{pv}^{\prime}\right) \mathrm{kann}$ nur als Teilstück der grösseren Papille gedeutet werden. Hier brauchen nun keine serösen Drüsenspontanzu entstehen, denn nachdem die senkrechte Teilfurche den Boden der Wallfurche erreicht, umwachsen die Drüsen den neuen W allgraben. Indem ich auf diesen wichtigen Fall noch zurückkommen werde, möchte ich nur noch bemerken, dass der Prozess der Teilung einer Wallpapille hier noch nicht als abgeschlossen betrachtet werden kann.

Es besitzt die Hapalezunge auch Randorgane, deren Elemente zwar mächtig aber gering an Zahl sind. Ich zählte an jeder Seite vier (Fig. 22, ro.), bei Stenops gracilis nur zwei. Es sind die Randorganelemente hier tiefe Furchen, die nach aussen durch einen Wall umsäumt und somit nach dieser Seite abgeschlossen erscheinen; während die Wälle nach innen dem dritten Felde zu offen sind und als Längsfalten dort sich allmăhlich verlieren. Nur links war das zweite mit dem dritten Element insofern in Beziehung, als ihre angrenzenden Walle ineinander umbogen.

Im dritten Feld münden die Schleimdrüsen, wo grosse, breite und abgeflachte Schleimpapillen vielfach mit angrenzenden $\mathrm{zu}$ 
längeren Wällen verschmelzen können. Dieses Feld ist klein und erinnert somit an niedere Säugetierzustände.

Die Zunge von Lemur varius (Fig. 23) zeigt bei sonst gleichbleibenden Zuständen an dem ersten Feld wie bei Hapale an dem hinteren Zungenende solche Verbaltnisse, die als phyletisch jünger bezeichnet werden müssen. Das Schleimdrüsengebiet hinten ist gross und scheint im Vergleich mit Hapale das dritte Feld (III) das zweite völlig dadurch verdrängt zu haben, dass hier kleinere Schleimpapillen aus den Zäunchenpapillen wurden, die ganz allmählich nach hinten zu in grössere bis sehr grosse übergehen. Alle Schleimpapillen sind zugespitzt und schauen nach hinten. An der einzigen untersuchten Zunge waren neun Wallpapillen vorhanden, von denen fünf zu einer, vier zu einer anderen Gruppe sich zusammen fanden. Fünfe standen in einer ganz geraden mediosagittalen Reihe. also genaustens in der Mitte des Schleimdrüsenfeldes (pv.). Dabei gingen ihre ansehnlichen, glatten Wälle so ineinander über, wodurch dieser Wallwulst einheitlich ward, wobei der Wall der hintersten Papille in zwei geringere WüIste auslief wie bei Hapale.

In diesem ganzen Wulst haben wir es somit mit dem Sagittalwulst jenes Affen zu tun und diese ganze Wallpapillenreihe kann nur von der Einzelwallpapille des Hapale abgeleitet werden. Die hinterste Papille ist gross, doch nicht so gross wie bei Hapale, die zweite anliegende etwas kleiner, die dritte wieder grössere liegt etwa in der Mitte des Sagittalwulstes, dann folgen zwei entferntere kleinere. Die erste ist die kleinste. Ähnliche Zustände bestehen nach $\mathrm{Mün} \mathrm{ch} \mathrm{(16)} \mathrm{auch} \mathrm{bei} \mathrm{Lemul} \mathrm{mongoz,} \mathrm{rufifrons,}$ melanocephalus bei zwischen fünf bis zehn variierender Papillenzahl. Die vorderen, nicht wie bei $L$. varius quer, sondern in nach vorne zu offenem Winkel gestellten also paarigen haben die grössere Zahl, die sagittal orientierten die geringere, zwei bis drei. Somit sind letztere für Lemur bezeichnend.

Die andern vier Wallpapillen sind quergestellt und gleichweit voneinander entfernt, ohne dass ein Zusammenhang unter ihnen bestünde. Die zwei ausseren sind grösser als die beiden inneren. Die Reihe liegt genauestens an der vorderen Grenze der Schleimpapillen. Diese nicht ovalen, wie die der sagittalen Reihe, sondern gleichmässig runden Papillen besitzen zwar gute Wälle, allein nur nach hinten $z u$ sind diese einheitlicher, auch 
dort laufen sie in Schleimpapillen aus, nach vorne zu bestehen sie aus kleinen fest beisammen liegenden Schleimpapillen. Das Verhalten der Wălle ist für die beiden Wallpapillenreiben, der sagittalen und queren, höchst bezeichnend bei Würdigung des Verhaltens zu dell Verhältnissen von Hapale und weisen auf ihre Genese hin. Ich glaube nicht zu weit zu gehen, wenn ich behaupte, dass die sagittale Wallpapillenreihe aus der grossen Wallpapille des Hapalezustandes, die quere aber von jenen Wallpapillen im Zahnchenpapillengebiet abzuleiten sind.

Die beiden Randorgane (ro.) waren besser entwickelt als bei Hapale und auch hierin zeigt sich ein Fortschritt dieser gegenüber. Ich zăhlte rechts dreizehn, links elf Elemente. Die Rinne ist an den drei hintersten Elementen nach hinten gerichtet und offen, die der mittleren grössten Elemente nach innen und hinten, indessen die vordersten fünf, beziehentlich sechs Elemente, die nach vorne zu immer kleiner werden, auch nach innen $z u$ geschlossen. Die Wände der grösseren Elemente sind măchtig und eingekerbt.

Wir können bezüglich der geschlossenen vorderen kleinen Elemente hier nicht von einer Rückbildung, eher von einer begonnenen Vermehrung sprechen, da die höheren Simier zahlreiche Elemente besitzen.

Unter den drei untersuchten Gattungen der Familie der Cercopitheciden, Cercopithecus, Semnopithecus und Macacus bestand insofern ein Unterschied, als die erste Gattung mehr Ursprüngliches aufweist, die zwei anderen miteinander sehr übereinstimmenden Späteres.

Bei Cercopithecus sabaeus ist der hinterste Teil, das dritte Feld (Fig. 24, III), nicht mit Schleimpapillen besetzt, sondern bat die Oberflache ein netzförmiges Relief mit tiefen und weiten Zwischenmaschenrăumen, in denen mit der Lupe viele kleine Öffnungen von Schleimdrüsen $z u$ erkennen sind. Die Zwischenmaschenräume werden nach vorne $\mathrm{zu}$ immer enger, bis sie sçlliesslich nur noch einer oder nur wenigen Drüsen zur Mündung dienen. Das vorderste Gebiet des dritten Feldes wird durch kleine Schleimpapillen überzogen. Inmitten des dritten Feldes zieht mediosagittal der breite Sagittalwulst nach vorne, wird dann breiter und teilt sich in zwei Äste, von denen jeder 
nach der entsprechenden Seite und nach vorne $z \mathfrak{u}$ gerichtet ist, um dann etwas hinter dem breiteren Ende des Randorganes, doch weit nach innen von ihm, mit je einer grossen, wohl umwallten Papille zu enden. Ausser diesen beiden Wallpapillen fanden sich an der Gabelungsstelle des Wulstes noch zwei gleichgrosse gut umwallte Wallpapillen von gleicher Grösse wie die vorderen. Es waren also im ganzen vier Wallpapillen vorhanden und eine mittlere unpaare fehlte. Der ganze Wall war von Schleimdrüsenmündungen durchlocht und waren die Papillenwälle ihm gegenüber gut abgesetzt.

Die kleinen zum Teil hier nicht mehr verbornten Papillen des vorderen Zungenteiles überragen den ganzen dreieckigen Raum zwischen den Schenkeln des Wulstes, ohne dass zwischen ihnen sich Pilzpapillen befunden hatten. Diese in gleichmässiger Verteilung auf dem ersten Felde hören vielmehr vor diesem dreieckigen Felde unter nach hinten gerichtetem Winkel auf. Dieses dreieckige Gebiet ist dann wohl der einzige Repräsentant des zweiten Zungenfeldes. Das Randorgan (ro.) hat 16 Elemente, die als schmale Spalten nach hinten und aussen gerichtet sind, wobei die drei letzten je in eine Rinne auslaufen, die sich aber auf die Seitenwand der Mundhöhle fortsetzen. Die Elemente sind sonst nur klein.

Die Zunge von Semnopitbecus entellus war der von Macacus (spec.?) gleich, wie dies auch für andere Macacus-Arten nach Münch (16) gilt, so dass ich mich bis auf das Randorgan, das bei Macacus etwas anders gestaltet war, bei der Beschreibung an die erste Form halten kann.

Die gleich breite Zunge (Fig. 25) verschmălert sich gegen das vordere Ende etwas, um dann an der abgestutzten Zungenspitze wieder die frühere Breite zu erlangen, wodurch die Zungenspitze bezeichnet wird. Das erste Zungenfeld (I) zeigt sich dem zweiten gegenüber gut begrenzt, denn erstens hörten mit ihm die zarten Zăhnchenpapillen auf, und das zweite Feld (II) zeigt in seiner Mitte ein deutliches Tuberculum. Auf diesem Tuberculum befinden sich zwar abgerundete, niclrt verhornte Papillen, allein an den beiden Seiten des Feldes besitzt die Schleimhaut ausserst zarte Querfurchen, die etwas nach vorne geneigt an die Zungenseite hinziehen. Demgegenüber befinden sich bei Macacus auch hier kleine Papillen, die jedoch sich in 
kleine Felder gruppieren (Fig. 8). Die Pilzpapillen sind an dem ganzen ersten Zungenfelde gleichmässig verteilt, setzen sich aber auch auf das Tuberculum des zweiten F'eldes (II) fort, ohne indessen die Wallpapillen zu erreichen.

Das dritte Feld (III) besteht aus einem hinteren und einem vorderen Abschnitt. Frsterer ist abermals von netzförmigem Relief, doch ist das Netz nicht so schön geformt als bei Cercopithecus und sind auch die Gruben viel kleiner. Ganz hinten vor dem Pharynx laufen die Netzmaschen in Längsfalten aus. Der vordere Teil des dritten Feldes ist mit kleinen Schleimpapillen bedeckt.

Eigenartig, schon an die Anthropoidenzustände mahnend, ist das Verhalten der Wallpapillen. Sie zeigten die Anordnung in einen nach vorne offenen Winkel wie bei Cercopithecus, allein nicht nur ist der Sagittalwall bis auf einen breiten hinteren Abschnitt verschwunden, sondern es zeigt sich auch eine starke Vermebrung der Zahl der Wallpapillen.

Eine, allerdings kleine unpaare Wallpapille, deren Wall nach hinten offen ist und die beiden Enden nach hinten auslaufen, erinnert noch an die Zustănde von Hapale, darauf folgen aber am vorderen Ende des Sagittalwalles zwei grösste, nebeneinander lagernde, gleichfalls gut umwallte Papillen, welcher Zustand an Cercopithecus erinnert. Auch des weiteren leiten sich die Zustände von dieser Form ab, da von hier ab die zahlreichen Wallpapillen sich in zwei Schenkeln anordnen, die ein nach vorne offenen Winkel bilden. Im rechten Schenkel waren drei gleich weit voneinander entfernte grössere Wallpapillen und neben dem ersten dieser lag ein ganz kleiner, auch gut umwaller ersterer fest an. Auf der linken Seite (pv.) begann der Scbenkel von hinten mit zwei kleinen Wallpapillen und hierauf folgten drei grössere.

In der Anordnung der Wallpapillen vereinigen sich somit Hapalezustănde mit Cercopithecuszuständen, das Dreieck mahnt an letztere, die unpaare Papille an erstere.

Das Randorgan besteht aus je 17 Elementen, von denen die vordersten an beiden Enden des Schlitzes in Furchen auslaufen, die grössere Zahl aber, die vordere nămlich, nur an einem Ende. Diese verlaufen sich in zarte Furchen, die auf das zweite Feld hineinlaufen. 
An Zahl der Elemente weist auch Macacus Semnopithecus gegenüber keine grosse Überlegenheit auf, allein die einzelnen Elemente sind kräftiger. Bei starker Lupenvergrösserung (Fig. 8) erscheinen all den vorderen mächtigeren Elementen (e.) auf jeder Seite des Schlitzes stark eingekerbte, verhältnismässig măchtige Wülste, die sowohl nach aussen, dem geschlossenen Ende des Schlitzes zu, als auch nach innen plötzlich abschneiden. Hierdurch entsteht eine äusserst bezeichnende Schlitzform. Diese Form änderte sich an den vordersten, allmählich kleiner werdenden Elementen ( $e^{\prime}$ ) dadurch, dass bei ihnen der vordere Wulst im Schlitz fehlt, der hintere aber um so kräftiger ist.

Die Zunge des Anthropoiden, ich habe eine Orangzunge vor mir gehabt, leitet sich direkt von der Semnopithecuszunge $a b$.

Mächtig und breit ist die Zunge hier (Fig. 26), wobei ein erstes Feld von einem zweiten nicht abgegrenzt ist, vielmehr bildet die ganze grosse vordere Zungenhälfte eine einheitliche Fläche. Ein schwach sich vorwölbendes Tuberculum ist indessen vorhanden. Diese ganze Fläche ist von kleinen, wenig verhornten Papillen überzogen, somit samtartig, zwischen denen eine grosse Zahl von Pilzpapillen einlagert und zwar in durchaus unregelmässiger Anordnung, doch ziemlich gleich weit voneinander. An der Zungenspitze sind sowohl die kleinen Papillen als auch die Pilzpapillen kleiner, letztere nehmen dafür aber ganz enorm an Zahl zu. Ein weiterer Unterschied zwischen der Zungenspitze von Semnopithecus und des Orang besteht dann noch darin, dass die Papillen bei ersterem an der unteren Zungenfläche nur einen dünnen Saum bilden und zwar ohne Pilzpapillen, indessen beim Orang der Papillenbesatz die ganze ventrale Zungenspitzenflache einnimmt. Es sind hier unten aber nur grosse, verschieden grosse runde Papillen vorhanden, von denen manche eine sehr deutliche Öffnung an der Kuppel haben. Man denkt dabei unwillkürlich an Schleimdrüsenmündungen, doch sind solche erst auf mikroskopischen Schnitten festzustellen, wie denn auch das Vorhandensein oder Fehlen von Pilzpapillen. Dafür war das untersuchte Exemplar ungeeignet.

Das dritte Zungenfeld (III) ist mit ungleich grossen abgeplatteten Papillen besetzt, von denen viele enormen Umfang erreichen. Diese liegen mehr im hinteren Abschnitt, vorne sind 
kleine vorbanden, die in Längsreiben angeordnet, in Längswülstchen übergehen können. Viele aller Papillen führen in der Mitte ihrer Kuppel die Yündung je einer Schleimdrüse.

Die kleinsten Papillen ordnen sich am Randorgan in Reihen, die dann zu den Elementen hinführen.

Ähnlich wie bei Cercopithecus zieht der Sagittalwall in der Mitte des dritten Zungenfeldes vom Frenulum pharyngis an entlang des ganzen Feldes nach vorne, um dann am vorderen Ende des Feldes sich in zwei nach aussen und vorn ziehende Schenkel teilend (w.), das dritte Feld nach vorne abzuschliessen und vor diesem ein Dreieck zu bilden.

Der ganze Wulst ist durch Langsfurchen durchsetzt, in die zum T'eil Schleimdrüsen münden und fransen sich seine Rander in spitz auslaufende Wülstchen aus. Solche Schlitze, wie diejenigen sind, welche Schleimdrüsenmündungen bergen, schliessen auch mancbe einzelne Wallpapille ein oder Längsreihen von dreien solcher, dadurch deren Walle bildend. Grössere Wallpapillen haben zwar auch eigene Wälle, doch gehen diese nacb vorne und hinten doch in den Wulst über. Nur die vordersten der Wallpapillen zeigen zum Teil Walle, die aus Papillen gebildet werden, wenigstens nach vorne zu. In dieser Weise entsteht eine so unendliche Mannigfaltigkeit, wie mir das sonst nirgends begegnete.

Manche Wallpapille ist in der Kuppenmitte durchbohrt, ob durch Drüsen muss erst entschieden werden, doch kommt ja ähnliches beim Menschen vor.

Die Grösse und Anordnung der Wallpapillen im Wulste ist somit sehr veränderlich, doch lässt sich feststellen, dass die hinterste, gut umwallte Wallpapille der unpaaren Zentralpapille niederer Formen entspricht.

Wenn mehrere Wallpapillen in gemeinsamer Umrahmung hintereinander stehen, kann wohl angenommen werden, dass dieselben durch Teilung entstunden, doch lagern Wallpapillen auch in der inneren Seite des Dreieckes halbbewallt nach vorne zu offen im Wulste und da sich hier fast angrenzend auch Pilzpapillen befinden, so ist auch die Annabme vollberechtigt, dass die immense Zahl der Wallpapillen des Orang - die Zahi beträgt an der untersuchten Zunge 27 - auch durch Umwandlung von Pilzpapillen erfolgte. 
Das Randorgan ist enorm entfaltet - wohl nur noch bei der Hystrix so stark - es sind 29 Elemente jederseits. Obgleich die meisten quergestellt sind, sind die vordersten drei oder vier nach innen offen und verlaufen dann in Längsrinnen, welche an einer ansehnlichen Längsfalte (f.) an der lateralen Mundhöhlenwand nach hinten führen. Diese Falte findet sich ja auch bei niederen Simiern, doch nie so mächtig wie bei den Antbropoiden und dem Menschen, denn auch bei dem Gorilla zăhlte Ehlers (7) jederseits 15 tiefe Schlitze.

Das Schleimhautrelief der Menschenzunge schliesst trotz mancher Eigenarten doch an das der Anthropoiden an. Grossen Schwankungen ist bekanntlich die Zahl der Wallpapillen unterworfen, denn nach Angabe sämtlicher Autoren variiert sie sebr. Nach diesen Angaben wäre die kleinste Zahl 6 (Kölliker) und die grösste 20 bis über 20 (A. v. Haller).

Die Beschreibung, die einstens $\mathrm{Henle}$ in seinem klassischen Handbuch (9, pag. 133) für diese Zungengegend gegeben, ist so zutreffend, dass ich sie hier wörtlich wiedergebe. „Die wallförmigen Papillen gleichen an ihrer freien Oberfläche den pilzförmigen. Die zahlreichen sekundären Papillen derselben, sowie der Säume, von welchen sie umschlossen werden, sind in der Regel in eine ausserliche glatte Epithelbekleidung aufgenommen, und ebenso finden sich als Varietăt wallförmige Papillen mit gesondert überzogenen sekundăren Spitzen. . . . Die freie Oberfläche ist eben und selbst grubenförmig vertieft; nur die kleiısten Papillen dieser Gattung haben eine sanftgewölbte Oberflache. Die grössten zerfallen durch tiefere Einschnitte in $z$ wei und mehrere Papillen, was sich auch so ausdrücken lässt, dass eine Anzahl von Papillen von einem gemeinsamen Walle umgeben werden. ${ }^{1}$ ) Nicht selten ist der Wall unvollkommen entwickelt, niedrig, einseitig oder er fehlt ringsum; dadurch geht der Unterschied der wallförmigen von den pilzförmigen verloren. Umgekehrt kommen hier und da zwischen wohlgebildeten wallförmigen Papillen enge ringförmige Säume ohne Papille vor, deren Öffnung sich wie die Mündung einer Drüse ausnimmt. Das Foramen coecum kann von einer breiten abgestutzten Papille so vollkommen ausgefüllt sein, dass es sich in nichts von einer gewöhnlichen wall-

1) Diese sah J. B e cker auch bei dem Hunde (1. c. Fig. 36). 
förmigen Papille unterscheidet. Ebenso oft beherbergt es nur eine oder einige kleinere Papillen, die die aussere Mündung nicht erreichen." Immer sind aber die Wallpapillen in nach vorne zu offenem, mehr weniger spitzen Winkel gestellt, der seinen Abschluss nach hinten mit dem Foramen coecum, in dem von mir abgebildeten Falle (Fig. 27) mit einer schönen grossen Wallpapille findet.

Sind die Reihen der Schenkel oft auch sehr verworfen, manchmal auch nicht, so zeigen die vorderen Schenkelenden immer die durch die Phylogenese vorgeschriebene Lage im Dreieck.

Der beim Orang sich noch findende Sagittalwulst mit den beiden Schenkeln besteht nicht mebr und eher ist von einer gleichgelegenen Rinne zu sprechen, welche das dritte oder Schleimdrüsenfeld (III) nach vorne abschliesst. Dieses Feld erinnert mit seinen grossen, von Schleimdrüsen durchsetzten niedrigen Papillen nur zu sehr an den Orang.

Die zahlreichen Pilzpapillen verbreiten sich ohne regelrechte Anordnung an der ganzen Zungenoberfläche wie beim Orang und nur in der Zungenmitte verdrängen sie einigermassen die grossen durch Verwachsung entstandenen eigenartigen Fadenpapillen (fp.).

Die laterale Zungenflache wird bekanntlich durch Querfurchen durchsetzt, die aber nicht weit nach innen reichen. Diese grenzen dann an die Elemente des Randorgans (ro.) nach hinten.

So wie die Zahl der Wallpapillen individuell schwankt, so ist auch jene der Randorganelemente verschieden.

In der hiesigen anatomischen Anstalt befindet sich ein ălteres Alkoholprăparat, das das Randorgan in ganz auffallender Entfaltung zeigt, es ist das von mir abgebildete. Die Elemente sind verschieden măchig, rechts die letzten drei sehr kräftig, dann folgen acht schwăchere, dann wieder ein măchtiges, darauf wieder drei schwăchere und endlich zwei ganz geringe, die entgegen den andern, die nur nach aussen abgeschlossen sind, durch ihren Wall auch nach innen begrenzt sind und nur zwei nebeneinander gelegene Öffnungen vorstellen. Im ganzen sind also 20 Elemente vorhanden. Eine ansehnliche Zahl. Links war die Sache anders. Die vier hintersten Elemente waren die grössten und zeigten in die Schlitze vorspringende starke Wülste, etwa wie bei Macacus (Fig. 8), doch noch kraftiger. Die folgenden 
acht waren etwa so gering wie die mittleren rechts, die drei letzten waren nur kleine Gruben. Also auch hier sind es 15 Elemente.

Fast durchgehends wird das Randorgan des Menschen als rudimentår betrachtet. Und dies rührt daher, weil solche măchtige Randorgane wie die oben beschriebenen, nicht hăufig sind. In einem anderen extremen Falle waren nur vier, allerdings kräftige und ein vorderes geringeres Element vorhanden, die alle ganz hinten lagen. Solche Fälle sind dann zumeist zur Darstellung verwendet worden. Auf die Struktur brauche ich hier nicht einzugehen, die ist genügentlich bekannt.

\section{F. Plantigraden.}

Hier diente mir die Zunge yom Steinmarder zur genauen Untersuchung, andere Vertreter erganzen das gewonnene makroskopische Bild.

An der Marderzunge, die gleichweit vorne, an der Spitze aber etwas verschmalert ist (Fig. 17), lassen sich nur zwei Felder unterscheiden. Das vordere bildet den grössten T'eil der Zunge (I) und entspricht dem ersten und zweiten Feld der niederen Formen, das hintere ist das dritte und ganz im Dienste der Schleimdrüsen. Diese münden an seiner ganzen Ausdehnung von der Epiglottis an bis zur Tonsille (t). Vorne stösst das Schleimgebiet (blau) auf das innere, nach aussen auf das aussere kleinere seröse Drüsengebiet (rot).

Das ganze Vorderfeld (l) wird von $n$ ich $t$ mehr verhornten, ganz gleichmåssigen, sehr dicht beisammen stehenden Zahnpapillen überzogen, die in von innen nach aussen und vorne ziehenden Parallelreihen angeordnet sind. Sie reichen genauestens bis an die Langsfalten des dritten Feldes und manche von ihnen zeigen sich als die Vorderenden solcher Falten (Fig. 3). Diese Papillen laufen fast alle in eine einheitliche Spitze aus, die aber nach hinten zu gerichtet ist (Fig. 4). An der Zungenspitze werden diese Papillen etwas kleiner (Fig. 17, zs.), sind weniger dicht gestellt, doch sind sie von denen des übrigen Vorderfeldes hauptsächlich dadurcb unterschieden, dass sie zwei- bis drei- und sogar sechszackig sind (Textfig. 15, z:). Zwischen den Zähnchenpapillen jiegen die Pilzpapillen in bestimmte Reihen angeordnet, wie bei den Insektivoren u. a. Ganz binten an den Wallpapillen liegen 
Pilzpapillen auch in der Mitte der Zunge, nahe an ersteren (Fig. 3, pf.), dann ordnen sie sich aber auf jeder Zungenhälfte in zwei bestimmte Reiben. Die innere Reihe liegt zwar medianwärts, doch entfernt von der sagittalen Längsfurche des Zungenrückens (Fig. 17), die äussere zuerst ganz lateral, dann etwas weiter nach vorne nach innen zu. Hinten, wo sie lateralst liegen $\left(\mathrm{pf}^{\prime}, \mathrm{pf}^{\prime}\right.$ ), sind sie am grössten und sind ziemlich gleich weit

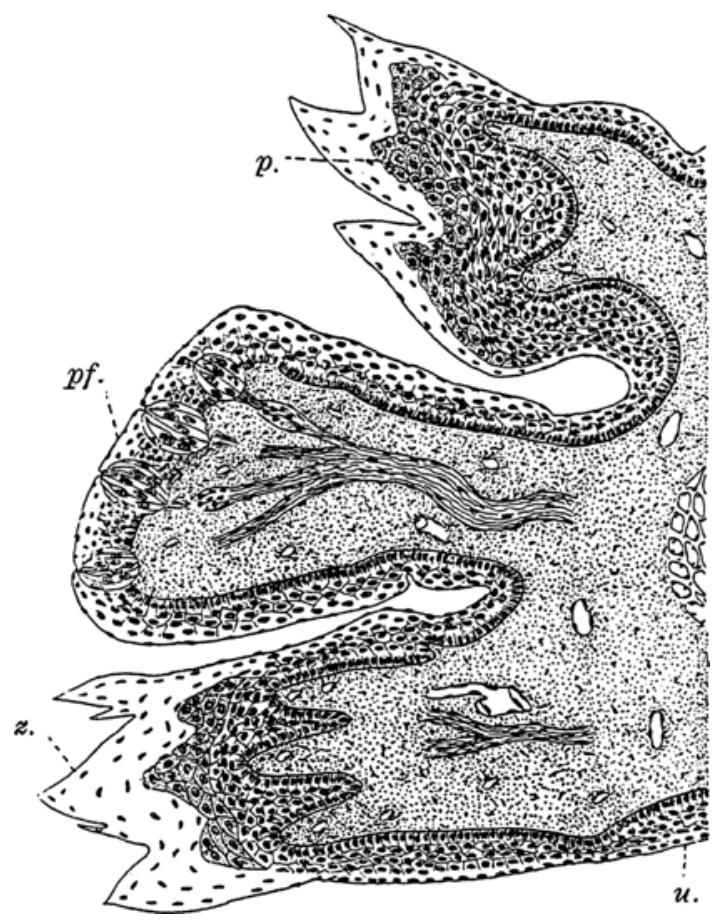

Fig. 15.

Mu utela f o in a. Sagittaler Längsschnitt durch die Zungenspitze. pf. $=$ Pilzpapille; z. $=$ Zahnpapille; p. $=$ Papillenpolster; u. = untere Zungenseite.

voneinander entfernt. Neben ihnen an der unteren Reibe, ausserhalb des Papillenbesatzes, verlauft vom dritten Felde her eine Langsfurche (r.), deren Bedeutung mir unbekannt blieb.

Die beiden Pilzpapillenreihen treffen sich vorne an der Zungenspitze jederseits an einer grössten Pilzpapille. Diese beiden grossen Pilzpapillen scheinen als Kompensation für eine Verdichtung der Pilzpapillen an der Zungenspitze zu gelten, denn 
sie sind nicht nur ungemein mächtiger als die übrigen, sondern haben auch viel mehr Geschmacksknospen an ihrer oberen Flăche. Auf Lăngsschnitten kann man vier solche zăhlen (Textfig. 15), doch beträgt ihre Zahl 7-9. Die übrigen Pilzpapillen haben nur zwei Geschmacksknospen und zwar auch nur an ihrer oberen Flăche. Auch konnte an den grossen zwei Papillen erkannt werden, dass die Nerven, bevor sie die Knospen erreicht hätten, sich zu kleinen Ganglien verdicken.

Auf die ventrale Zungenfläche setzen sich keine Papillen fort (Textfig. $15 \mathrm{u}$ ).

Die Struktur der Zähnchenpapillen leitet sich von jener der verhornten Zähnchenpapillen $a b$, da jedoch hier die Verhornung der Fortsătze fehlt, gelangt auch keine Papillenscheide zur Entfaltung. Die Bindegewebspapille (Textfig. 15) zerlegt sich in so viele Zapfen, wie viel freie Fortsătze die Papille besitzt. Dann folgt a uf die Hornschichte eine mehrschichtige Epithellage, worauf, wie bei den verhornten Zahnchenpapillen anderer Saugetierformen, das Zähnchenpolster (p.). Dieses hat so viele Höcker, wie viele freie Zacken grösserer Art vorhanden sind und ist genauestens aus so grossen gekörnten Zellen gebildet, wie jenes verhornter Zăhnchenpapillen.

Hinten, an dem dritten Felde, wo diese Zähnchenpapillen in die Lăngsfalten des dritten Feldes übergehen, rundet sich ihre Oberfläche allmählich $a b$ und damit schwindet auch das Papillenpolster.

Das Relief des dritten Drüsenfeldes ist ein ganz eigenartiges, wie es sonst in dieser Weise weder Lutra noch Meles oder Nasua aufweisen. Es sind die Schleimpapillen in Längsfalten vereinigt (Fig. 17, II) und indem dann diese Lăngsfalten durch andere Falten zusammenhängen, entsteht ein langgestrecktes Netzrelief, wobei zwischen Pharynx und Tonsille dies Netz zu einem quergestellten wird. Medianwärts ist das Netz weniger ausgeprägt, doch walten die Lăngsfalten vor, deren Enden auf Einzelpapillen stossen (Fig. 3), aus welchen sie ja hervorgegangen sind. Viele stossen mit ibrem spitzen Ende auf die Spitzen von die Wälle der Wallpapillen bildenden Einzelpapillen.

Lateralwărts ist das Netz vollkommen, doch erkennt man überall an den Kanten der Falten noch stellenweise Papillen. 
Am besten ist dies freilich an den mittleren auf die Wallpapillen hinziehenden Längsfalten zu erkennen.

Im letzten oder vorletzten lateralsten Netzraum befindet sich eine spaltförmige Vertiefung, es ist das einzige Element eines Randorganes (ro.).

Die Struktur der Schleimhaut dieses Faltensystems ist genauestens dieselbe wie auch sonst im Schleimdrüsengebiet, es münden die Schleimdrüsen $\mathrm{z} w$ ischen den Falten dichtgestellt (Textfig. 16, m, $\mathrm{m}^{\prime}$ ), zum Teil mit erweitertem Endstück des Drüsenganges, und ich würde weiter darauf nicht eingehen, wenn ein Umstand mich dazu nicht veranlassen würde. Schon Poulton sah im Epithel der Zungenschleimbaut der Marsupialier Blutkapillaren, die allerdings 0 ppel nicht wieder finden konnte. g.

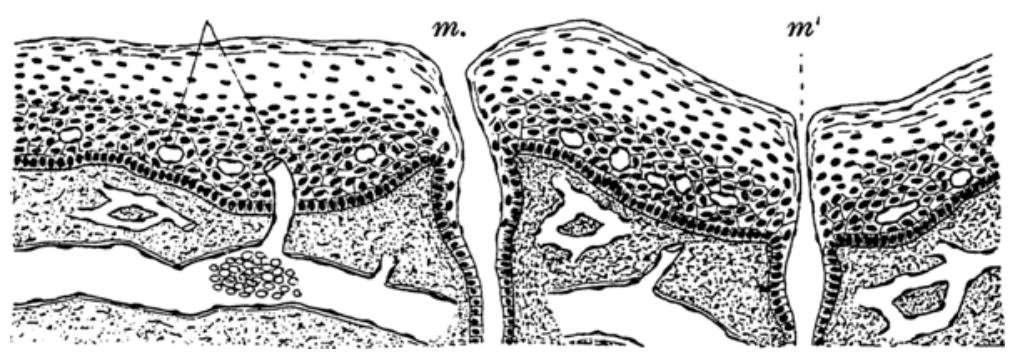

Fig. 16.

Mustela foina. Längsschnitt durch das dritte Zungenfeld. $\mathrm{m} ., \mathrm{m}^{\prime}=$ Mündungen von Schleimdrüsen; $\mathrm{g}$. = Blutkapillaren.

Mir sind solche bis auf das dritte Feld der Marderzunge auch nicht begegnet. Hier sind sie indessen sehr deutlich. Man sieht hier überall Gefässe bis in das Epithel aufsteigen (g.), doch bleibt das Kapillarnetz oberhalb der Keimlage und nie sieht man in den oberen Schichten solche.

Die Zahl der Wallpapillen betrăgt bei dem Steinmarder vier und diese Zahl scheint recht konstant, wenigstens habe ich in fünf Fällen es immer so gefunden. Doch schon bei nächstverwandten Formen vermehrt sich die $\mathrm{Zahl}$ und Gmelin hat bei Putorius vulgaris $6-7$ Wallpapillen gefunden, was ich insofern bestätigen kann, als ich bei einem Exemplar links zwei, rechst drei gefunden habe, die beiden vorderen durch Teilung entstanden, also in einem gemeinsamen Wall. 
Eine unpaare Zentralpapille gibt es indessen auch bei dem Steinmarder nicht, sondern die vier Papillen stehen so, dass sie den bekannten offenen Winkel nach vorne bildell (Fig. 3, 17, pv.). Sie sind aber weit entfernt von dem hinteren Zungenende und der frühe Verlust der unpaaren Papille gelit darum schon daraus hervor. Alle Papillen sind von einem gut entfalteten Walle umgeben, wie aber die sehr genau nach dem Präparat gezeiclnete Abbildung auf Fig. 3 zeigt, ist der Wall nur bei einer Papille des Exemplares vollkommen einbeitlich (pv.), doch auch hier nach hinten offen; die anderen drei Papillen aber, insbesondere die gleichseitige, setzt sich sehr deutlich aus Papillen (aus sechs) zusammen, so deutlich wie dies bisher nur für eine Wallpapille einer Ziege durch J. Becker beschrieben und abgebildet ward. Bei den anderen zwei Papillen

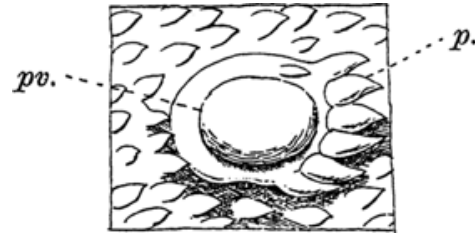

Fig. 17.

Canis a ureus. Eine einzelne Wallpapille (pv.) mit noch gut erhaltenen wallbildenden Papillen (p.). waren schon Verschmelzungen vorhanden und der Wall der unteren linksseitigen war seitwărts durch einen Längswulst geschlossen. Doch besser als die Beschreibung vergegenwärtigt dies die Abbildung. Ähnliche Zustände finden sich ja bei den Caninen auch und nebenan ist eine Abbildung (Textfig. 17), welche deutlich zeigt, dass der sonst gut geschlossene Wall eines

Canis aureus nach vorne durch sechs zugespitzte Papillen geschlossen wird.

Diese wallbildenden Papillen sind zum Teil Pilzpapillen gewesen, denn sie führen noch an der dem Wall zugekehrten Seite Sinnesknospen (Textfig. $18 \mathrm{k}^{\prime}$ ).

Die Oberflache der Wallpapillen ist nicht ganz glatt, doch auch nur wenig rauh, dann aber legen sich die. Seiten bis zum Sinnesring in Falten (pv.). Die Sinnesknospen reichen somit nicht allzuweit auf die Papille hinauf, doch ist der durch die Summe der vielen Knospen gebildete Ring um die Papille herum immerhin breit (k.), etwa 12-14 Lagen hoch. Die serösen Drüsen münden nur zum Teil im Boden des Wallgrabens, zum Teil in der Wand des Walles in den Graben (sd.). Doppelpapillen in einem Walle habe ich keine beobachtet. 
Das Randorgan hat jederseits nur ein Element (Figg. 3, 17, ro.) und auch dies ist ausserlich bloss eine unansehnliche Spalte, und so verhält es sich auch bei Lutra, Meles und Nasua. Was eben an grosser Zahl von Elementen eingebüsst wurde, das ist zum geringen Teil wenigstens ersetzt durch die mächtige Entfaltung des einzigen Elementes in die Tiefe. Es bildet das Element (Textfig. 19, B, ro.) einen vielfach an seinem Boden gefalteten Beutel, wie etwa auch bei Procyon lotor nach Tuckerman, von grosser Oberflächenvergrösserung und dieser

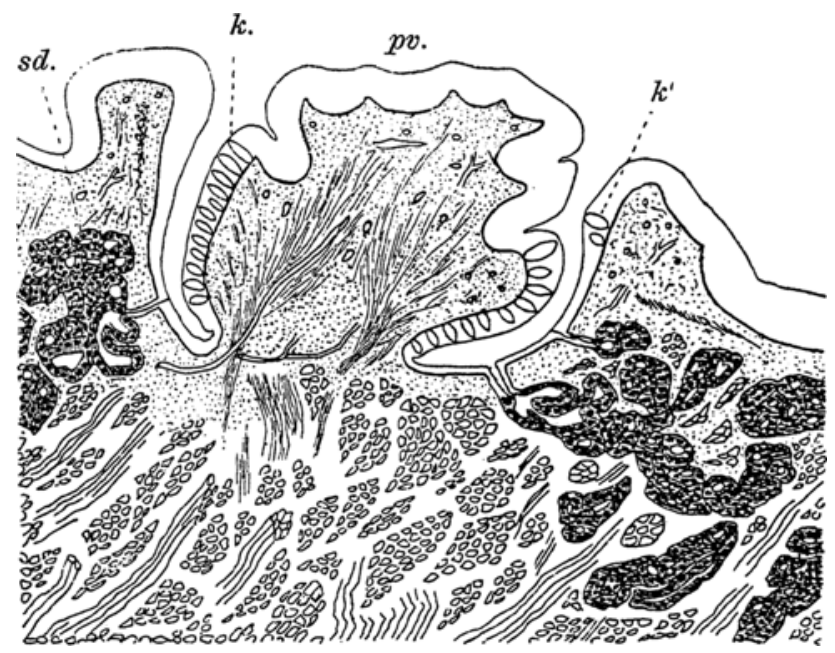

Fig. 18.

Mustela foina. Querschnitt durch eine äussere Wallpapille (pv.). sd. $=$ seröse Drüse; $\mathbf{k} .==$ Geschmacksknospen der Papille; $\mathbf{k}^{\prime}=$ solche des Walles.

ganze Beutel bis weit hinauf an die Mündung ist mit dicht beisammen liegenden Geschmacksknospen versehen. Zwischen Boden und den Wänden münden dann in den Sack etwa 6-8 sehr grosse, reich verästelte acinöse Drüsen, die recht kompakten seröse Drüsen (sd., sd'). Der Mündungsgang selbst ist weit und verzweigt sich entsprechend dem Umfange der Drüsen reichlich. Sonst münden nirgends Drüsen in den Sack. Es lieg† das Element völlig randständig, von anderen etwa rudimentären Elementen war wenigstens beim Steinmarder nichts zu sehen. 
Zwei dem Marder nahe stehenden Formen, nämlich Lutra und Meles zeigen, obgleich sie unzweifelhaft jüngere Formen sind, doch ursprünglichere Zustände bezüglich der Anordnung der Wallpapillen als jener und sonderbarerweise Meles ursprünglichere als Lutra. Ein Beweis wieder dafür, dass jüngere Formen nicht in allen Einrichtungen gleichen Schritt aufweisen.

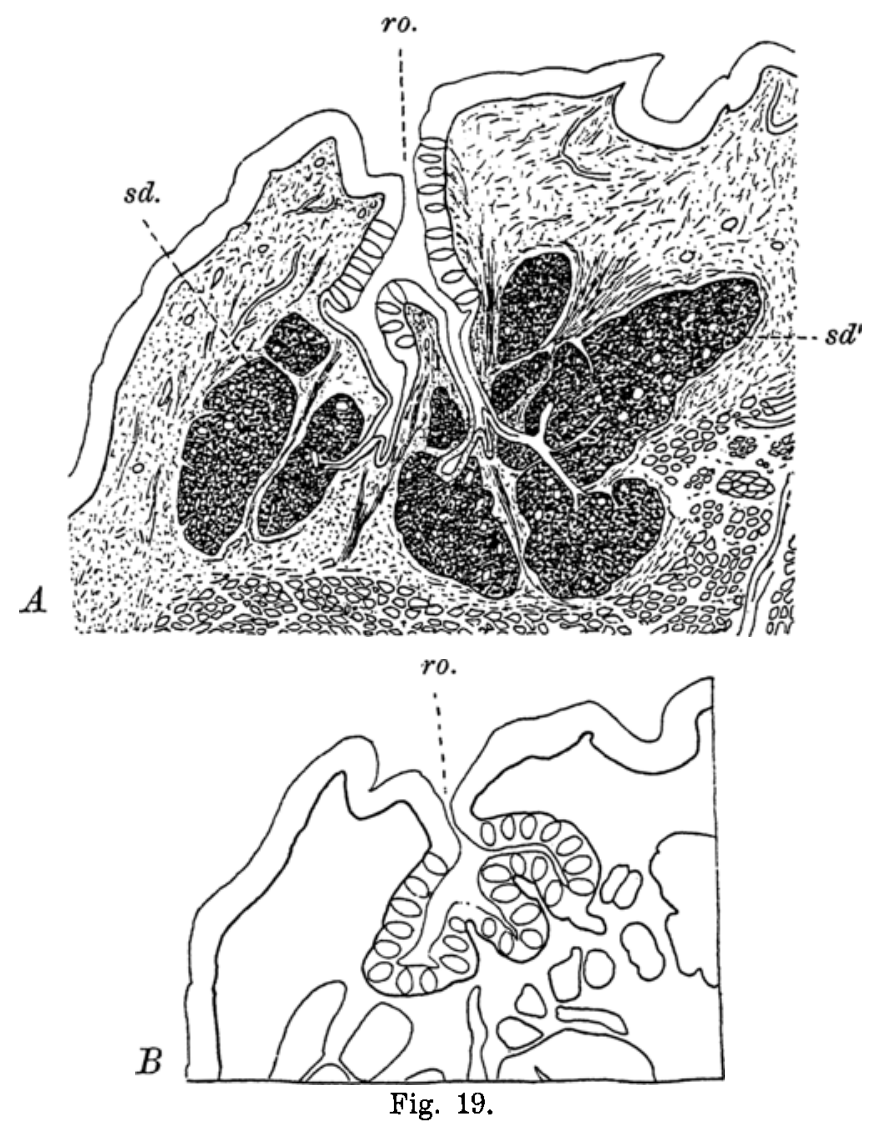

Mustela foina. Zwei Querschnitte durch das einzige Randorganelement. ro. = Mündung des Elementes; sd.= seröse Drüse.

Bei Meles fossor befindet sich eine unpaare Zentralpapille ganz hinten am hinteren Zungenrande (Fig. 18). Ihr Wall ist nach hinten offen und die beiden Wallenden laufen in zwei Lăngswülste aus, die zwei anderen Wülste zwischen sich fassend. Dann folgen rechts zwei kleine, fest beisammen liegende 
Wallpapillen mit eigenen Wällen, hierauf in gleicher Entfernung ein einzige etwa gleich grosse und in gleicher Entfernung wird der rechte Schenkel des Dreiecks durch eine grosse Wallpapille geschlossen. Links liegt einer grossen Papille eine kleine Doppelpapille an, also zwei in demselben Wall, dann in gleicher Entfernung wie drüben eine mittelgrosse Papille, deren Wälle in Falten nach hinten auslaufen. Dieser nach innen liegt eine kleine Wallpapille mit aus Papillen gebildetem Walle an. Den Schluss nach vorne macht auch hier eine grosse Wallpapille. Das dreieckige Feld innerhalb des Wallpapillen-Dreiecks enthält einzelne kleine Papillen mit einem deutlichen Wall von gesonderten Papillen, von denen wir wohl annehmen können, dass sie Übergangspapillen sind. Sonst endigen die walllosen Pilzpapillen schon vor dem Dreieck. Sie waren im ersten Zungenfelde nicht nach Reihen angeordnet, so etwas äusserte sich erst gegen die Zungenspitze $\mathrm{zu}$.

Hier liegt somit zweifellos eine Vermehrung der Wallpapillen sowohl durch Teilung als durch Neubildung vor.

Bei Mustela sahen wir, dass das Netzrelief des Schleimdrüsengebietes sich bis auf die ausssere Seite der Epiglottis und bis unter die Tonsille (Fig. 17, t.) fortsetzt und dass der Hinterrand der Zunge keine deutliche Abgrenzung zeigt. Demgegenüber grenzt die Zunge sich sowohl bei Meles (Fig. 18) als auch bei Lutra auch durch ihr Schleimhautrelief jenem zwischen Tonsillen und Pharynx gelegenen Gebiet gegenüber gut ab. Bei Meles ziehen von den Wallpapillen her dicht aneinander gelagerte Schleimhautfalten etwas weiter nach hinten und gehen dann am hinteren Zungenrande in fest aneinander liegende flache Papillen über. Zwischen Falten und Papillen, aber auch auf diesen münden die zahlreichen Schleimdrüsen. Die Schleimhaut bildet dann vor den Tonsillen ein nach lateralwärts dem übrigen Mundhöhlenrand gegenüber stark abgesetztes Faltensystem (sf.) und zwischen den Wülsten münden die Schleimdrüsen. Bei Lutra (Fig. 19) ist es ähnlich (sf.) doch sind dann Papillen in jenem Bezirk vorhanden, die sich auf den hinteren Zungenrand fortsetzen. Von hier ziehen dann Lăngsfalten zu den Wallpapillen. Diese liegen bei Lutra viel weiter nach vorne als bei Meles, also ahnlich wie bei Mustela. Die unpaare Zentralpapille ist zwar klein, doch deutlich entfaltet. Auffallenderweise liegt vor ihr gleich eine 
andere gleich starke Papille, doch lagen sie nicht fest beisammen. Die Annahme, dass sich die Zentralpapille geteilt hartte, könnte darin somit keine Stütze finden. Jederseits neben der Zentralpapille befand sich je eine etwa gleich grosse Wallpapille, mit denen jederseits die beiden Schenkel des nach vorne zu offenen Dreiecks begannen. Links folgt eine gleich grosse Wallpapille und zum Schluss eine viel grössere. Die dieser letzteren entsprechende gleich grosse Wallpapille war auch rechts vorhanden, doch fehlte dann die Zwischenpapille.

Die Zunge von Nasua socialis zeigt bei mustelidenähnlichen Zuständen Eigentümlichkeiten. Es ist die Zunge, entsprechend den verlängerten Kiefern, länger als bei den Musteliden (Fig. 16). Sie ist vorne auch abgestutzt. Das vor den Wallpapillen gelegene grosse Zungenstück (I) zeigt keine Abgrenzung in zwei Felder. Überall sind kleine, nicht verhornte Zahnpapillen vorhanden, zyischen denen wie bei Lutra und Meles die Pilzpapillen in gleich weiten Entfernungen eingestreut sind. So etwa in der Mitte der Zunge gibt es aber ein rundes Gebiet, ein Zentrum, an dem die Pilzpapillen vollstandig fehlen. Vor diesem Gebiet sieht man dann Längsfurchen, die jedoch die Zungenspitze nicht erreichen und auch am Zungenrande fehlen.

Die nach vorne im offenen Dreieck angeordneten Wallpapillen sind zahlreich. Eine unpaare Zentralpapille fehlt und an ihrer Stelle liegt eine Gruppe von Scbleimpapillen. Den linken Schenkel bilden sechs, den rechten fünf Wallpapillen.

Das Scbleimdrüsengebiet der Zunge (III) ist durch weit auseinander gelegene Falten überzogen, zwischen denen zwei ausserst charakteristische Reihen von kleinen Pilzpapillen auf jeder Seite sich befinden. Die beiderseitigen hinten bilden einen vorne und hinten offenen Ring, die beiden vorderen ziehen nach aussen und hinten und sind kürzer.

Die Schleimhautfläche zwischen Pharynx und den Tonsillen wies zarte Falten auf, die vorne vor der Tonsille in eine Grube (sf.) ausliefen, die genauestens jenem starken Faltensystem der früheren Formen ihrer Lage nach entsprach.

Procyon lotor besitzt drei Wallpapillen und somit eine unpaare Zentralpapille, doch kann die erste paarige Papille eine Doppelpapille sein. 
An einer Zunge von Phoca vitullina fand ich vier Wallpapillen. Zwei standen hinten hintereinander, die beiden anderen seitwärts und vorn davon im Dreieck. Der Fuchs hat secbs Wallpapillen. Alle diese hatten nur je ein Randorganelement, so auch Hyaena.

Eine grosse Vermehrung der Wallpapillen soll nach $\mathrm{H}$ önigschmied (12) beim Baren (Ursus fuscus) sich eingestellt haben, da dort 19-20 vorhanden sein sollen. Es wäre dann dies die höchste Zahl bei den Carnivoren, da der Tiger nach meiner Erfahrung nur 10--12 solcher besitzt und eine ganz jugendliche Löwenzunge wies bloss neun auf. Damit im Zusammenhange scheint das Verkümmern des Randorgans der Felinen zu stehen. Beim Löwen sind nur zwei ganz unansehnliche Elemente jederseits vorbanden und beim Tiger fehlen auch diese. Auch Felis lynx soll nach Hönigschmied olne Randorgan sein.

Überhaupt zeigen die Katzenzungen jenen der übrigen Carnivoren mit ausgesprochenem Mustelidenzungentypus gegenüber eigenartige Umwandlungen. Eine ausführliche Beschreibung der Schleimhaut der gewöhnlichen Katzenzunge gab J. Becker. Nach ihm stehen die vier bis sieben Wallpapillen "auf dem hinteren Teile der Zunge in zwei nach hinten konvergierenden Reihen, die gewöhnlich nicht an die Mittellinie der Zunge heranreichen". Somit gebe es also keine unpaare Zentralpapille. In der lateralen Seite des dritten Feldes finden sich enorm lange Schleimpapillen. Die Pilzpapillen umgeben den ganzen Zungenrand des ersten Feldes und ist eine dritte Gruppe auch vor den Wallpapillen vorhanden. Vor dieser Pilzpapillengruppe liegt median auf der vorderen Zungenhälfte eine weite Stelle, an der die Pilzpapillen fehlen, und welche von grossen Hornzăhnen besetzt ist. Ähnlich ist die Zunge nach meinen Erfahrungen auch beim Löwen und Tiger.

Das Randorgan kann bei der Katze nach Becker auf beiden Seiten fehlen, einseitig oder beiderseitig vorhanden sein. Sowohl dieser Umstand als auch ein von Becker abgebildeter Schnitt durch das Randorgan, bezeugen nur zu deutlich, dass bei den Felinen nicht ein stark vergrössertes Element wie etwa bei Musteliden sich findet, sondern bloss ein Rudiment. 


\section{G. Glires.}

Schon seit F. J. C. Maye $r$ her ist es bekannt, dass Cricetus bloss eine Wallpapille besitzt und Hönigschmied fand bei Mus sylvaticus auch nur eine Wallpapille, wie denn auch bei sehr vielen anderen. Beidesmal handelte es sich nur um eine Zentralpapille. Demgegenüber sind aber durch den letzten Autor bei Mus avellanarius drei Wallpapillen gefunden worden. Und drei solche in Winkelstellung finden sich ausserdem noch bei Tamias, Sciurus u. a. Aber auch fünf können mit einer centrelen in der Mitte vorkommen, so bei Arctomys nach $\mathrm{Hönigschmied.}$ Bei dem Hasen und Kaninchen sind jedermann die beiden weit auseinanderstehenden Wallpapillen bekannt.

Bezüglich des Randorgans gibt schon Hönigschmied für Cricetus fünf bis sechs Elemente an. Sind bezüglicb der Zahl der Wallpapillen verănderliche Zustănde vorhanden, so zeigt auch die gesamte Zunge bei den einzelnen Formen weitgehende Verschiedenheiten, wie dies schon aus der Beschreibung der Zungen auch nur weniger Vertreter wie Hystrix, Mus musculus und dem Feldhasen klar werden wird. Zuvor möchte ich aber die kurze Mitteilung hier über die Zunge von Dasyproca aguti machen, die viele Pilzpapillen unregelmăssig auf dem ersten Zungenfelde verteilt hat und die an: dichtesten an der Zungenspitze stehen. Die Randorgane sind kräftig entfaltet. Bei fehlenden-Randorganen weist Phascogale penicillata drei in Dreieck gestellte Wallpapillen, eine zentrale und zwei andere auf; bei dem Aguti fehlt die zentrale Wallpapille.

Die Zunge von Hystrix dürfte nach der Beschreibung von Brü cher und Brian (5) einer Ergänzung bedürfen, da letzterer nur einen Teil derselben berücksichtigt hat. Ich hatte dieselbe Zunge vor mir. Wie aus der Brians Schrift beigegebenen schönen Abbildung des Institutszeichners Herrn Vierling (l. c. Fig. 1) hier hervorgeht, ist die ziemlich lange Zunge etwa biskuitförmig. Weiter vorne engt sie sich dann etwas ein, um sich dann hinten wieder zu verbreitern. Diese Biskuitform der Zunge ist eine Eigentümlichkeit der Nager und erklärt sich aus deren Zahnformel. Zwischen den Schneidezähnen und den Mahlzähnen liegt eben eine lange zahnlose Stelle im Kiefer und an dieser kann sich die Zunge infolgedessen verbreitern; so kommt die 
vordere Verbreiterung zustande, indessen der enge Zungenabschnitt an die Molares stösst.

Die ganze Hystrixzunge ist bis an die Wallpapillen mit kleinen verhornten Zähnchenpapillen überzogen, von denen, wie uns oben Brian zeigte, an dem vorderen Ende der Zunge jederseits an einer ovalen Stelle enorme quergestellte Hornzahnreihen sich entwickeln.

Etwas vor den Wallpapillen (Fig. 15 pv.) hören die Zähnchenpapillen auf und beginnen unverhornte rund endende Papillen, die hinter den Wallpapillen zu breiten, zumeist durch Sclleimdrüsengänge durchbobrten Schleimpapillen werden. Diese erhalten sich dann in der Gegend bis zum Pbarynx und das ganze stellt das dritte Zungenfeld (III) oder das Schleimdrüsengebiet dar. Über die Verteilung der Pilzpapillen vermag ich nichts zu sagen, da sie ohne der mikroskopischen Untersuchung nicht feststellbar waren und dazu eignete sich die untersuchte, schlecht konservierte Zunge nicht. Nur drei grössere Pilzpapillen konnte ich auch so erkennen, sie liegen in der Zungenmitte weit vor den Wallpapillen, zwei links hintereinander, eine links. Ob es sich in diesen (p.) um Übergangspapillen bandelt, weiss ich nicht zu sagen. Bei dem Brücherschen Exemplar scheinen viel mehr solche Papillen gewesen zu sein.

Wallpapillen gibt es dreie (pv.), eine mittelständige kleine Zentralpapille und zwei grosse vordere. Sie stehen in einem nach vorne offenen Winkel. Diese Papillen sind dadurch ausgezeichnet, dass ihre ziemlich flachen Wülle weit über sie zusammengreifen und nur einen geringen Teil der dorsalen Papillentlache unverdeckt lassen, weshalb diese kleiner erscheinen als sie wirklich. sind. Meine Angaben bezüglich der Zahl der Wallpapillen stimmen somit nicht mit jenen der Autoren, die alle nur zwei grosse Wallpapillen gesehen haben, überein. Entweder besteht hier somit auch dieser Fall, oder ist die mittlere Wallpapille - so etwas geschieht ja nicht zum ersten Male infolge der Zusammenlegung ibrer Wallränder übersehen worden. Übrigens ist die Brüchersche Abbildung auch sehr ungenau und lässt auch die von Carus und Otto (die Wiedergabe in $\mathrm{Oppel)}$ viel zu wünschen übrig.

Ungemein entfaltet ist das Randorgan (ro.), hierin würde Hystrix sogar den Orang übertreffen. Ich zählte jederseits 
29 Elemente. Gut umwallt und nach innen zu geschlossen liegt die lange Reihe entlang des Innenrandes. Die hintersten zwanzig sind nach seitwärts offen und die rordersten in der Reihe eben so klein wie die hintersten. Jene zwischen fünf und fünfzehn sind die machtigsten. Unter dem Randorgane befindet sich eine ansehnliche Lăngsfalte (lf.), die bei allen langen Randorganen, wie auch bei dem Orang, sich vorfindet.

Die Zunge des Hasen (Fig. 14) zeigt die Biskuitform noch deutlicher als jene von Hystrix.

Das erste Feld (I) reicht bis zum Randorgan (ro.), das zweite (II) beginnt vor den Wallpapillen (pv.) und ist in Form

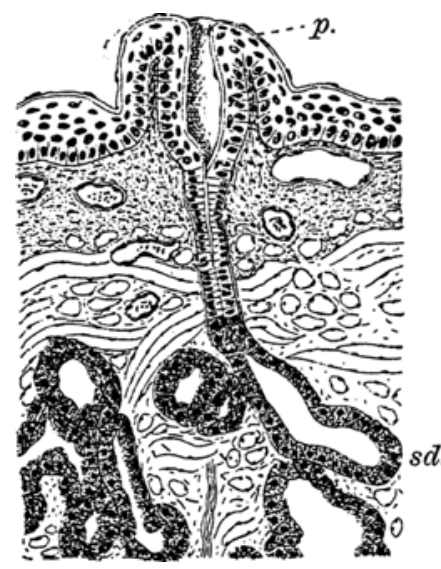

Fig. 20.

Mus m us cu lus. Querschnitt. sd. = Schleimdriuse; p. $=$ deren Mündung in einer Schleimpapille. eines nach vorne $\mathrm{zu}$ sich verschmälernden Tuberkels in den hinteren schmalen Abschnitt des ersten Feldes eingeschoben.

Während dann das erste Feld nur zarte, wenig verhornte Papillen fübrt, ist das zweite mit kleinen Kronpapillen überzogen und besitzt keine Pilzpapillen. Diese verteilen sich vielmehr auf das erste Feld und sind da überall bis zu den Randorganen in durclıaus gleichmassig, nicht in Reihen angeordneter Weise verteilt. Sie sind gross. An der runden Zungenspitze sind die Pilzpapillen ungemein viel kleiner, dafür aber um so zahlreicher, und bilden einen ganz dichten Bestand. An der Stelle, wo nach hinten das zweite Feld endigt, beginnt das dritte Feld (III) in der Mitte in Form einer niedrigen weiten Rundtäche (f.), deren Hals das Frenulum pharyngis ist. Dieser innere Teil des Schleimdrüsenfeldes ist quergefurcht; das Seitengebiet vom Randorgan bis zum Pharynx besitzt Langsfurchen, die sich vielfach verbinden. Das ganze Furchensystem, in das die Schleimdrüsen münden, ist indessen unansehnlich.

Auf jeder Seite, dort wo das dritte das zweite Feld berührt, befindet sich eine Einbuchtung und genau in diesem seitlichen stumpfwinkligen Einschnitt liegt je eine grosse, gut umwallte 
Wallpapille (pv.) So in den meisten Fällen, doch fand ich in zwei Fallen auch rechts zwischen Wallpapille und dem Randorgan noch eine dritte kleine Wallpapille. Es fehlt beim Hasen somit eine unpaare Zentralpapille.

Das Randorgan liegt bekanntlich auf einer länglichen Scheibe, deren ausserer Rand der grossen Randfalte von Hystrix entspricht. Die 8-9 Elemente sind nur geringe Spalten, die Geschmacksknospen liegen im oberen Teil der Wände ohne die Spaltenmündung zn erreichen und die serösen Drüsen münden im Boden der Furche.

Wie genügentlich bekannt, macht der sagittale Längsschnitt ganz den Eindruck von bintereinander gelegenen Wallpapillen, und diesem Verhalten angepasst ist die Bezeichnung Papillae foliatae.

Die Biskuitform der Măuse zunge ist um so vollkommener, als die Zunge auch binten gut abgerundet ist (Fig. 13). Das zweite Feld (II) ragt in Form eines ovalen Tuberkels in das erste (I) Feld hinein, wobei eine geringe ausgleichbare Rinne es nach vorne umgrenzt. Das Tuberkel ist mit gut verhornten niedrigen Kronpapillen (Textfig. 24) überzogen, die daun nach hinten zu mit Beginn der Schleimgebiete (blau) allmăhlich die Verhornung einbüssend, in Schleimpapillen übergehen. All dies lässt sich freilich mit der Lupe bei der Kleinheit der Gebilde nicht beobachten und wurde auf Schnittserien ermittelt. Erst hinter der Wallpapille (Fig. 13, pv.) und somit zwischen hinterem Zungenrand und Pharynx lässt sich das Schleimdrüsengebiet auch mit der Lupe erkennen. Es zerfallt hier in einen mittleren, schmäleren Abschnitt (f.) der dem Frenulum entspricht und in je ein seitliches, scheibenförmig rundes Gebiet daneben. Diese drei Teile sind mit Papillen überzogen, die sebr niedrig aber um so breiter sind.

Das erste Zungenfeld (I) ist mit haarförmigen, nach hinten gebogenen Hornpapillen bedeckt, die an der Zungenspitze viel niedriger werden und dann auch einen Nebenzacken besitzen können.

Die Pilzpapillen finden sich nur im ersten Felde, das zweite Feld entbehrt solcher. Sie sind dort in bestimmter Weise angeordnet. Da die Pilzpapillen in das Epithel versenkt sind und nur an der Zungenspitze sich daraus etwas bervorheben, so 
konnten sie erst nach Durchsicht von Längs- und Querschnittserien in das fertige Bild der Zunge eingetragen werden.

Eine Reihe von Pilzpapillen umgreift, ăhnlich wie bei unseren einheimischen Chiropteren, das Tuberkel vor dessen Rinne,


Fig. 21.

Mus muculus. Zwei Querschnitte durch die Wallpapille (pr.), seröse Drüsen grau, die Schleimdrüsen schwarz. eine zweite und dritte Parallelreihe ziehen bis in die abgerundete Zungenspitze und endigen in der dichstgesteliten Pilzpapillengruppe dort.

Je eine Langsreibe jederseits zieht median entlang der Zunge vom Tuberkel aus und erreicht die am vorderen verbreiterten Teil des ersten Zungenfeldes gelegene mediosagittale Furche, um mit deren Beginn zu endigen.

Die einzige median gelegene Wallpapille (pv.) liegt in einer geringen Vertiefung, die als Foramen coecum gelten darf, mit kräftigem, glatten Wall umgeben, deren beide hinten sich nicht berührende Enden, wie überall, in bezeichnender Weise in Längswülsten, hier der Frenulumoberfläche (f.) übergehen.

Seitwärts jederseits, doch vor der Wallpapille und genauestens am Zungenrande, liegt das Randorgan (ro.) mit drei bis vier Elementen. Im abgebildeten Falle waren rechts vier kleinere und links drei aber etwas grössere Spalten vorhanden. Die serösen Drüsengebiete richten sich wie denn überall nach ihren Sinnesorganen. Um die Wallpapille gibt es jedorseits je ein Drüsengebiet (rot) und die beiden berühren sich 
medianwärts nicht (Textfig. 21): Sie beginnen hinter der Wallpapille (Fig. 13, rot), verbreitern sich dann etwas, um dann wieder schmaler zu werden und so noch weit vor der Wallpapille für sich $z u$ enden. Das ăussere seröse Drüsengebiet umgibt das Randorgan (rot) und ist weit vom inneren entfernt.

Das Schleimdrïsengebiet zerfällt in drei Untergebiete. Das mittlere Gebiet umfasst das Frenulum und zieht mit ihm bis zur Wallpapille, vor dieser aber teilt sich das mittlere Schleimdrüsengebiet (Fig. 13, blau) in zwei Portionen, von denen jede getrennt von der anderen vor der Wallpapille, doch nicht so weit wie das seröse Mittelgebiet und auswärts von diesem endet.

Das seitliche Schleimdrüsengebiet reicht nicht auf die Epiglottis hinauf wie das mittlere, sondern umfasst jene schon erwähnte scheibenförmige jederseitige Fläche, wird dann recht schmal, bis einreihig, und endet (blau) vor dem seitlichen Gebiet der serösen Drüsen. $\mathrm{Zu}$ Glandulae sublinguales minores kommt es somit bei der Maus nicht. Die Schleimdrüsen münden zum Teil wie überall in Papillen und zwar in einer Weise, wie ich das sonst nicht beobachtet habe. Die ampullenartige Erweiterung findet sich nămlich nicht zu Beginn des einschichtigen Mündungsstückes der Schleimdrüse - sie kann auch fehlen sondern der sonst enge Gang im Epithel der Schleimhaut ist ampullenartig erweitert (Textfig. 20). Damit gewinnen diese kleinen breiten Papillen ein eigenartig trichterförmiges Aussehen auf den Schnitten.

Wie der Querschnitt der Wallpapille zeigt, ist diese trotz ihrer verhallnismåssigen Grösse recht niedrig (Textfig. 21, pv.), ibr Wall nicht hoch und damit der Graben von geringer Tiefe. Auf den Schnitten erkenntlich, ist der Sinnesring nur drei Knospenlagen hoch und die Knospen erreichen bloss den Rand, nie aber die dorsale Papillenfläche. Auch die Innenseite des Walles trăgt Papillen, die die gleiche Höhe wie an der Papille erreichen.

Für wichtig erachte ich eine Längsfurche auf der dorsalen Papillentläche, wenn ich dies Verhalten mit jenem in Zusammenhang bringe, dass die serösen Drüsen, die ausschliesslich am Boden des Wallgrabens münden, in zwei seitliche Gruppen zerfallen und, dass diese mittleren serösen Drüsenfelder, wie schon angegeben, sich nie berühren, ferner dass hinten und vorne in Einklang 
damit keine Drüsen in den Wallgraben münden. Es liesse sich dies am ehesten so deuten, gleiches haben wir ja schon bei Pteropus erwähnt, dass die unpaare Papille durch Vereinigung zweier nebeneinander gelegener Papillen entstand, worüber die Ontogenie das entscheidende Wort hatte.

Die Elemente der Randorgane sind glattwandige Spalten, an deren Wänden ohne den Boden zu berühren, wo ausschliesslich die serösen Drüsen münden, die Sinnesknospen liegen. Auf einem abgebildeten Längsschnitt (Textfig. 22) waren zwei Elemente getroffen; an der hinteren Seite des hinteren (ro') fanden sich keine

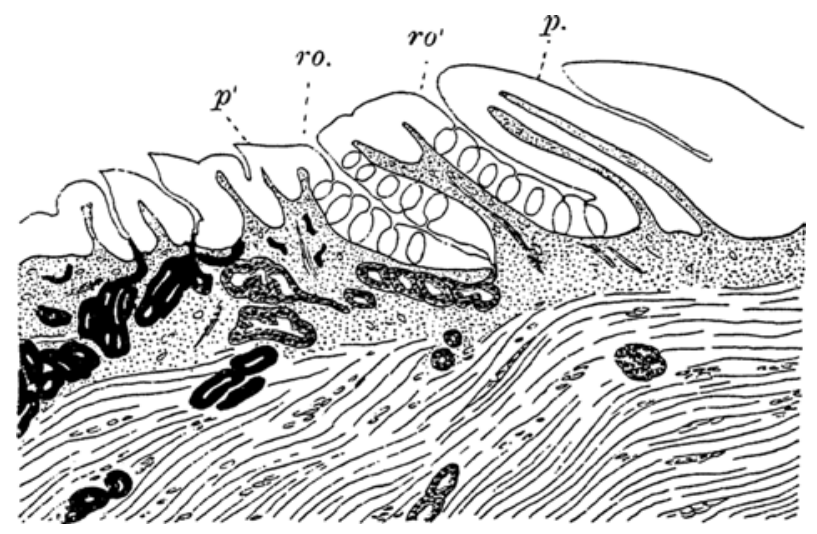

Fig. 22.

Mus musculus. Längsschnitt, der zwei Randorganelemente traf. ro. $=$ vorderes, $\mathrm{ro}^{d}=$ hinteres Randorganelement. Die serösen Drüsen grau, schwarz die Schleimdrüsen.

Sinnesknospen und der Wall hier war eine grosse Schleimpapille, indessen der vordere Wall des ersten Elementes (ro.) durch eine Zahnchenpapille ohne Verhornung gebildet war. Dieses Bild machte dann ganz den Eindruck von einer Wallpapille mit dem umgebenen Wallgraben.

Hier möge noch einiges über die Zahn- und Pilzpapillen gesagt werden.

Wie ich schon mitgeteilt habe, sind die Pilzpapillen am dichtesten an der Zungenspitze angeordnet und mit den übrigen Papillen greifen sie für eine ganz kurze Strecke auch auf den Zungenboden über. 
Sehr bezeichnend ist es für die Pilzpapillen der Maus, dass sie, mögen sie wo immer vorkommen, nur eine Sinnesknospe besitzen, denn wenn Gleiches bei Vesperugo und Vespertilio sich auch zeigte, so galt es doch nur für einen Teil der Pilzpapillen.

Diese Sinnesknospen der Hausmaus sind sehr grosse Gebilde (Textfig. 23) und da sie die Höhe des Epithels an der Papillenkuppe um vieles übertreffen, so ragen sie nach unten weit in die Bindegewebspapille hinein. Über die Papillen ziehen die obersten Lagen des Schleimhautepithels (e.) so hinweg, dass nur die Hornzähne herausragen und somit die Pilzpapille ( $\mathrm{pv}$.) völlig überdeckt ist; nur die Mündung der Sinnesknospe erreicht die Oberflache. Es stehen die Sinnesstifte (Textfig. 23, B) nur in einer flachen Mulde und der Told tsche Gang konnte sich nicht entfalten.

Nur an der Zungenspitze ist das oberste Ende jeder Pilzpapille, bis etwa zur halben Höhe der Sinnesknospe,
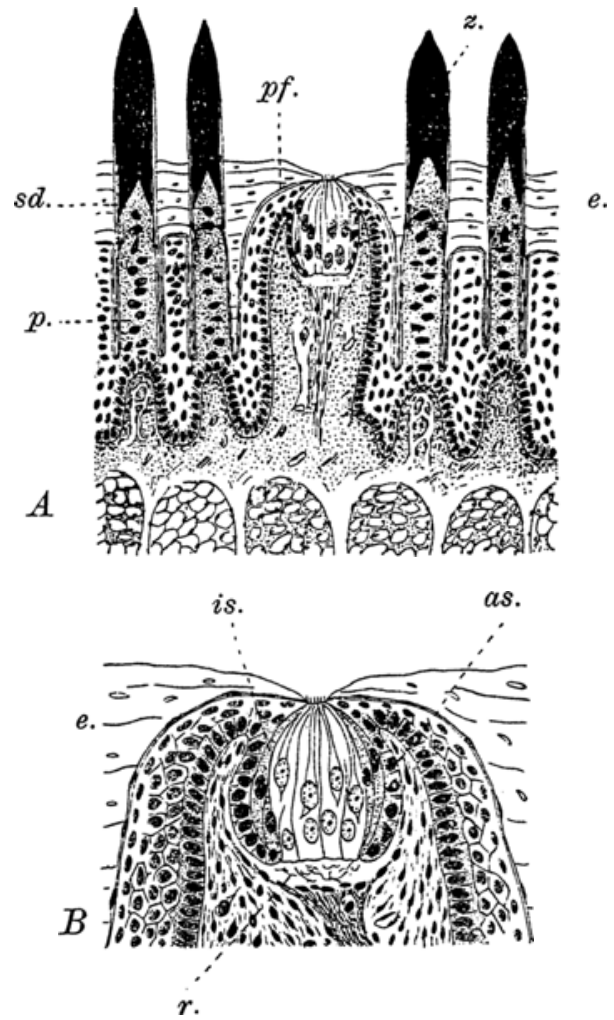

Fig. 23 .

Mus musculus. A Querschnittstück durch die Mitte des ersten Zungenfeldes. pf. = Pilzpapille; $\mathbf{z} .=$ Hornzahn $;$ sd. = Papillenscheide p. = Papillenpolster der Zahnpapille. B oberes Ende einer Pilzpapille stärker vergrössert. as. = äussere, is. = innere Deckzellenscheide der Sinnesknospe. erhoben über die Schleimbautoberfaache und hier ist denn auch eine tiefere Mulde über den Sinnesstiftchen, ohne aber, wie gesagt, dass es zu einem Gange kăme. Auf diese Weise würden die Sinnesstiftchen äusseren Insulten preisgegeben werden, wenn 
nicht eine andere Einrichtung, auf die ich bereits bei den Chiropteren hinwies, bestehen würde. Es findet sich nămlich unter jeder dieser grossen Sinnesknospen ein Raum vor (B, r.), dessen ungemein lockere Füllung nur die feinen Nervenfasern enthălt, und somit bei der Retraktion der Knospe den nötigen Raum gewährt. Dann würde sich die Mulde über den Sinneshaaren vertiefen und der nötige Schutz wăre durch einen provisorischen Kanal geboten.

Wo die Knospe sich in den bindegewebigen Teil der Papille versenkt, schlägt sich die Keimlage des Epithels auf sie um und bildet für ihren versenkten Teil eine aus kubischen Zellen gebildete aussere Scheide (B, as.). Es biegt dann diese in die

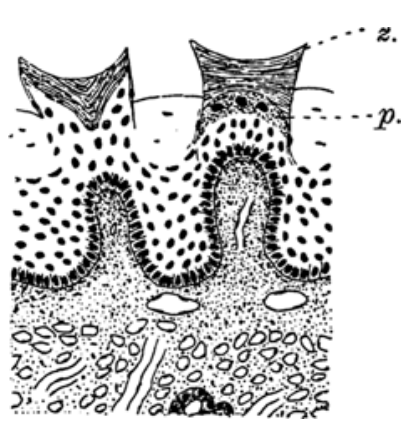

Fig. 24.

Mus musculus. Querschnittstück aus dem hinteren Teil des zweiten Zungenfeldes. $\mathrm{z} .=$ Hornzahn $; \mathrm{p} .=$ Papillenpolster. aussersten Zellen der Knospe um, die besser färbbar wie die Sinnes- und Stützzellen der Knospe, ihre in nere Scheide (is.) vorstellen. ${ }^{1}$ ) Diese wird bei Geschmacksknospen an anderen Stellen und bei allen Săugetieren von einer bisher nicht beachteten plattenepitheligen Hülle ersetzt, die direkt in die oberste Lage des Epithels der Schleimbaut übergeht und als dessen Vertreter $\mathrm{zu}$ betrachten ist.

Dem bereits bei Vesperugo Gesagten über den Bau der Zăhnchenpapillen habe ich hier eigentlich wesentliches nicht anzufügen. Gleich wie dort sitzt der Hornzahn (Textfigur 23) einem immer der Höhe des Zahnes entsprechend hohen Epithelpolster (p.) auf, das aus eben solchen Zellen gebildet wird wie dort. Ebenso ist die Papillenscheide gut erkennbar (sd.). Gleiches zeigt sich denn auch bei den Kronpapillen des zweiten Feldes (Textfig. 24). Auch diese Papillen sind in das Epithel versenkt bis auf den zwei- und dreispitzigen Hornzahn (z.) und dieser erweist sich wie überall aus Lamellen gebildet, obne dass die Zellkerne noch sichtbar wăren. Die Papillenscheide ist

1) Diese beiden Scheiden sind nach W. B a rth (1) an den Geschmacksknospen der Vögel und der Crocodilinen gleichfalls vorhanden und erreicht die innere öfter eine immense Entfaltung. 
erkennbar; das Polster (p.) ist entsprechend seinem Aufsatz bloss einschichtig.

Erst im Schleimgebiet erheben sich die Papillen über die Schleimhautoberfläche mit allmăhlichen Übergăngen von den Kronpapillen her. Ihnen fehlt da das Polster.

Da meines Erachtens nach das hier über die Nagerzunge Mitgeteilte für den allgemeinen Überblick, der doch hier leitend sein soll, genügt, habe ich mich auf genauere Studien anderer Nagerzungen nicht eingelassen.

\section{H. H uftiere.}

Besonders auf die Huftiere beziehen sich die Untersuchungen J. Beckers. Hier möchte ich jedoch seine speziellen Ergebnisse nur insoweit besprechen, als sie sich eben auf die betreffende Tierform beziehen, die ich untersuchte, oder aber als Referat seiner Ergebnisse über von mir nicht untersuchten Formen. ${ }^{1}$ ) Vor allem möge die von mir nicht untersuchte Einhuferzunge in dieser Weise besprochen werden.

Die Pilzpapillen des Pferdes ziehen nach Becker in zwei bis vier Reihen entlang der Seitenfläche nach der Zungenspitze vom Randorgane an, auch finden sich wenige von ihnen in der Nahe der Wallpapillen, sonst aber ausser an der Zungenspitze nirgends an der Rückenfläche der Zunge. Wallpapillen sind in der Regel nur zwei vorhanden, doch können auch drei, dann eine zentrale, und viere sein. Sie stehen im Dreieck. Die Papillen sind schlecht umwallt.

Die Zahl der Randorganelemente schwankt zwischen sechs und zwölf und diese Spalten können miteinander sich auch unter spitzem Winkel vereinen oder durch eine Querfurche miteinander in Zusammenhang stehen. Es kommt auch vor, dass seröse Drüsen auf dem Wall zwischen zwei Spalten münden, wobei die Geschmacksknospen sich bloss an den Wandungen der Spalten finden. Es gebört somit das Pferd zu denjenigen Huftieren, bei denen eine Vermehrung der Vallatae ausbleibt.

1) Die Angabe B r ü chers (6), dass bei Hyrax es keine Wallpapillen gebe, können wir wohl mit demselben Rechte ühergehen wie alle derartigen negativen Befunde. 
Ich will nur nebenbei bemerken, dass Gmelin bei Tapirus ein gut entfaltetes Randorgan mit bis elf Elementen abbildet. Auch bei Hyrax ist das Randorgan bekannt.

Fadenförmige Papillen bedecken nach Becker auch die ganze Rückenfläche und die vordere Hälfte der Seitenfläche der Rinderzunge. Die Pilzpapillen finden sich gewöhnlich in vier grösseren Gruppen „und zwar zu beiden Seiten des Zungenkörpers und der Zungenspitze". Bei Kälber- und Fötenzungen erkannte dann Becker, „dass die Pilzpapillen nicht planlos über die Zungenrückenfläche verstreut sind, sondern in Reiben geordnet stehen, die beiderseits vom Zungenrande in spitzem Winkel gegen die Mittellinie der Zunge verlaufen“. „Dieser von den beiderseitigen Papillenreihen gebildete Winkel ist auf dem Zungenteile hinter der Querfurche, also auf dem Zungenkörper, gegen den Zungengrund, vor der Querfurche, also auf der Zungenspitze, gegen das freie Zungenende gerichtet. Die einzelnen Papillenreihen einer sagittalen Zungenhälfte laufen parallel, und zwar hinter der Querfurche, dann nach dem Rande gegen die Mittellinie nach hinten, vor der Querfurche vom Rande nach der Yittellinie nach vorne." Die grössten Pilzpapillen finden sich am Zungenkörper, die kleinsten an der Spitze.

Leider ist die Betrachtung dieser Zustände durch keine Abbildung begleitet.

"Die Wallpapillen liegen in zwei Gruppen beiderseits am Rande des Zungenkörpers vor der Einpflanzungsstelle des Arcus palotoglossus." „Das ganze "Papillenfeld zieht sich, vorn am aussersten Zungenrande mit einzelnen Papillen schon mehr auf der Seitenflache beginnend, nach binten medianwărts, kann aber doch als am Zungenrande liegend betrachtet werden." Es legen sich die Wallpapillen nicht als Doppelreihen an, sondern diese Doppelreihen sind aus drei bis fünf Reihen hervorgegangen, "die hintereinander liegend, parallel zu den Pilzpapillenreihen verlaufen“. „Die hinterste Reihe kann noch durch eine einzelne, meist ziemlich grosse Papille angezeigt sein." Nach hinten zu nehmen die Wallpapillen an Grösse zu und die medianen sind zumeist grösser als die lateralen.

Die Wallpapillen haben die mannigfaltigste Form, sie können auf der dorsalen Fläche einen spitzen Papillenfortsatz aufweisen, oder es münden dort seröse Drüsen in eine Langs- 
furche. Am wichtigsten aber ist jener Befund Beckers, wonach Papillen einseitig bewallt sein können, wobei der einseitige Wall sich dort befindet, „wo die vorderste Papillenreihe auf die Grenze vom Eiweissdrüsenbezirk zu stehen kommt". Es liegt dann der Wallteil der Papille gegen die serösen Eiweissdrüsen $z u$, auf welcher Seite auch die Geschmacksknospen in der Seitenwand der Papille liegen. In den Halbgraben münden seröse Drüsen.

Solche Papillen nennt Becker Übergangspapillen von Pilzzu Wallpapillen. Doch fehlen auf diesen Papillen dorsalwärts Geschmacksknospen, was doch zu berücksichtigen wăre.

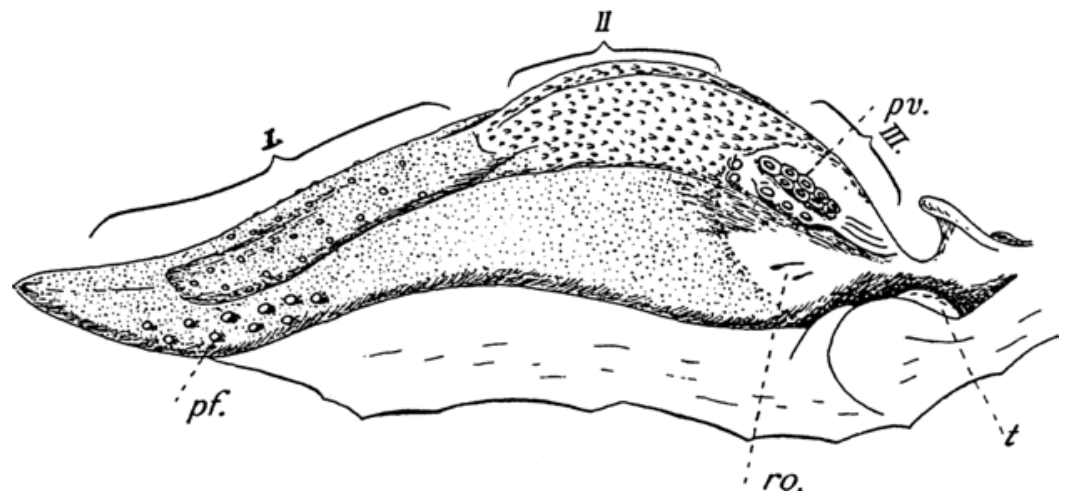

Fig. 25.

Kalbszunge von der linken Seite. I, II, III = erstes, zweites und drittes Zungenfeld $; \mathrm{t} .=$ Tonsille; $\mathrm{pv} .=$ Papillae vallatae $;$ pf. $=$ Pap. fungiformes ; ro. = Randorgan.

Die Randorgane können in wenigen Făllen ganz oder einseitig feblen, zumeist aber kommen sie auf beiden Seiten vor. „Es stellt gewöhnlich eine mehr oder weniger tiefe Grube dar, die entweder ganz oder nur an der lateralen, unteren Seite von einer wallahnlichen Erhebung der Schleimhaut umgeben ist."

Nach meinen Untersuchungen an der Kalber $\mathrm{z} u n g$ e überziehen die Fadenpapillen, die von den Zăhnchenpapillen niederer Formen sich ableiten, nur die Seitenflache bis zu den Randorganen (Textfig. 25, ro.) und dann die ganze dorsale Fläche bis etwas hinter der Zungenhälfte, wo sich dorsal eine Querfurche befindet. Die ganze dorsale Fläche von hier aus, welche auch tuberkelăhnlich sich erheben kann (II), wird von grösseren 
Schleimpapillen bedeckt, die sich auch auf das hinterste Gebiet (III) vor dem Pharynx erstrecken. Man kann also hier von einem ersten (I), zweiten (II) und dritten (III) Zungenfeld reden.

Auf der dorsalen Zungenflacche des ersten Feldes liegen auch grössere Pilzpapillen in der von Becker angegebenen
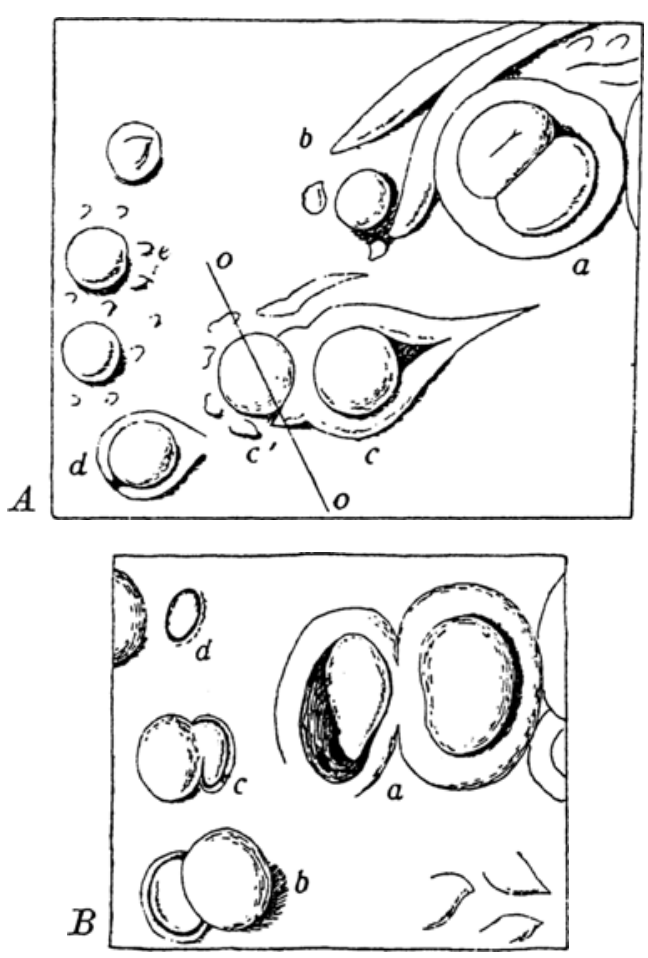

Fig. 26.

K a l b. Das vordere Ende der Wallpapillenreihen zweier verschiedener Tiere. $a=$ Doppelpapille der beiden inneren Reihen; $c=$ Einzelpapille mit anliegender Übergangspapille der dritten Reihe; $\mathrm{e}=$ Übergangspapillen.
Anordnung. Ebenfalls finden sich solche auf der Z ungenspitze sehr dicht beisammen, wie es Becker angibt, sind aber von ganz besonderer Kleinheit (auf der Figur nicht eingezeichnet). Die grössten Pilzpapillen liegen seitlich, hinter der Zungenspitze, etwa zehn bis zwölf an Zabl. Randorgane fand ich entweder nur aus einem oder aus $z$ wei Spalten bestehend. B ecker hat darüber ausführlichere Beobachtungen gemacht, aus denen nur zu deutlich erhellt, dass wir es hier mit einem starken Rückbildungsprozess zu tun haben.

Die zahlreichen Wallpapillen liegen in der von Becker angegebenen Weise in drei Lăngsreihen angeordnet, seitlich an der Zunge weit hinten (pv.) und die Reihenrichtungen konvergieren miteinander nach hinten zu.

Ich finde zwei ganz dicht beisammen liegende Reihen, die vorne mit einer unpaaren Papille enden können. Doch liegt 
hier zumeist eine Doppelpapille (Textfig. 26, A, B, a.). Die dritte Reihe der Wallpapillengruppe liegt weiter laterąlwărts und berühren sich die Walle nicht immer.

Von Wichtigkeit ist das vordere Ende der Wallpapillengruppe. Einmal lag eine, die oben erwăhnte, in ganz einheitlichem Wall gelegene Doppelpapille (A, a.) zuvorderst. Davor eine kleine wallose Papille (b.). Seitwärts davon befand sich eine gutumwallte Papille, deren vordere Wallseite die anliegende kleine Randpapille $\left(c^{\prime}\right)$ zu umgreifen begann. Andere kleinste Papillen lagen um diese. Dann folgte nach aussen zu eine kleine, gutumwallte Papille (d.), der innen noch drei nichtumwallte (e.) folgten.

Im zweiten Falle (B) war die erste Doppelpapille nur insofern als solche zu bezeichnen, als die sich berührenden Wallseiten verwachsen waren (a.). Davor lagen vier Übergangspapillen. Innen eine nichtumwallte, dahinter gleich eine kleine versenkte (d.), dann folgte nach aussen eine Doppelpapille, von der nur der kleine hintere Abschnitt umwallt war (c.). Die auswărtigste Doppelpapille (b.) kehrte das umwallte Stück nach vorne.

Die Struktur dieser Papillen soll erst weiter unten mit der des Schafes gemeinsam erörtert werden.

Von der Schafzunge berichtet Becker, leider wieder, ohne ein Gesamtbild von der Zunge beizugeben, dass die Fadenpapillen ăhnlich seien wie beim Rinde, doch sind Hornfortsătze an ihnen vorhanden, die nach hinten $\mathrm{zu}$ an Höhe und Stărke zunehmen. Hinten am Rückenwulst (Tuberkel) der Zunge befinden sich dreizackige, runde und knopfförmige Papillen. Die Pilzpapillen sollen sich so verhalten wie beim Rinde, doch lässt sich erkennen, dass die „auf der Zungenmitte $z$ wischen den beiderseitigen Wallpapillen stehenden Pilzpapillen die mediane Fortsetzung der Wallpapillenreihen bilden". Dieser Satz blieb mir darum völlig unverstăndlich, da an angegebener Stelle sich überhaupt keine Pilepapillen befinden.

Die Wallpapillen, deren Zahl zwischen 30 und 60 variiert, liegen auf jedem Rande in vier bis sechs Reihen und vereinigen sich die beiden Reihengruppen miteinander. Unter diesen nicht grossen Wallpapillen gibt es auch Doppelpapillen. Ein Randorgan feblt.

Letzteres fand ich in jedem Falle, was um so leichter zu erkennen ist, da an dem ganzen Gebiet zwischen hinterem Zungen- 
rand und Pharynx, weiches Gebiet in gleicher Form auch auf die Stelle, wo die Randorgane zu liegen hätten, sich erstreckt, völlig glatt ist. Es ist das ursprüngliche dritte Gebiet (Fig. 21, III). Es ist somit die ganze Zunge aus diesem Gebiet nach vorne zu herausgerückt und der vordere Teil des ganzen Schleimdrüsengebietes schiebt sich nach vorne auf das langgestreckte Tuberculum, das wie bei dem Rinde das zweite Zungenfeld ist (II). Gleiches gilt bezüglich dieser Drüsen auch für das Rind und in beiden Fällen haben sich seitlich von dem seitlichen Schleimdrüsengebiet, in der bei Chiropteren und Insektivoren vorgeschriebenen und begonnenen Weise vorderste Drüsen gesondert, die nun in der Năhe der Sublingualis als Glandulae subinguales minores sich erbalten.

Die eigentliche Zunge der Cavicornier besteht somit aus einem ersten (I) und zweiten Zungenfeld (II). Die Zunge des Schafes selbst ist im zweiten Feldgebiet breiter, wird dann etwas von dem Tuberculum eingeengt, um sich dann an der Spitze, die im Gegensatz zur Rinderzunge abgestutzt ist, wieder etwas $\mathrm{zu}$ erweitern. Hierdurch entsteht eine biskuitförmige Gestalt. Die Haarpapillen verhalten sich wie dies Becker gefunden und erstrecken sich auch auf das Tuberculum wie auch seitwärts davon, doch verlieren sie bald am vorderen Tuberkelende ihren Hornaufsatz und machen grossen, zwar verschieden gestalteten, doch zumeist spitz auslaufenden Schleimpapillen Platz, welche dann die ganze Tuberkelmitte einnehmen, mit Ausnahme einer länglichen zentralen Stelle, die bei der Ziege fehlt. An der hinteren Halfte des zweiten Feldes sind überhaupt nur noch Schleimpapillen vorhanden, die ganz hinten und lateralst zu langen, fast mit ihrer ganzen Lange festsitzenden Gebilden werden. Es erstrecken sich bei manchen Individuen aber für kurze Strecken die Schleimpapillen in einem medialsten schmalen Streifen auch auf das erste Zungenfeld.

Die Pilzpapillen sind jederseits in eine lateralste, nicht gut eingehaltene Reihe angeordnet und greifen auch viele auf die untere Zungenflache noch über, wie dies Becker angibt. Am Tuberkel angelangt, setzt sich die Reihe innen von den Wallpapillenreihen, zwischen diesen und den Schleimpapillen, auch auf das Tuberkel fort, ohne dessen Hinterende zu erreichen. Manche von ihnen sind die Vorderenden der inneren Wallpapillenreihen. 
Vorne an der Zungenspitze, die durch eine mediosagittale Furche oben halbiert wird, vereinigen sich die beiderseitigen Papillenreihen mit dem dichten Pilzpapillenbesatz. der, wie denn auch die sie umgebenden Papillen, auch auf die Unterseite umgreifen. Die ganze dorsale Fläche der Zunge ist somit frei von Pilzpapillen.

In mehreren, bis vier, Reihen besetzen die vielen Wallpapillen die Zungenseiten des zweiten Feldes, den lateralen Tuberkelrand begrenzend $\left(\mathrm{pv}^{\prime}\right)$. So ziehen sie nach hinten und vereinigen sich bei manchen Tieren vor dem hinteren Zungenrande oder bleiben die Reihen offen, wie in dem abgebildeten Falle. In diesem Falle, ich habe in sieben Fallen dies dreimal gefunden, befindet sich zu hinterst zwischen ihnen, doch etwas vor ihrem Ende, eine kleine gut bewallte Wallpapille (pv.) als
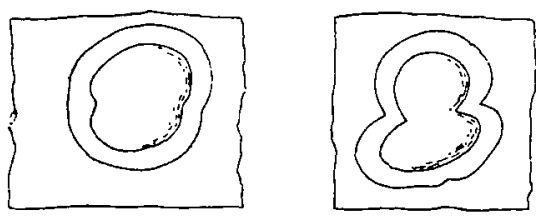

Fig. 27.

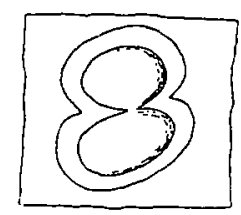

$\mathrm{Sch}$ af. Drei Doppel-Wallpapillen.

Papilla vallata centralis. Somit ist wenigstens bei dem Schafe das ursprüngliche Verbalten noch angedeutet, was doch beim Rinde nicht mehr der Fall ist.

Nur die innerste Reihe der Wallpapillen ist gut erhalten, die anderen vielfach ineinander geschoben, und zu lateralst der ventralen Seite genähert, finden sich, die Reihen nicht mehr einhaltend, kleine Einzel- und Doppelpapillen, die versenkt aber ohne Wall sind und wie wir sehen werden, für die Entstehung von Wallpapillen als Wegweiser dienen.

Die übrigen umwallten Wallpapillen können vollständige Wälle besitzen, nach hinten offen sein (Fig. 6), wann denn die Wallenden in Lăngsfalten auslaufen oder mit einem Rande mit dem Rand einer benachbarten Wallpapille sich verlöten. Dann gibt es so viele aus diesen Zuständen sich herleitende Modifkationen, dass man fast alle für sich beschreiben müsste. Auch gibt es viele in einen Wall eingeschlossene Doppelpapillen und 
dann solche Doppelpapillen, die zwar einen einheitlichen Wall haben, dieser beginnt aber zwischen den beiden Papillen von zwei Seiten einzuwuchern und diesbezüglich gibt es alle Übergănge bis zum vollständigen Getrenntsein der beiden Papillen. Es sind dann solche fest aneinander liegende Wallpapillen an der einen Wallseite miteinander verwachsen. Ich habe auf Textfig. 27 drei solche Doppelpapillen aus den verschiedensten Gegenden der Wallpapillenreihen ausgesucht und zusammengestellt.

Am vorderen Ende der Wallpapillenreiken, aber auch lateralst, finden sich auch solche, deren Wall entweder ganz oder doch teilweise von Einzelpapillen gebildet wird. Am ersten Ort gibt es neben solchen oft ganz kleine Wallpapillen (Fig. 7, c.), auch solche, die nur in der angegebenen Weise einseitig bewallt sind (b.) und daneben Pilzpapillen (a.). Auf diese Verbălnisse komme ich spăter noch zurück.

Aus Brüchers (6) Beobachtungen an den Zungen von Camelopardalis geht es hervor, dass diese Zunge sich vielmehr dem Typus der Cavicornierzunge anschliesst als die der Cerviden und dass die Tylopodenzunge einen ursprünglicheren Zustand darstellt, aus dem sich die Bovidenzunge ableitet, der gegenüber, zwar fest anschliessend, die der Oviden, von Capra und der Antilopiden, welche drei letzteren die grösste Übereinstimmung zeigen, ein jüngerer Erwerb ist. Die Cervidenzunge hat mehr Anschluss an die der Oviden, wenn wir von den eigenartigen Zustănden von Moschus absehen. Hier liegen nach Blücher die Wallpapillen in je einer umwallten Spalte, die ganz hinten liegend von oben nach unten und vorne zieht, damit die ursprüngliche Dreieckform noch zeigend.

Die Schweinszunge ist verschieden von der der Cavicornier und erinnert an ursprünglichere Zustände, da sich ja auch ein gut entfaltetes Randorganpaar daran vorfindet, etwa wie beim Tapir. Die Zungenverhaltnisse des Hausschweines sind durchaus bezeichnend für die Familie der Suiden, wie aus der Beschreibung Brüchers von der Zunge von Dicotyles deutlich hervorgeht.

Die Zahl der Wallpapillen ist von jeher auf zwei festgestellt worden, die mit ihren Lăngsachsen nach linten konvergieren, doch fand Becker manchmal noch eine kleinere dritte neben 
der einen oder sogar eine Zentralpapille. Diese konnte ich nur einmal beobachten. Die Fadenpapillen bedecken den Zungenrücken, lassen jedoch die Gegend der Randorgane frei.

„Die Pilzpapillen", schreibt B ecker, „sind auf dem vorderen Drittel der Zunge des Schweines gleichmässig verteilt, weiter nach hinten setzen sie sich, in zwei Schenkel gegen die Rănder hinziehend, auf die Seitenflachen fort, wo sie in einem nach unten geschweiften Bogen bis in die unmittelbare Năhe des Randorganes reichen. Ganz vereinzelt findet man solche auch noch auf dem Randorgane selbst. Ein grösseres Feld dieser Papillen liegt vor und zwischen den Papillae vallatae bis an die zottenförmigen Fadenpapillen bin. ${ }^{*}$ Rückgebildete Pilzpapillen sollen auch um das Frenulum herum sich noch vorfinden.

Ähnlich sind meine Befunde. Die lăngliche, vorne abgestutzte, doch sich hier verjüngende Schweinszunge wird an ihrer dorsalen Seite bis zum dritten Feld (Fig. 20, III) von feinen Fadenpapillen überzogen, die aber das Randorgangebiet (Fig. 1, ro.) frei lassen, so auch zu Beginn hinter der Seitenflache. Dabei zeigt sich, dass jenes Gebiet, welches das zweite Feld (II) vorstellt, in seichte Querfalten gelegt ist, die konstant sind. Mit den Wallpapillen (Figg. 1, 20, vp.) gehen diese Fadenpapillen in allmăhlich sich vergrössernde grosse Schleimpapillen über, die das dritte Feld in nach hinten gerichteten Lângsreihen bis an das Frenulum bedecken und einige kleinere gehen auch auf dies über. Ihre Reihen, sehr niedrig werdend, setzen sich am Randorgan lateralwarts in rinnenbildende Falten fort, in welche Rinnen die Randorganelemente (ro.), soweit sie nach innen zu offen sind, sich mit ihrer Spalte fortsetzen. Die Pilzpapillen verhalten sich, wie es Becker angibt. Sie überziehen, von der Zungenspitze an grösser werdend, den Zungenrücken in gleichmässiger, recht dichter Anordnung, um dann in der Mitte der Zunge, in je einen seitlichen Schenkel nach den Seiten weichend, den Zungenrücken frei zu lassen. Dieses pilzpapillenlose Gebiet, das kein Tuberkel bildet, würde dem zweiten Zungenfelde (Fig. 20, II) entsprechen. Seitlich reichen die Pilzpapillen in verschiedener Grösse fast bis zu dem Randorgan (Fig. 1). B e cker erwahnt eine Gruppe von. Pilzpapillen, die vor den grossen Wallpapillen auf dem Zungenrücken liegen. Ich konnte um diese Papillen schon mit der Lupe sehr gut einen Wall erkennen 
(Figg. 1, 20, pv'). Es handelt sich hier um Übergangspapillen zu Wallpapillen.

Die beiden sehr grossen Wallpapillen (pv.) konvergieren nach hinten mit ihren Längsachsen, sie sind gewiss Urformen, obgleich sie auch Doppelpapillen sein können (Fig. 1), wie dies Becker feststellte. Aber sie können auch sonst Unebenheiten auf ihrer Dorsalflache aufweisen (Fig. 2). Ihrem gut entfalteten Wall sitzen Fadenpapillen auf.

Becker will im Schleimfeld in der Năhe des Frenulums rückgebildete Pilzpapillen beobachtet haben. Ich habe auf jeder Seite je eine runde Papille $z$ war gesehen (Fig. 20, p.), aber es

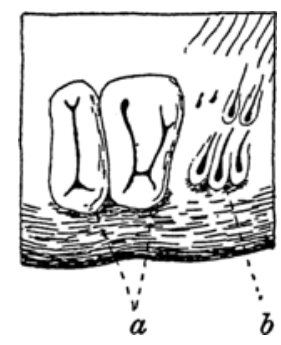

Fig. 28.

H a s s c hwein. Rechtes Randorgan. $a=$ vergrössertes, beziehentlich aus zweien entstandene Elemente; $b=$ Einzelelemente, die sich zur Verwachsung anschicken. waren auch nur Schleimpapillen. Ich möchte überhaupt vor dem Bestreben warnen, dort Pilzpapillen zu suchen, wo phyletisch kein Ort für sie vorgezeichnet ward. Anders verhält es sich aber auch mit der vermeintlichen, durch Becker abgebildeten „rudimentăren Pilzpapille“ hinter den Wallpapillen bei dem Hunde, denn diese hat im Walle Mündungen seröser Drüsen und ist folglich keine Pilzpapille. Es wird sich hier um die bei Raubtieren rückentfaltete Zentraipapille handeln.

Die beiderseitigen $R$ and org an e liegen an dem überall gleichen Orte vor dem Arcus palatoglossus (Figg. 1, 20, ro.) in gleicher Querebene mit den grossen Wallpapillen. Nach Becker, tritt jedes der Organe in die Erscheinung als eine grössere oder kleinere Anzahl gleich oder verschieden grosser Furchen oder Spalten in der Schleimhaut mit dazwischen liegenden, mehr oder weniger über das Niveau der Schleimhaut hervortretenden Leisten". Ihre Form soll mehr weniger langlichoval sein. Ich kann diese Angaben nur zum Teil bestătigen. Wenn es sich um so etwas handelt, betrifft es nur einen Teil des Randorganes. Auch in einem von mir abgebildeten Falle (Textfig. 28) waren die beiden vordersten Elemente (a.) - die, oder wenigstens das zweite, durch Verwachsung mit einem angrenzenden Element entstanden, zeigten hobe Walle und tiefe Furchen, beim zweiten 
die beiden Elementfurchen durch eine Querfurche verbunden da, doch lagen hinter ihnen noch andere. Es waren in diesem Falle zwei umwallte, nach innen offene Elemente immer vor drei anderen ăhnlicher, doch etwas grösserer (b.) gelegen. Schon auf der anderen Seite sah die Sache anders aus. Hier (Fig. 1, ro.) lag eine Reihe von stark umwallten ausserlich birnförmigen, am verjüngten inneren Ende offenen Elementen, von denen die bintersten drei die grössten waren, in einer Reihe, sieben an der Zahl. Allmählich kleiner werdend, waren die beiden ersten die kleinsten. Innen von den fünf ersten lagen diesen fest an,

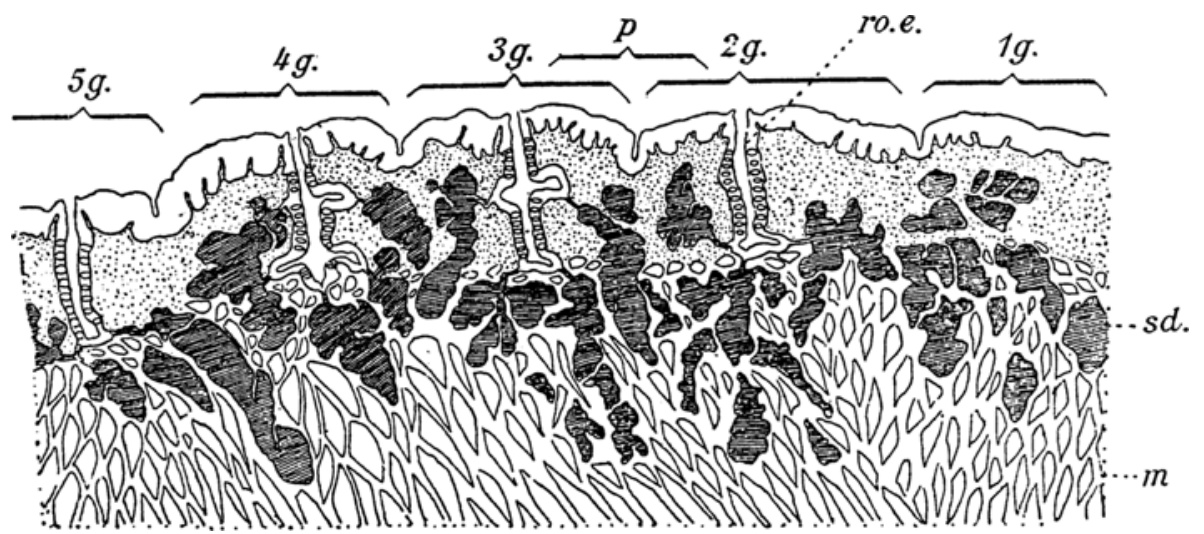

Fig. 29.

S chwein. Sagittaler Längsschnitt durch die Elementenreihe des Randorganes. $1 \mathrm{~g}$. bis $5 \mathrm{~g}$. = erstes bis fünftes Element; sd. = seröse Drüsen; m. = Muskellage.

mit ihnen aber altenierend, fünf andere, auch allmăhlich nach vorne zu kleiner werdende Elemente.

Es haben sich also hier die zwei Reihenenden der ursprünglichen Reihe übereinander geschoben. Wenn wir dann dies Verhalten mit dem der anderen Seite vergleichen, erhalten wir den Modus der Umgestaltung. Die vordersten Elemente werden grösser durch Wachstum oder dadurch, dass sie mit einem benachbarten Element durch einen $Q u e r g a n g$ verwachsen, a u ch verschliessen sie sich. Die anderen Elemente beginnen sich $\mathrm{r} u ̈ c k z u b i l d e n$. In gleicher Weise mag das einzige Element bei den Musteliden entstanden sein. 
Ein Långsschnitt über die beschriebene Elementenreihe (Textfig. 29), es sind die fünf ersten getroffen, zeigt, dass es sich hier um einfachere Zustande handelt als bei Mustela. Die kleinen Elemente ( $5 \mathrm{~g}$.) sind einfache Spalten bis kleine Grübchen, im letzten Fall nur mit ganz wenigen Sinnesknospen, und stets münden die serösen Drüsen, wie bei der Maus etwa, in den Boden der Spalte. An den tieferen grösseren Elementen münden sowohl weiter oben ( $4 \mathrm{~g}$. bis $2 \mathrm{~g}$.) als am Boden Drüsen und an der Mündung erweitert sich die Spaltenwand ampullenartig, in der nie Geschmacksknospen münden. In so eine Erweiterung können 4-8 Drüsen münden, je nach der Grösse des Elementes. Die kleinsten besitzen nur eine Drüse.

Obgleich also bei dem Schweine die Rückentfaltung der Randorgane begonnen hat, sind diese noch kraftig entfaltet.

Überhaupt ist die Zunge des Schweines ein Übergang von niederen Zuständen zu jenen der Cavicornier und würden dann bezüglich der Mächtigkeit des Randorganes noch höhere Zustände walten als beim Tapir, die höchsten aber bekanntlich bei Hyrax. Allmahlich hat sich somit das Randorgan rückgebildet, bis es den Oviden völlig fehlt.

Hier soll nun im Zusammenhang das feinere Verhalten der Wallpapillen und ihre Phylogenese bei den untersuchten Huftieren besprochen werden.

Die Pilzpapillen haben je nach dem Orte ihres Vorkommens bei den Cavicorniern verschiedene Form, welche Verschiedenheit hauptsächlich in ihrer Höhe begründet ist. Die hintersten Papillen dieser Art sind jedoch fast alle niedrig und breit, dabei von gleichmăssig rundem Umfang. Auch kann sich bekanntlich öfter um die Papille ein ganz seichter Ringgraben befinden, so, dass letzterer Umstand nichts an der allgemeinen Bedeutung andern würde. Dafür ist ein anderer Umstand an den hinteren, dem vorderen Ende der Wallpapillengruppen sich nähernden Pilzpapillen auffällig: sie, wie alle bis auf die der Zungenspitze, besitzen viele kleine Geschmacksknospen auf ihrer Dorsalflache, wăhrend diese aber gewöhnlich gleichmăssig verteilt sind, sind sie hier so angeordnet, dass ein kleiner runder Platz im Zentrum von ihnen freibleibt (Textfig. 30, A). 
Solche Papillen, die fertigen Wallpapillen anlagern und, wie es schon weiter oben erwahnt wurde, in einem Falle - die Fălle stehen aber nicht einzeln da - deren Wall sie zu umwachsen beginnt (Textfig. 26, $c^{\prime}$ ), zeigen vorgeschrittenere Verhaltnisse. Der früher geringe Ringgraben um die Pilzpapille (Textfig. $30, A)$ ist nun bedeutend tiefer geworden $(B, g$.) und infolge davon ist die Pilzpapille nun höher. Auch auf diesen $\mathrm{Pa}$ -
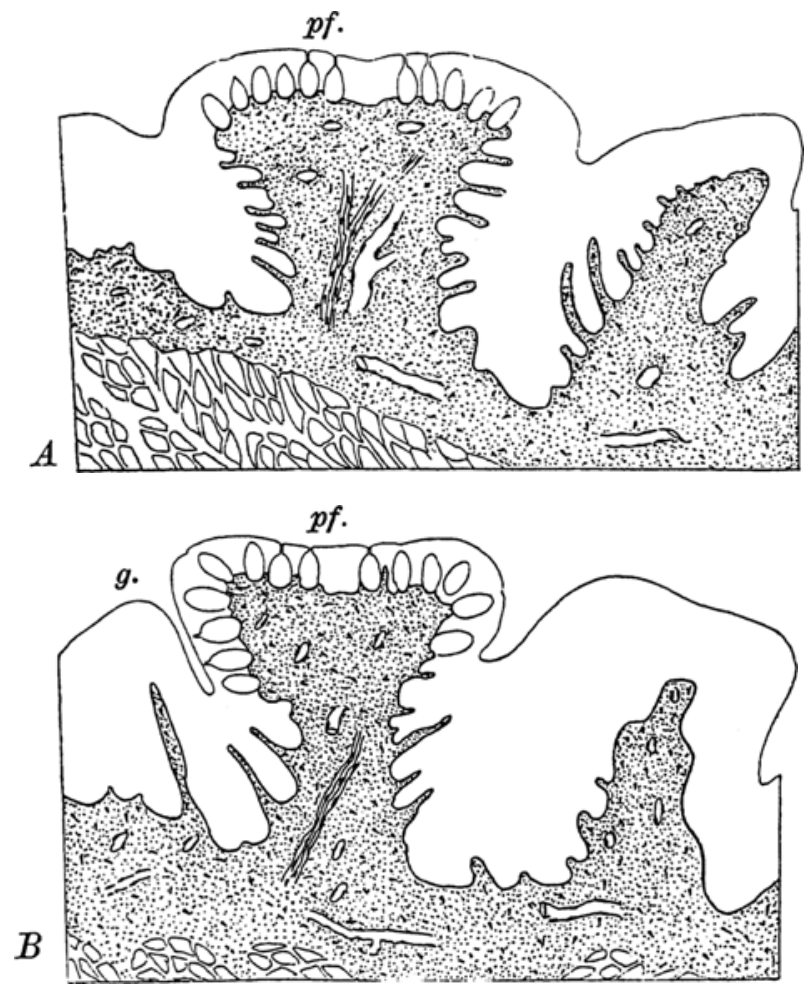

Fig. 30.

K a I b. Querschnitte über zwei Übergangspapillen ersten Grades vor der Wallpapillengruppe.

pillen, - in deren immer noch geringen Graben noch keine seröse Drüsen münden, sie folglich nur Pilzpapillen sind, -- ist die Anordnung der Sinnesknospen auf der dorsalen Seite dieselbe wie an den oben beschriebenen, allein ein Unterschied besteht nun darin, dass diese Geschmacksknospen a u ch a uf die Seitenwănde der Papille sich fortsetzen. Ganz 
ahnlich sind diese Papillen am vorderen Ende der Wallpapillenreihe des Schafes, so dass die Beschreibung, die ich hier für das Kalb gegeben, auch auf dasselbe genauestens passt. Solche Papillen nenne ich Übergangspapillen ersten Grades.

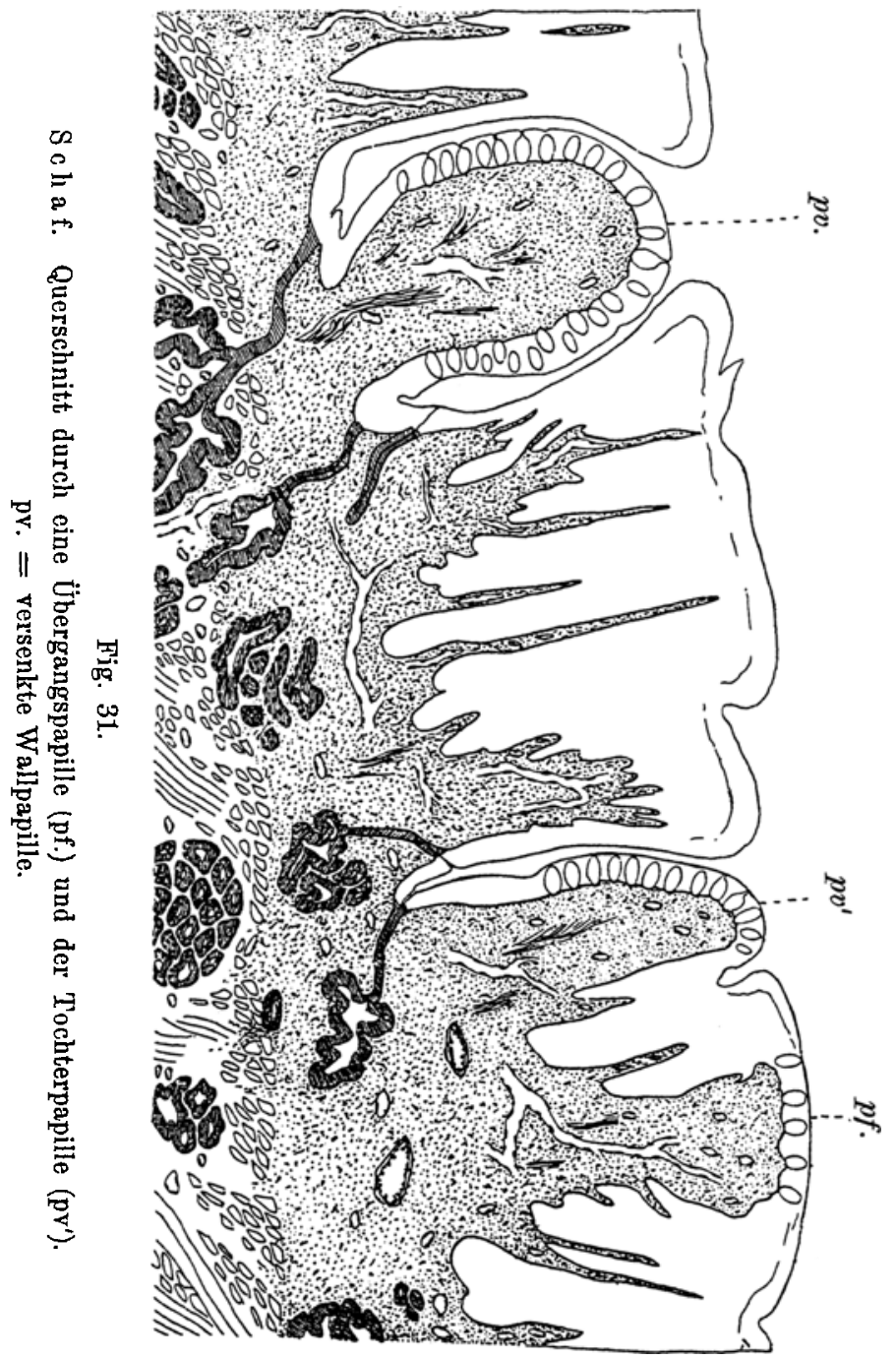

Ein weiteres Stadium zeigt sich bei ähnlichen Papillen, die einen halben Wall um sich haben (Fig. 7, b.). Der Querschnitt über solche Papillen wies entweder Zustănde auf, wie sie 
bereits von den halbumwallten Papillen vom Rind durch Becker bekannt wurden (1. c., Fig. 16). Es münden seröse Drüsen in den Halbgraben, während die Papille doch sonst Pilzpapille ist. Ich fand dann die Sinnesknospen immer an der dorsalen Fläche der Papille, doch schon auf die bewallte Seite überbiegend. Dieser Schritt bezeichnete schon eine weitere Stufe der Umgestaltung. Auf Textfigur 31 ist so eine Papille mit halbem Wallgraben (pf.) abgebildet. Die Papille war diesmal ganz niedrig, der halbe Wallgraben sehr tief, mit Mündungen nur weniger seröser Drüsen am Wallgrabengrunde, und jen er Teil d er Papille, der im Wallgraben versank, fing an sich durch eine dorsale Furche von der Mutterpapille abzugrenzen. Diese Tochterpapille hatte überall Sinnesknospenüberzug bis hinunter in den Wallgraben. Darin lag ihre Bedeutung. Dieses Stadium könnte einstweilen als in direkte Übergangspapille zweiten Grades gelten.

In vielen Fallen blieb

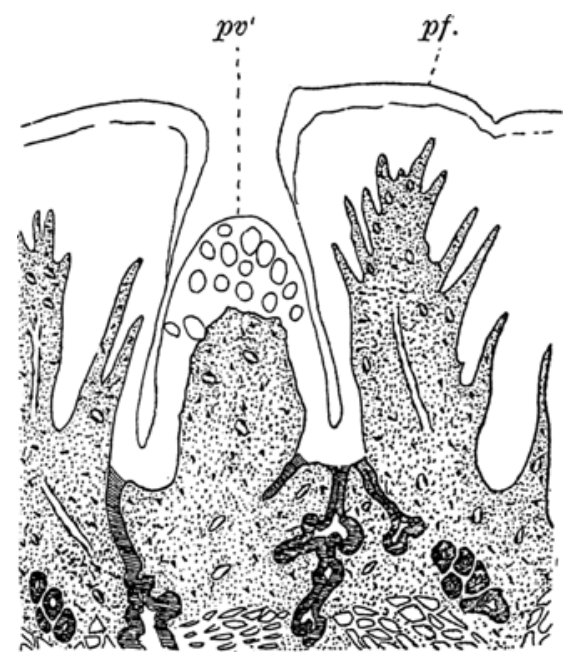

Fig. 32.

Sch af. Ein weiterer Schnitt durch dieselbe Tochterpapille wie auf der vorigen Figur rechts. $\mathrm{pf}^{\prime}=$ Mutterpapille. es bei dem beschriebenen Verhalten, in anderen aber, so auch in den beschriebenen, wal ein weiterer Fortschritt dadurch erzielt, dass die Tochterpapille, wie weitere Schnitte durch diese Papille zeigten (Textfig. 32, $\mathrm{pv}^{\prime}$ ), sich an dem einen Ende des Halbgrabens von der Mutterpapille (pf.) völlig abgetrennt hatte. Dadurch sank an dieser bezeichneten Stelle die Mutterpapille zum blossen Wall herab.

Solchermassen gestaltete Doppelpapillen, halb Wall-, halb Pilzpapille, sind an dem vorderen Ende der Wallpapillenreihe auch häufig und wurden schon weiter oben erörtert. Die Textfigur 26, B). zeigt drei verschiedene, anfeinander folgende Stadien 
(b., c., d.), in der dann die kleine versenkte Wallpapille sich von der anderen abgetrennt häte, was folglich nur eine Modifikation. bedeuten würde. Denn solche versenkte kleinste Wallpapillen sind besonders an der lateralsten Seite der Wallpapillenreihe hăufig. Ihr Wall gelangt bei oberflachlicher Betrachtung nicht in Sicht und ist erst auf Schnitten sichtbar. Gleich an demselben Schnitt, der oben erörtert wurde (Textfig. 31), ist eine solche Papille zu sehen (pv.). Sie liegt in einem tiefen Wallgraben, in den spärliche sersöse Drüsen münden und hat von der der grösseren Wallpapillen insofern eine verschiedene Form, als sie

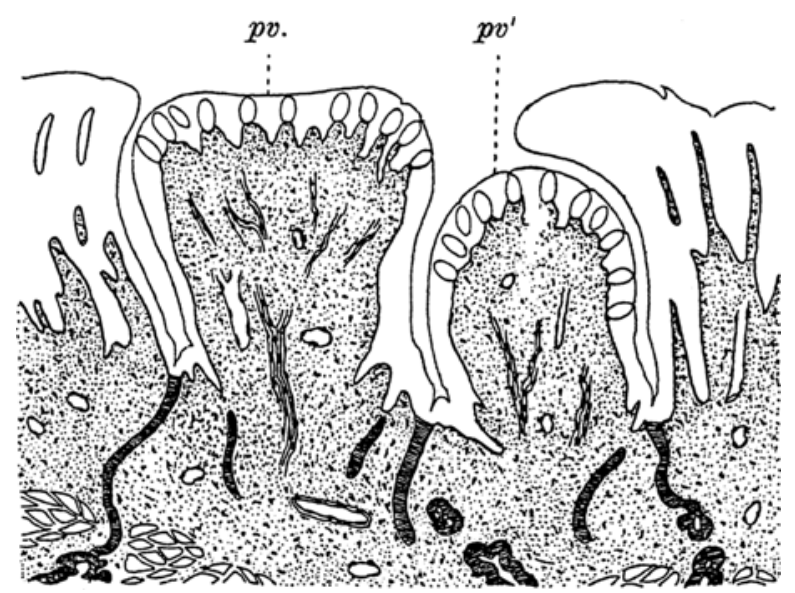

Fig. 33

Schaf. Querschnitt durch eine seitliche Doppelpapille. pv. $=$ Mutter-, $\mathrm{pv}^{\prime}=$ Tochterpapille.

oben nicht abgeplattet ist. Dazu kommt noch, dass ihre ganze Oberflache, also auch die Seiten, mit Sinnesknospen überzogen ist.

Solche versenkte Wallpapillen können aber auch Doppelpapillen sein, doch sind solche auch bei dem Schafe seltener. In diesen Fallen ist es dann ganz auffallig, dass die eine der Papillen eine oben kuppelförmig runde, die andere eine oben abgeflachte Papille ist. Beide sind mit Geschmacksknospen überzogen, wăhrend diese aber bei der in neren kleineren Randpapille (Textfig. 33, pv.) stets auf die Seitenrănder, wie immer, tief hinunter greifen, bedecken sie die abgeplattete grössere Papille (pv.) nur von oben, allerdings über die Rander noch etwas abwärts 
biegend. Wie wäre die Genese solcher Doppelpapillen anders denkbar, als dass eine Übergangspapille ersten Grades sich zu einer Wallpapille gestaltete und dass dann diese so entstandene Wallpapille eine Tochterpapille von sich abschnürte.

Aber auch grosse fertige Wallpapillen können sich durch Teilung vermehren, solche sogenannte Spaltpapillen hat ja auch Becker vielfach beobachtet, so auch bei dem Hunde, und weiter oben glaube ich gezeigt zu haben, dass nach erfolgter Teilung der Wall an den beiden Grenzrändern einwuchert und dann in dieser Weise die Teilung beendet. Dabei können die Tochterpapillen gleich gross sein oder es erfolgt nur eine knospenartige Abschnürung (Hapale).

Demnach sind folgende Arten gangbar bei der Vermehrung von Wallpapillen:

1. Es wandelt sich eine Pilzpapille durch Ausbildung eines Walles und $n a c h$ erfolgter Erwerbung der serösen Drüsen zu einer Wallpapille um. Es ist dies die ursprüngliche Entstehungsart, die aber auch noch bei höheren Formen, wie eben die Ungulaten sind, fortdauert.

2. Nur ein Teil einer Pilzpapille gestaltet sich zur Wallpapille, sie aber wird zu einem Teil des Walles.

3. Es kombinieren sich diese beiden Arten der Vermehrung, indem eine Pilzpapille, nachdem sie zur Wallpapille eigener Art wurde, aus sich eine Tochterpapille sprossen lăsst, wodurch versenkte Doppel-Wallpapillen entstehen. Ob sich solche völlig dann voneinander abtrennen, weiss ich nicht.

4. Eine völig fertige Wallpapille teilt sich in $z$ wei oder bildet eine Tochterpapille.

Durch diese Arten der Wallpapillenvermehrung entstanden die zahlreichen Wallpapillen der Ungulaten, wobei beim Schwein durch den ersten Modus eine grosse Zahl von Wallpapillen, besser Übergangspapillen, sich vor den beiden Wallpapillen bildeten. 
Aber auch bei den Simiern beherrschen alle diese Arten die Vermehung, und gilt dies für alle andern Falle, wo eine grössere Zahl von Wallpapillen sich findet wie beim Baren. Mit der Versenkung der Wallpapillen ist eigentlich nur der Wallgraben gegeben, doch kann allerdings bei der zweiten Vermehrungsart ein einseitiger Wall entstehen. In der weiteren Entfaltung nun gelangen angrenzende Papillen bis an den Grabenrand und vereinigen sich dann zu dem sekundären Wall, wie dies in vorliegender Arbeit des öfteren gezeigt wurde. Dabei beteiligen sich nicht bloss indifferente Papillen an der Wallbildung; sondern auch $\mathrm{zufällig}$ angrenzende Pilzpapillen. Hieraus erklărt sich dann der Geschmacksknospenbesatz des Wallgrabenrandes, da ein Teil der sekundaren Wallwand bei Vertiefung des Grabens weit mit eingezogen wird.

Hier möchte ich noch den Umstand hervorheben, dass bei allen solchen Übergangspapillen, die bereits seröse Drüsen besitzen, diese sich in geringerer Menge vorfinden als bei fertigen Wallpapillen, mag die Grösse der Papille auch dieselbe sein. Dies geht freilich aus einzelnen Schnitten nie so deutlich hervor, dass es sofort überzeugen würde, dazu bedarf es der ganzen Serie von Schnitten über dieselbe Papille. Auch habe ich öfter die Beobachtung gemacht, dass die Drüsen bei Übergangspapillen seitlich weniger verzweigt sind.

Nur nebenbei möchte ich bemerken, dass die Sinnesknospen auch bei vielen grösseren Doppel-Wallpapillen der Cavicornier bis weit hinauf reichen auf die Papille, ja sich sogar stellenweise für eine kurze Strecke auf die dorsale Seite umschlagen können. Dies ist der Fall bei den vordersten Papillen der Wallpapillenreihe der Cavicornier und erklart sich aus dem Umstande, dass diese Wallpapillen noch verhaltnismässig phyletisch junge Wallpapillen sind. Die Einzelwallpapillen zeigen dies nicht.

Dass der Fortgang der Wallpapillenbildung im Gange ist, wăre bewiesen und wird wohl bei jugendlichen Tieren eine grössere Rolle spielen, als bei den alten, denn nach dem physiologisclien Bediurfnis vermehren sich eben die Wallpapillen a $\mathrm{uch}$ bei dem Individu um und manche Menschenzunge weist mehr Wallpapillen auf, als die eines anderen.

Noch möchte ich hier auf einen Punkt hinweisen, den ich schon bei der Maus erwăhnt habe. Bei der Besprechung der Deckzellen der Knnospen der Pilzpapillen sagte ich, dass statt 
ihrer bei allen anderen Geschmacksknospen sich ein Plattenepithel befande, welches oben die Knospe allseitig umgibt und in die oberste Zelllage des Epithels übergeht. Diese Decke (Textfig. 34, C) finde ich überall. Die sich sehr tief tingierenden Zellkerne fallen auf auch auf quergetroffenen Knospen und dann erst.

Die Schleimdrüsen sind die ursprünglichsten der beiden Drüsenarten der Zungenschleimhaut, daran wird nicht gezweifelt, besitzen doch die Amphibien nur solche (einzellige) und die serösen treten erst auf, nachdem die schon bei den Amphibien vorhandenen Geschmacksknospen der Mundhöhle sich zu Gruppen konzentrieren, mit den Wallpapillen und dem Randorgane. Diesen beiden müssen phyletisch die Pilzpapillen vorgesetzt werden. Diese müssen also schon damalsbestanden haben, als seröse Drüsen sich noch nicht gebildet haben. Erst nachdem der Graben sichgebildet, musste durch den chemischen Reiz im Graben die erste Veranlassung
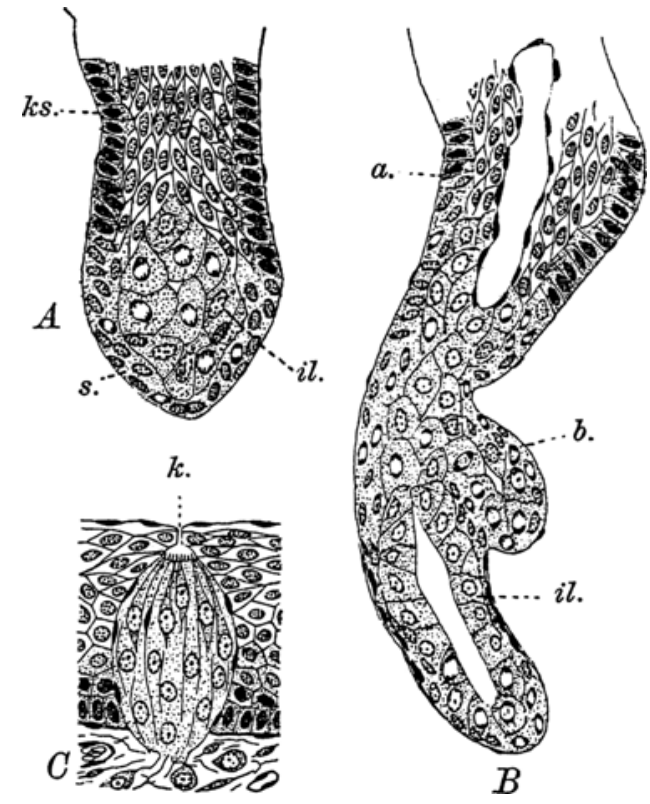

Fig. 34.

Schaf. A und B Schnitte durch Epithelstränge, die an versenkten Pilzpapillen, den Übergangspapillen an jener Stelle am Wallgrabenboden sich in das Bindegewebe ausstrecken, wo später die serösen Drüsen liegen. Zwei verschiedene Entwicklungsstadien. ks. = Kleinschichte; s. = deren Fortsetzung; il. = innere Zelllage. $\mathrm{C}$ eine Einzelknospe aus einer Wallpapille des Kalbes. $\mathrm{k}$. = Toldtscher Gang. zur Bildung der serösen Drüsen gewesen sein. Von diesem Gesichtspunkte ausgehend, suchte ich an den Übergangspapillen eine Stelle der nach innen gerichteten Epithelfortsătze ab, die an gleicher Stelle lag, wo spăter bei der Wallpapille für gewöhnlich die serösen Drüsen in den Wallgraben münden. 
Es zeigte sich dann wirklich, dass dort Drüsen in der Bildung begriffen sind. An einem der kürzeren Fortsătze (Textfigur 34, A) ist erkenntlich, dass der Epithelfortsatz - nicht jeder der sich dort befindenden Fortsătze ist Drüsenanlage an seinem Ende anders gestaltet ist, als weiter oben. Von hier aus setzt sich die Keimschichte des Epithels (ks.) auf die Knospe fort, allein die Zellgrenzen schwinden, die Zellkerne liegen durcheinander und das Plasma ist nicht mehr so intensiv tingierbar. Manche Kerne sind in Teilung begriffen. Unter dieser Zelllage (s.) ist das Epithel auch völlig verschieden von dem im oberen Abschnitt des Epithelfortsatzes. Es sind die Zellen (il.) gross, stark gekörnt und viele Kerne in regster Teilung begriffen. Ein anderer längerer Fortsatz (B), der schon eine Anlage eines Drüsenacinus zeigte (b.), hatte bereits an zwei Stellen Lumina, die aber noch nicht zusammenhingen. Oben (bei a.) war das Lumen durch eine Plattenepithellage überzogen, die später in die oberste Lage des Wallpapillenepithels sich fortsetzt. Die grossen Drüsenzellen (il.) bilden die innerste Schichte des Fortsatzes und die auussere Lage, die die der Drüsenzellmutterschichte ist, die Fortsetzung der Keimlage war auch hier in reger Proliferation.

Einzig wie die vereinsamte Abteilung steht die Sirenenzunge, die ich hier nicht etwa darum anschliesse, weil ich eine Verwandtschaft mit der der Huftiere annehme, sondern wegen der starken Vermelurung der Wallpapillen. Hierüber hat B ed dard (3) zuletzt berichtet. Es liegen hier Wallpapillen in sehr grosser Zahl nicht nur am hinteren Zungenrücken, die ursprünglich V-förmige Anordnung vollstanndig einbüssend, sondern selbst an der lateralen Seite der Zunge, und zwar entlang der Anheftungsstelle. Sie ziehen hier von einem durchlöcherten Wulst, dem sogenannten Mayerschen Organ - der von dem hinteren Zungenrand nach aussen vorn, seitwarts und unten zieht, und nur das eigentümlich umformte Randorgan sein kann - in verworfener Reihe bis nahe an die Zungenspitze. Diese zeigt einen Zahnpapillenbesatz.

\section{Allgemeine Betrachtungen.}

Wenn die phyletische Entfaltung der Zungenschleimhaut, speziell der Sinnesorgane, diskutiert werden soll, so muss natur- 
gemass die Sache dort beginnen, wo die ersten Anfange einer Zunge vorliegen. Dies ist bei den Ichthyden noch nicht der Fall und setzt die Zungenbildung erst bei den Amphibien ein. Sind die rezenten Amphibien auch nur eine Astspitze jenes măchtigen Astes, von dem die Säugetiere nach der einen und die Sauropsiden nach der anderen Seite sich abzweigten, der Stegocephalen nămlich, so sind bezüglich der Zungenverbaltnisse bei den Urodelenlarven noch Zustande erhalten geblieben, die mit einiger Vorsicht bei der Spekulation verwendet werden können.

Bei diesen nun, bei denen die höhere Zunge sich oben in der allerersten Anlage zeigt, besteht die Zunge bekanntlich aus zwei Anlagen : aus der Vorderzunge (Textfig. 35, A, vz.), die bei dem erwachsenen Tier zum drüsigen Vorderteil der bleibenden Zunge wird, und von Anfang an als dicke Drüsenlage sich zu erkennen gibt, und aus jenem Teil des durch den Hyoidbogen (Hy.) nach vorne zu abgeschlossenen Vorsprunges, in dessen Mitte jetzt noch die Copulae des Kiemenbogenapparates gelegen sind(Gaumen). Dieser ganze Vorsprung dient zur Begründung der späteren Zunge, soweit eben die Schleimbaut in Betracht kommt und wenn wir den vorderen drüsigen Abschnitt der definitiven Amphibienzunge als etwas Eigenartiges auffassen. Die Muskularierung dieses hinteren Abschnittes ist ein spaterer Prozess, wobei ich mich mit der Frage der phyletischen Zungenentwicklung hier nicht weiter beschäftigen möchte. Uns interessiert die Schleimhaut auf diesem Abschnitt, da ihr Verhalten direkt als Grundlage für spatere Zustande gelten kann. Diese Anlage würde somit nur aus einer bindegewebigen Unterlage und dem Epithel bestehen und, wie gesagt, nur bezüglich der Zungenschleimhaut in Betracht kommen. Diese Hinterzungenanlage (hz.) ist vorne derVorzunge (vz.) gegenüber bei alten Larven bekanntlich durch eine Querspalte abgegrenzt, in welcher das Epithel fast einschichtig und völlig indifferent ist, das heisst weder Drüsenzellen noch Sinnesorgane trăgt. Auf der dorsalen Flache der ${ }_{n}$ Hinterzunge ${ }^{*}$ ist das Epithel am dicksten und besteht jetzt aus einer zweischichtigen unteren Lage und einer darüberliegenden flimmernden Zylinderzellenlage (Textfig. 35, B). Den Abschluss bildet ein feiner cuticularer Saum. In dieser oberen Lage nun finden sich oft recht dicht gestellt Drüsenzellen; sogenannte Becherzellen (sz.), die mit ihrem oberen offenen Ende den Cuticularsaum durchbrechen. Der 
Sekretinhalt der Theca fărbt sich so tief blau oder rot durch die angewandten Färbemittel wie der Schleim und ist somit auch solcher.
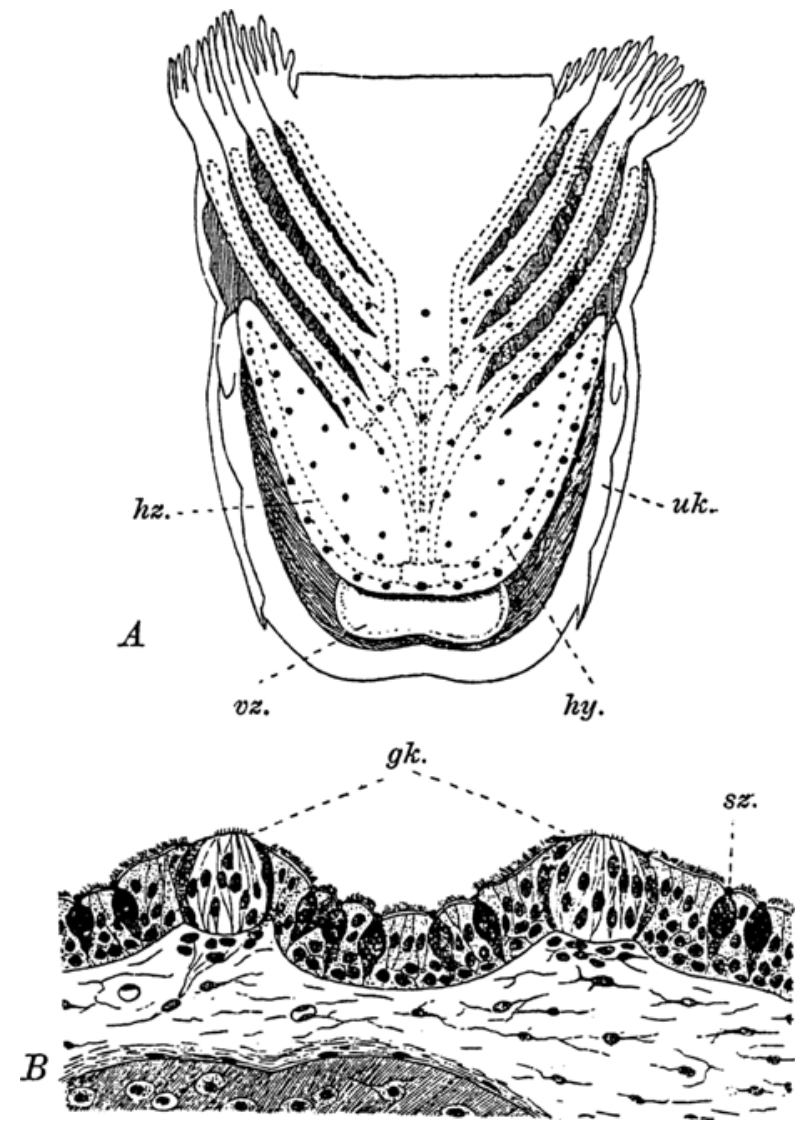

Fig. 35 .

Salamander-Larve (alt). A die untere Mundhöhlenwand von oben gesehen. $\mathbf{v z .}=$ Vorzunge; hz. = Hinterzunge; uk. = Unterkiefer; by. = Hyoidbogen. Die Geschmacksknospen schwarz. B Längsschnitt durch die Schleimhaut der Hinterzunge. gk. = Geschmacksknospen.

Es überziehen diese Schleimzellen bekanntlich nicht nur

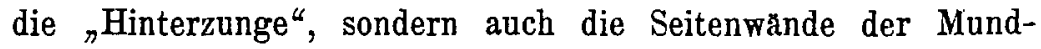
schleimbaut und reichen bis zum dritten Kiemenbogenpaar, wo sie über dem Herzen mit Beginn des Ösophagus wie abgeschnitten 
aufhören. Sie sind die Vorgänger der vieizelligen Schleimdrüsen der Mundhöhle der Sauropsiden und der Säugetiere.

In der Schleimhaut dieser „Hinterzunge“ gibt es eine Menge kleiner Papillen, auf denen je eine Geschmacksknospe (gk.) auflagert. Diese sind etwas höher als die Epithellage, was gleichfalls zu ihrer Hügelform beitrăgt. Umgeben von Deckzellen ist die Sinneshaare tragende freie Fläche recht breit. Sie sind somit ähnlicher den Geschmacksknospen der Săugetiere in ihrer Form, als den von $\mathrm{Merkel}$ (15), F. E. Schulze (24), Holl (11), Retzius (22) und anderen beschriebenen breiten Sinnesknospen der Zunge und Mundhöhle der Batrachier, und mehr denen der erwachsenen Salamander ăhnlich.

Ich habe die Verteilung der Sinnesknospen auf Textfigur 35, A mit schwarz eingetragen. ${ }^{1}$ ) Sie sind auf der ganzenOberflache der Hinterzunge " gleichmässig verteilt, genau bis dorthin, wo hinten die Schleimdrüsen aufhören und erstrecken sich auch zu Beginn der Kiemenbogen auf diese, wie denn bekanntlich auch auf die seitlichen Ab-

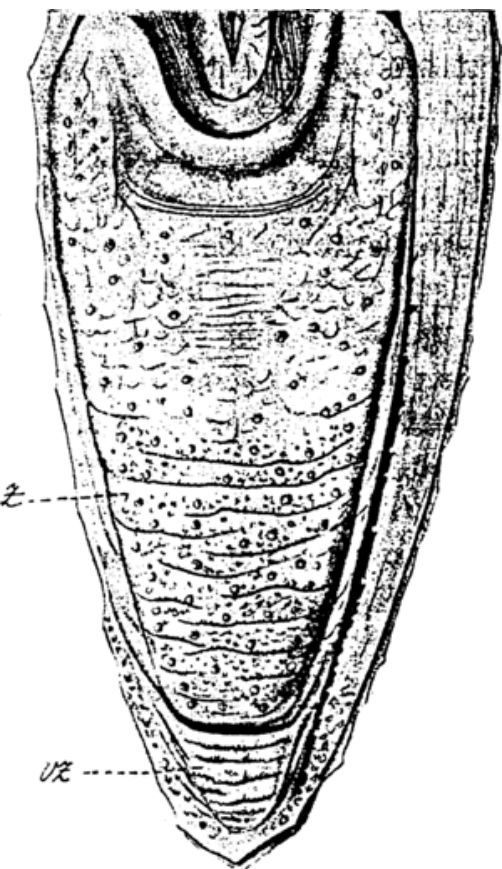

Fig. 36.

Zunge von Crocodilus sclerops von oben. $\mathbf{v z},=$ Vorderzunge, $\mathbf{z},=$ Zunge. schnitte der Mundhöhle.

Die Verteilung der Geschmacksknospen, abgesehen von jenen an verschiedenen anderen Stellen der Mundhöhle und Lippen, ${ }^{1)}$ Es kam dieses Bild auf die Weise zustande, dass, nachdem ich ciner gehärteten Larve den Unterkiefer samt dem Kiemenapparat abgetragen und mit Methylenblau gefärbt habe - das ja den Knorpel tief blau färbt -.., das so gewonnene Präparat in Xylol aufhellte und dann bei schwacher Vergrösserung mit der Camera zeichnete. In dieses Bild wurden dann nach Längs- und Querschnittserien die Geschmacksknospen eingetragen. 
sind bei den Reptilien im allgemeinen wegen manch eigenartigen Umbildungen der Zunge, wie auch bei den Vögeln, nicht mehr ursprünglich und gleichmässig verteilt. Nach Merkel (14) besetzen sie bei Anguis und Lacerta die Zungenspitze, weiter reichen sie nach hinten bei Chaloniern. Die am Mundboden ibrer ganzen Lănge nach angewachsene Zunge von Crocodilus sclerops (Textfig. 36, z.) ist vorne an ihrer Spitze durch eine Querfurche von einer Vorzunge (vz.) völlig getrennt. Ob letztere drüsigenBaues ist, weiss jch nicht. Thre Oberflăche besitzt Querfalten mit dichtem Papillensaum. Jedenfalls ist sie, wenn nicht analog, so doch homolog einer Vorzunge der Urodelenlarven und somit eine primäre Einrichtung.

Die Zunge zeigt in ihrer hinteren, breiteren und grösseren Hălfte eine rauhe Oberflache mit zahlreichen runden aber niedrigen Papillen, die nur in der Mitte fehlen. Diese reichen lateralwarts nicht ganz bis zum Pharynx und lassen die vorpharyngeale Umgebung, die aus einem halbringförmigen Faltensystem besteht, frei. Die vordere Zungenhalfte war quergefaltet und der Rand der Falten ausgekerbt, was von niedrigen Papillen herrührt. Auf den Falten sassen die niedrigen runden Papillen etwas dichter, und überall an der Zungenflăche, also an der hinteren Zungenhalfte. Ein guter Teil dieser Papillen ist durchlöchert von den Mündungen der Schleimdrüsen, die sich somit auf die ganze Zunge erstrecken. Die anderen zeigten diese Durchbohrung nicht. Trotz des wenig gut erhaltenen Materials verfertigte ich einige Schnitte, die ausser den Schleimdrüsen eben noch erkennen liessen, dass auf den nicht durchbohrten Papillen im Epithel Knoten waren, die auffallend Geschmacksknospen auch in ihrem defekten Zustande ähnlich sahen. Immerhin bin ich wegen ungeeignetem Material nicht in der Lage, hierüber Bestimmtes aussagen zu können. Dadurch, dass W. Barth (1) bei den Crocodilinen, gleich wie Botezat (4) und er bei Vögeln, zerstreute Geschmacksknospen jederseits seitlich an der Zungenwand gruppiert fand, ist damit noch nicht gesagt, dass sie nicht auch auf den von mil angegebenen Papillen auf der Zunge sich făden, denn Barth hat an jener Stelle gar nicht gesucht.

Jedenfalls ist diese Krokodilzunge geeignet dazu, um mit Berücksichtigung der "Hinterzunge" der Urodelenlarve die ursprüngliche Gestaltung der Zungenoberflăche der Săugetiervorfahren sich vorzustellen. 
Es wird diese Zunge ein einheitliches Gebilde gewesen sein, das aus den Zustanden der Urodelenlarvenzunge durch Verlangerung nach vorne wie bei dem Krokodil entstand. Es durchzogen die ganze Zunge die Schleimdrüsen, worauf nacb Oppels Untersuchungen heute noch Ornithorhynchus direkt hinweist, und die Sinnespapillen, primärste Pilzpapillen, verbreiterten sich auf die ganze dorsale Zungenschleimbaut. Seröse Drüsen fehlten noch.

Diese Auffassung deckt sich mit jener von Oppel (17, pag. 196) schon vor neun Jabren ausgesprochenen Anschauung, nach der aus vorher schon vorhandenen Geschmackspapillen durch sekundare Bildung von Eiweissdrüsen an denselben die Wallpapillen und das Randorgan sich entfalteten. „Er sieht in den Geschmacksdrüsen der Săuger ganz neue Erwerbungen, in den Geschmacksknospen tragenden Papillen der Säuger dagegen ältere, schon von niederen Wirbeltieren übernommene Bildungen." Hierin wären wir also gleicher Meinung. Anders in einem anderen Punkte. Oppel glaubt nämlich nicht, dass beutzutage Wallpapillen aus Pilzpapillen hervorgingen und zwar darum, weil Übergangsformen, als welche er Pilzpapillen mit spärlichen Geschmacksdrüsen betrachtet, vollständig fehlen. Dieser Einwand ist nun durch vorliegende Arbeit wohl behoben, liesse sich aber auch sonst noch wankend machen, durch den Einwand namlich, dass ja die Natur in ibrer Weiterentwicklung auch heutzutage nicht innehält und dann durch die begründete Tatsache, dass bei verschiedenen Individuen, so auch bei dem Menschen, die Zahl nicht nur der Wallpapillen, sondern auch die Grösse des Randorgans Schwankungen unterworfen ist, die doch auf Vermehrungen (oder auch Reduktionen) beruhen. Münch (16), der die Vermehrung der Wallpapillen entweder durch Teilung vorhandener oder durch Neubildung aus Pilzpapillen sich denkt, glaubt auch nur an eine embryonale Vermehrung, aber an keine postembryonale melı, oder halt letzteres für nicht erwiesen. Diese Auffassung ist nach dem schon bei den Huftieren Mitgeteilten nicht haltbar, denn bei jungen Individuen sind Übergangspapillen mit Drüsenanlage zu finden, nicht aber bei dem alten Tiere, wenigstens ist es mir da nicht gelungen. Ich glaube vielmehr, dass nach der Laktationszeit die Neubildung nach allen Modi kraftig einsetzt und da 
werden dann wohl andere Umstände schuld sein, die bei dem einen Individuum früher, bei dem anderen spater Halt gebieten. $\mathrm{Ob}$. dabei die Nabrung eine Rolle spielt, nehmen wir an, eine üppigere Weide beim Rind, die abwechselnden Nahrungsmittel eines Kulturmenschen, eines nur mit gewissen Volksnahrungsmitteln sich ernäbrenden wild oder halbwilden bis halbkultivierten Yolkes, das. sind Fragen, die nicht obne weiteres umgangen werden können. Zum Beispiel möchte ich nur anführen den äusserst feinen Geschmack für Weinsorten bei gewissen Leuten, der oft geradezu verblüffend wirkt und wozu die Vorbedingung im Geschmacksorgane gegeben sein muss, wenngleich die Übung unerlässlich ist. Sollte dann diese Übung des fachmannischen Weinversuchers nicht als Reiz gelten dafür, dass die Drüsenbildung und Teilungen der Wallpapillen einsetzen?

Ich übergehe diejenigen Autoren, welche die drüsenbesitzenden Papillen nicht aus anderen ableiten wollen, sie sind in dem grossen Werke 0 ppels und bei Becker ausführlich angeführt und möchte hier mit Beckers Ansichten mich etwas beschäftigen. Dieser Autor nimmt an, wie ich zu Begim dieser Schrift erwähnt habe, dass ausser dem Entstehen von Wallpapillen aus einer Pilzpapille, Wallpapillen auch aus melıreren Papillen verschiedener Art entsteben könnten, dafür glaube ich aber hat er den Beweis nicht erbracht. Es kann eine Wallpapille nach ihm auch aus der Vereinigung einer Fadenpapille mit einer Pilzpapille hervorgehen. So weit ich es ersehe, schliesst er dies daraus, dass an der oberen Fläche einer Wallpapille sich auch ein spitzer Fortsatz befinden kann, wie er es auf einem Schnitte auf seiner Fig. 13 abbildet. Allein dies beweist nichts, denn die freie Oberflache kann bei Wallpapillen oft zugespitzt enden, wie dies ja für das Rind auch: Becker abbildet (Fig. 54) und wie einen solchen mittelstandigen Fortsatz Oppel (18, Fig. 59) bei der Wallpapille von Manis javanica dargestellt bat. Es ist ja bekannt, dass die Oberfläche von Wallpapillen öfter uneben ist, $d . h$. viele kleine Wülste oder Hügelchen besitzt. Yit dem Abrücken der Sinnesknospen von der dorsalen Fläche der fertigen Wallpapille ist bei jenen das Tastvermögen eben nicht geschwunden und können sich somit sekundăr dort papillăre Bildungen einstellen.

Bezüglich der Pilzpapillen meint.Becker, dass je höher die umgebenden Fadenpapillen wărell, um so höher würden sich 
die dazwischen befindenden Pilzpapillen gestalten, da erstere ibnen Schutz gewähren. Trifft dieser Fall auch manchmal $z u$, so kann dies doch nicht verallgemeinert werden, ich verweise diesbezüglich auf die Zustände bei der Maus, bei der an der Zungenspitze doch niedrige Zahnchenpapillen sich befinden und die früher zwischen den hohen Papillen in das Epithel versunkenen Pilzpapillen aus ihrer früheren Lage sich hervorheben.

Überhaupt möchte ich auch den Wallgraben um die Wallpapille herum nicht als eine Schutzausrüstung betrachten, vielmehr als eine solche, die dazu dient, dem Sekret Raum zu schaffen und damit auch den aufgelösten, zur Perception gelangenden Stoffen. Gibt es doch ungeschützte Geschmacksknospen bei Amphibien (und bier noch dazu mit grosser freier Obertläche), Reptilien und Vögeln, wie ja, wie wir seit Botezat (4) nun wissen, letztere der Sinnesknospen auch nicht ermangeln. Freilich könnte dagegen eingewendet werden, dass mit dem Kaugeschäte der Saugetiere sich auch andere Zustinde einstellten, allein bei ihnen gibt es gerade genug völlig ungeschützte Pilzpapillen. Ibr ScLutz liegt dann vielmebr in der ursprünglich nur temporaren, spater bleibenden Versenkung derSinnesknospe, wodurch der bleibende Toldtsche Kanal zustande kommt.

Richtig ist es ja jedenfalls, dass der Zungenriicken vielfach, und dies gilt besonders dort, wo das Kauen stark einsetzt, oder doch das zweite Zungenfeld, wo öfter das Tuberculum sich entfaltet, von Pilzpapillen frei bleibt, allein hier handelt es sich um viel stärkere Druckwirkungen.

Ferner möchte ich bemerken, dass aus einer Fadenpapille nie eine Pilzpapille hervorgehen kann; wie dieses Becker bewiesen zu haben glaubt (l. c. pag. 588), und zwar aus dem triftigen Grunde nicht, weil ersterer die Sinnesorgane fehlen, ganz abgesehen von den ursprünglichen Zuständen.

Damit möchte ich wieder zurüicklsommen auf jenen hypothetischen Zustand der Zungenoberflăche der Săugetierzunge, in welchem der Zunge noch Wallpapillen und das Randorgan fehlten und ausser den mechanischen Papillen und den Schleimpapillen nur Pilzpapillen als die einzigen Träger des Geschmackssinnes eigen waren. 
Das Entstehen von Wallpapillen aus solchen braucht hier nunmehr nicht mehr erörtert zu werden, bloss ihre urspriing liche Zahl und dann die Phylogenese des Randorganes.

Oppel meint, ,jede Anknüpfung an die Verbältnisse bei niederen Vertebraten fehlt zur Zeit noch für die grössere Geschmacksknospen tragenden Papillen, wie die Papillae vallatae und foliatae" (17, pag. 166). Dies ist aber auch nicht zu erstreben, denn so eine Anknüpfung kann durch diese, speziell für die Säugetiere zur Zeit geltenden hohen Bildungen nicht gefunden werden, sondern wir müssen die mit Geschmacksknospen versehenen, aber der serösen Drüsen noch ermangelnden Pilzpapillen zur Verknüpfung heranziehen und dies ist jedenfalls möglich. Hier kämen dann in erster Linie jene Pilzpapillen der Săugetiere in Betracht, die nur eine Geschmackspapille haben.

Solche sind durch die Erhebung der nächsten Umgebung einer Sinnesknospe der Zunge eines Amphibs ganz gut denkbar und tatsăchlich sind schon seit Leydig her Papillen von pilzförmiger Gestalt auf dem hinteren Zungenabscbnitt der Anuren bekannt und in neuerer Zeit durch Holl (11) wieder genauer beschrieben worden. Wir werden dann bei einem StegocephalenAhnen der Säugetiere diese so gleichmăssig auf der Zunge uns verteilt denken müssen, wie sie sich bei Crocodilus sclerops heute noch finden.

Ein Teil dieser Papillen blieb denn auch bei dem niedersten Säugetier auf dieser niedrigen Stufe als ihre Pilzpapillen, indessen die übrigen in der hintersten Zungengegend sich mit Erwerb der serösen Drüsen zu höheren Funktionăren der Geschmacksempfindung gestalteten. Bezüglich der Randorgane, deren Phylogenese noch erörtert werden soll, ist die ursprünglich paarige Anlage entschieden und nur bezüglich der Wallpapillen ware hier eine Frage zu erörtern, ihre Umformung aus Pilzpapillen als erledigt betrachtend.

Die Monotremenzunge zeigt sehr viel eigenartig Erworbenes und vieles in ihrer Anatomie, was die beiden rezenten Vertreter zweien Endåsten zuweist. So zeigt auch ihre Zunge dies Verhalten, allein in einem Punkte sind sie sich bezüglich der Zungenschleimhaut gleich und wenn zwei sonst auseinander liegende Formen einer Abteilung in einem Punkte übereinstimmen, dann können wir diesen als ein gemeinsames Erbe, somit als etwas 
Primăres auffassen. Sie haben beide nicht nur paarige Randorgane, sondern auch paarige Wallpapillen. Diese sind ursprünglich, denn sie sind auf ihrer ganzen Flache mit Geschmacksknospen überzogen, wie es ihr Werdegang in der Phylogenie erfordert und wie dies die Ontogenie heute noch (bei jungen Säugetieren) wiedergibt.

Bezüglich dieses Punktes glaube ich somit von keiner Seite auf Widerspruch zu stossen. Die Wallpapillen sind ursprïnglich parig und ihre Dreizahl, womit eine neue Ära für die gesamten Säugetiere mit den Marsupialiern einsetzt, ist diesbezüglich jüngerer Erwerb.

Hieran soll weiter unten angeknüpft werden, doch zuvor möge die Phylogenie des Randorganes besprochen werden.

Die Auffassung, dass das Randorgan aus nebeneinander gelegenen Wallpapillen durch deren Verwachsung sich entfaltete, dürfte von vielen schon angenommen worden sein.

Dieser Auffassung gegenüber sind zwei andere zu nennen, die Poultons und Gmelins, nach welcher die Randorganelemente mit Geschmacksknospen versehene Drüsenausführungsgänge seien. Diese Auffassung bedarf kaum einer Widerlegung. Die andere rührt von Becker her.

Zum Ausgange seiner Auffassung diente Becker das Randorgan des Schweines, wobei er aber bloss die. rudimentären Teile desselben in Betracht zog. Darnach würde sich das Randorgan nicht aus vorgebildeten Wallpapillen entfalten, , sondern sich bilden, indem über ein Eiweissdrüsenfeld das Oberflächenepithel in die Tiefe dringt, um mit den Ausführungsgăngen der serösen Drüsen in Verbindung zu treten. Durch den Druck des Drüsensekretes spaltet sich dann das Epithel, die obersten Zellschichten der Wand der entstehenden Rinne werden abgeplattet, und in demselben Maße, wie dies von der Tiefe nach der Oberflache fortschreitet, lagern sich in die den Selkretstrom umgebenden Epithelmassen der Grabenwand Geschmacksknospen ein " (1. c. pag. 605). Ferner sagt Becker, diese vermeintliche "Bildung des Randorganes beim Schwein beweist, dass die Entstehung eines Geschmacksorganes nicht von dem Torhandensein wahrer Papillen abhăngig ist, sondern sich überall da bilden kann, wo seröse Drüsen sich entwickeln, und dass diese Drüsen demnach nicht, 
wie Oppel annimmt, in Abhängigkeit, d. h. als ein Produkt von Papillen entstehen, sondern als selbständige Gebilde unabhängig von bestimmten äusseren Reizen".

Vor allem betrachten wir einmal das Randorgan dort, wo es sich am ursprünglichsten zeigt, also bei den Monotremen. Nach Oppel (18) besteht das einzige Randorganelement bei Ornithorhynchus aus einer einzigen, wenig tief versenkten runden Papille mit Geschmacksknospen auf ibrer lateralen Fläche, in dem Graben mit Mündungen seröser Drüsen. Bei Echidna finden sich links fünf, rechts drei solcher "Geschmackspapillen". Sie liegen oberflächlicher als die Wallpapillen, was doch keinen grundsätzlichen Unterschied bedeutet. Es handelt sich hier somit um Einzelpapillen mit Grabenring und dadurch unterscheiden sie sich wesentlich vom Randorgan anderer Süugetiere. Nichts spricht aber besser für die Einzelpapillennatur als die Abbildung des der Beschreibung beigegebenen Schnittes (Fig. 18).

Bezüglich der Ontogenese des Randorganes sind, soweit mir bekannt, ausser den F. Hermannschen Angaben (10) keine weiteren da. Nach diesen Angaben sind es nebeneinander gelegene Epithelleisten die ersten Anlagen, deren beide Ränder allmählich in das bindegewebige Stroma einzumünden beginnen, in Form von Zapfen, wie ich hinzufügen möchte. Es sind dies die ersten, noch soliden Anlagen der serösen Drüsen, wie sie für die Ontogenese der menschlichen Wallpapillen auch Graberg (30) gefunden hat.. Indem sich nun die die Leisten begrenzenden Furchen zu vertiefen beginnen, erhalten die soliden Drüsenanlagen Lumina und münden in jenen Graben. Der erste Zustand gilt für Embryone von $70 \mathrm{~mm}$ Länge. Ich habe nun über diese Anlage solcher Kaninchen-Embryonen der Richtung der Leisten nach Schnitte geführt, also Querschnitte durch den Embryo, und finde, dass in diesem Stadium die Leisten durch Querfurchen in sieben bis neun Partien abgegrenzt sind, doch schwinden diese sehr seichten Querfurchen schon bei Embryonen, die etwa $80-85 \mathrm{~mm}$ messen.

Diesen Befund halte ich für die Erklärung des Randorganes vom Kaninchen und Hasen von einiger Bedeutung, denn er zeigt, dass die einzelnen Leisten, (deren Querschnitt bekanntlich auch bei dem erwachsenen Tiere einer Wallpapille völlig ăhnlich ist, und sa ein Querschnitt durch die Reihen, - 
also sagittal zur Zungenlangsachse - einer Zahl von fest nebeneinander gelegenen Wallpapillert völlig ähnlich ist), des $R$ andorganes aus serial angeordneten Wallpapillen abzuleiten sind. Damit würde aber der Zustand bei den Monotremen eine andere Erklärung finden als Oppel meint, der jenen Zustand für sekundäl halten geneigt ist. Die primäen Pilzpapillen ordneten sich, soweit nicht wie bei Ornithorhynchus bloss eine jederseits für die Bildung des Randorganes Verwendung fand, bei dem Săugetierzunge in eine Reihe (Echidna) oder in nebeneinander verlaufenden Reihen wie bei den Hasen und wurden zu Wallpapillen. Dieser Zustand ist uns rezent nur bei Echidna zur Stunde bekannt.

Aus solchen Papillenreihen wäre somit das Randorgan entstanden, wofür noch die Ontogenie, soweit sie bekannt, auch Beweise liefert. Allein dabei bleibt es nicht. Entlang jeder Papillenreihe bildet sich eine mediane Furche, die sich mit der der benachbarten Reihe an dem geschlossenen Ende der Spalten vereinigt und so die Elemente des Randorganes einander gegenïber markiert (Fig. 8, e, e'). Jedes Randorganelement bildet sich somit von den beiden dem Graben $z u$ gekehrten Seiten zweier benachbarter, verwachsener Papillenreihen (Textfig. 29, g.) und entspricht somit nicht einer Papille (p.).

Der einheitliche Zusammenhang eines Elementes spricht sich dann darin aus, dass bei Abtrennung von Randorganeinheiten stets ein solches sich von der Reihe abhebt (Textfig. 7, A). Bei starken Redulitionen kann sich ein halbes Element erhalten wie bei Erinaceus (Textfig. 13) oder ein oder mebrere ganze. Entweder vertieft sich der Graben sehr, womit die Höbe der Geschmacksknospen zunimmt, im Falle keine Rückbildung des betreffenden Elementes sich einstellt oder es vereinigen sich zwei Elemente miteinander, wie u. a. manchmal beim Schwein und im einzigen Element der Musteliden (Textfig. 19). Man könnte in diesem Falle dann von sekundarien Elementen sprechen.

Eine einzige Geschmacksknospe ausserhalb der Spalte (Textfigur $7, \mathrm{~B}$, es.) würde als Überbleibsel auf der ursprünglichen Papille zu deuten sein.

Sind diese phyletischen Zustände auch einleuchtend, so bleibt doch noch ein Punkt unklar, nämlich jener betreffs der 
Vermehrung der Randorganelemente, wie sich dies bei manchen Nagern (Hyrax) und dann in der ganzen Reibe der Simier zeigt. Wie entstehen neue Elemente, etwa aus Pilzpapillen? Diese Frage wird wohl durch die Verfolgung der Ontogenese bei irgend einer Affenart zu beantworten sein.

Hier möchte ich noch auf jene Frage zu sprechen kommen, wie verhalt sich die Grösse des Randorganes zur Wallpapillenzunahme. Werfen wir einen Blick auf die einzelnen Saugetierabteilungen. Bei den Monotremen gibt es nur ein Paar Wallpapillen und ein primärstes Randorganpaar. Die Marsupialier zeigen schon eine Zunahme. Die Zahl der Wallpapillen hat um eine unpaare, der zentralen, zugenommen, denn die Zweizahl der Wallpapillen als ursprünglich anzunehmen, dafür lıaben wir einen triftigen Grund. Nicht den etwa, dass die Monotremen solches aufweisen, sondern weil konzentrierte Sinnesorgane sich bei allen Bilaterien dieser Bauart nach verhalten, wie dafür ja auch die Paarigkeit der Randorgane spricht. Die Dreizahl der Wallpapillen ist für die Masupialier geradezu kennzeichnend.

Bezüglich des Randorganes zeigen sich verschiedene $\mathrm{Zu}$ stände, denn wăhrend Phalangista, Didelphys, Belideus u. a. hochentwickelte, d.i. Elemente aufweisende Randorgane haben, können bei anderen solche angeblich fehlen, wie bei Phascolomys, jedenfalls aber sehr reduziert sein, beziehentlich ursprüngliche Zustände aufweisen wie bei Aepyprimnus, Phascolactos, Sminthopsis. Da bei Halmaturns allem Anschein nach reduzierte Zustande bestehen, können wir behaupten, dass sowohl Fortschrittliches wie Rückschrittliches hier das Randorgan bei gleichbleibender Wallpapillenzahl aufweist.

Die Pilzpapillen zeigen eine gleichmassige Anordnung und reichen nach hinten bis an die Wallpapillen und dem Randorgan herum, auch letzterem vielleicht zur weiteren Vermehrung dienend.

Die Chiropteren zeigen entweder den Urzustand bezüglich der Wallpapillen, deren Zahl bei den Mikrochiropteren zwei beträgt, oder des fortschrittlich dreizahligen, der den jüngeren Formen unter ihnen, den Makrochiropteren zukommt, indessen die Randorgane auf einer beginnentlichen Mittelstufe stehen bleiben und die Mikrochiropteren auch hierin sich ursprünglicher erweisen. Bezüglich der Pilzpapillen zeigt sich jetzt zuerst eine reihen- 
weise Anordnung, wobei die Zungenspitze einen reichen Besatz vor ihnen aufweist. Eine sinnespapillenlose hintere Zungenfläche ist nur bezüglich der Marsupialier neu, indessen das Vorderfeld bezüglich der mechanischen Papillen einen Neuerwerb bei Pteropus aufweist, der bei der Ergreifung der Nahrung Dienste leistet und schon bei. Ornithorhynchus sich in anderer Weise zeigt und in jeder Abteilung der Säugetiere sich einstellen kann, mit Ausnabme der Ungulaten.

An die $\mathrm{Cbiropteren} \mathrm{schliessen} \mathrm{sich} \mathrm{auch} \mathrm{bezüglich} \mathrm{dieser}$ Zungenverhaltnisse die Insektivoren an und gleich wie bei den Fledermäusen kann der Dreier- oder Zweierzustand der Wallpapillen auftreten. Dabei ist das Randorgan auf ein Minimum reduziert, selbst den Marsupialiern gegenüber; indem sich nur die Hălfte eines Elementes jederseits erhält (Igel) oder vielleicht bei den anderen auch diese fehlt.

Die Zustande bei den Edentaten sind nur insofern von Wichtigkeit, als sich hier neben dem Urzustand von zwei Wallpapillen auch der Marsupialierzustand zeigt, aus der heraus sogar eine Vermehrung zum ersten Male einstellt bei Myrmecophaga jubata, damit aber schwinden die Randorgane vollständig.

Bei den Simiern zeigen sich Zustande, die in ihrer beginnentlichen Form an niedere Zustände der Marsupialier erinnern, mit drei Wallpapillen und einer geringeren Zahl von Randorganelementen und mit der Anordnung von Pilzpapillen. Aus diesem niederen Zustand dann mit den möglichsten Übergängen wird der Anthropoiden-Zustand mit vermehrter Wallpapillenzahl, welche die Dreieckanordnung durchgehends überall wahren, und mit einer grossen Zahl von Randorganelementen erreicht, wobei die Vermehrung beider nebeneinander eine Eigentümlichkeit der Gruppe ist. Gleiches gilt für den Menschen, bei dem aber das Randorgan variable Zustände aufweist.

Die Carnivoren zeigen ein Verhalten, das aber auch schon an diejenigen der Insektivoren erinnert, wobei eine grosse Gleichmässigkeit vorherrscht. Wie bei den Insektivoren reduziert sich ihr Randorgan, zwal weniger bei Plantigraden, aber vollständig bei den Felinen. Dabei zeigt sich das Bestreben, die Wallpapillen bis $\mathrm{zu}$ einem gewissen, sogar hohen Grade (Bär) in Simierart zu vermehren. 
Der seltene Zustand einer einzigen Wallpapille ist eine Eigentümlichkeit eines 'Teiles der $\mathrm{Nager}$, während die anderen entweder den Dreierzustand aufweisen oder die Zentralpapillen einbüssend, einen scheinbaren Monotremenzustand erreichen. Dabei zeigt sich die Konservierung des Randorganes nicht nur, sondern sogar eine bohe Entfaltung desselben bei Hystrix.

Die eigenartigste Umwandlung erfahren aber zweifellos die Ungulaten. Hier zeigt sich das Bestreben von niederen $\mathrm{Zu}$ ständen an die Zahl der Wallpapillen ins Ungeheuerliche zu vermehren, womit mit Einbusse der unpaaren Zentralpapille neue topographische Anordnung sich einstellt. Obgleich bei ihren Abnen, den Klippschiefern ein hochentfaltetes Randorgan besteht, tritt dieses allmäblich mit der Vermehrung der Wallpapillen zurück und verschwindet endlich ganz.

Trotzdem dürfen wir das Verschwinden der Randorgane nicht mit der Vermehrung der Wallpapillen in Verbindung bringen, wie dies unter anderen die Simier deutlich bezeugen.

Es kommen sicherlich den drei Sinnesorgangruppen, den Pilz- und Wallpapillen und dem Randorgan, drei verschiedene Geschmacksfunktionen $\mathrm{zu}$, worauf denn auch der Umstand hinzuweisen scheint, dass bei Omnivoren sich das Randorgan gut erhalt. Diese waren undifferenziert bei den Ahnen der Säugetiere in den Pilzpapillen vereinigt, von denen mit deren weiteren Entfaltung zu Wallpapillen and Randorgan sie sich in vervollkommneter Weise trennten. Hier wird sich das Experiment naturgemäss immer nur auf den Menschen beschränken müssen.

Ein sehr einfacher Versuch beweist dann deutlich, dass den beiden hinteren Geschmacksorganen, - vielleicht auch den Geschmacksknospen auf dem Kehldeckel - eine andersartige Geschmacksfunktion zukommt, als den Pilzpapillen.

Giesst man in zwei Becher, die den Inlaalt dem Auge entziehen, in einen Wein, den anderen ein gleich hochgradige AlkoholWassermischung, so wird der davon nichts Ahnende bei Berülrung der Flüssigkeiten mit der Zungenspitze nur den Alkohol herausfinden, den Wein aber erst erkennen, wenn er davon etwas auf den hinteren Zungenabschnitt gelangen lãsst. Becker gelangte dann zu gleichem Ergebnis, indem er den Pilzpapillen nur die 
Prüfung der festen und flüssigen Nahrungsmittel lässt, während er den Randorganen und den Wallpapillen, befähigt durch das Sekret der serösen Drüsen, gasförmige Schmeckstoffe wahrnehmen lăsst, also bei unserem Experiement flüchtige Öle.

Heidelberg im April 1909.

\section{Literaturverzeichnis.}

1. Barth, W.: Die Geschmacksknospen der Vögel und der Krokodile. Arch. f. Biologie (Berlin), Bd. 1, 1906.

2. Beclker, J.: Über Zungenpapillen. Jenaische Zeitschr f. Naturwiss., Bd. $43,1908$.

3. Beddard, F. E.: Notes upon the Anatomie of a Manatee etc. Proc. of the Zool. Soc. of London, 1897.

4. B otezat, E.: Geschmacksorgane und nervöse Endapparate im Schnabel der Vögel. Biolog. Zentralbl., Bd. 24, 1904

5. Brian, 0 .: Beiträge zur Kenntnis der Hornzähne auf der Zunge von Hystrix cristata. Morphol. Jahrb., Bd. 37, 1907.

6. Brü cher, C.: Verteillng und Anordnung der Geschmackspapillen auf der Zunge der Huftiere. Deutsche Zeitschr. f. Tiermed. u. vergl. Pathol., Bd. 10, 1884 (Inang.-Diss.).

7. Ehlers, E.: Beiträge zur Kenntnis des Gorilla und Schimpanse. Abt. d Königl. Gesellsch. d. Wiss. zu Göttingen, Bd. 29, 1881.

8. Gmelin: Zur Morphologie der Papilla vallata und foliata. Arch. f. mikr. Anat., Bd. 40, 1892.

9. Henle, J. : Handbuch d. system. Anatomie, Bd. 2, 1873.

10. Hermann, F.: Beiträge zur Entwicklungsgeschichte der Geschmacksorgane beim Kaninchen. Arch. f. mikr. Anat., Bd. 24. $188 \bar{j}$.

11. H o 11, M. : Über das Epithel in der Mundhöhle von Salamandra maculosa. Sitzungsber. d. Wiener Akad. d. Wiss., 3. Abt., Bd. 42, 1885.

12. H ö n i g s c h m i e d: Kleine Beiträge, betreff. die Anordnung der Geschmacksknospen bei den Süugetieren. Zeitschr. f. wiss. Zool., Bd. 47, 1888.

13. Derselbe: Ebendort, Bd. 29, 34, 1877, 1880.

14. Ludwig Ferdinand K. Prinz von Bayern: Zur Anatomie der Zunge. München 1884.

1.5. MerkeJ, F.: Über die Endigungen der sensiblen Nerven in der Haut der Wirbeltiere. Rostock 1880.

16. Münch, F.: Die Topographie der Papillen der Zunge des Menschen und der Säugetiere. Morphol. Arb., Bd. 6, 1896.

17. O p p e l, A.: Lehrbuch d. vergl. mikroskop. Anatomie d. Wirbeltiere, Bd. 3, Jena 1900. 
18. Derselbe: Über die Zunge der Monotremen, einiger Marsupialier and von Manis javanica. Semon's Zool. Forschungsreisen in Australien etc., Bd. 4, Lief. 15, 1899.

19. Parsons, F. G: On the Anatomy of Petrogate xanthopus etc. Proc. Zool. Soc. of London, 1896.

20. Poulton, E. B.: The Tongue of Perameles nasuta etc. Quarterly Journal of microscop. Sc., N. S., Vol. 23, 1883.

21. Derselbe: The Tongue of Ornithorhynchus paradoxus. Ibid.

22. Retzius, G.: Die Nervenendigungen in den Geschmacksorganen der Säugetiere und Amphibien. Biolog. Untersuch., N. F., Bd 4, 1892.

23. Rabl, H.: Notiz zur Morphologie der Geschmacksknospen an den Epiglottis. Anat. Anz., Bd. 11, 1896.

24. Schulze, F E.: Die Geschmacksorgane der Froschlarve. Arch. f. mikr. Anat., Bd. 6, 1870.

25. Tu c.kerman, F.: Observation of the structure of the gustatory organs of the bat (Vespertilio tabulatus). Journ. of Morphology, Vol. 2, 1888.

26. Derselbe: On the gustatory organs of Arctomys monax. Anat. Anz., 1889.

27. Derselbe: On the gustatory organs of Edentata. Internat. Monatsschr. f: Anat. a Phys., 1890.

28. Derselbe: On the gustatory organs of some of the Mammalia. Journ. of Morphol., 1 S 91.

29. Thomson, W.: Note on the viscera of Tarsipes. Stud. from the Museum of Zoology in University College Dundee, 1890.

30. Graberg, J.: Beiträge zur Genese des Geschnacksorgans des Menschen. Morphol. Arb., Bd. 8, 1898.

\section{Erklärung der Abbildungen auf Tafel XIX-XXI.}

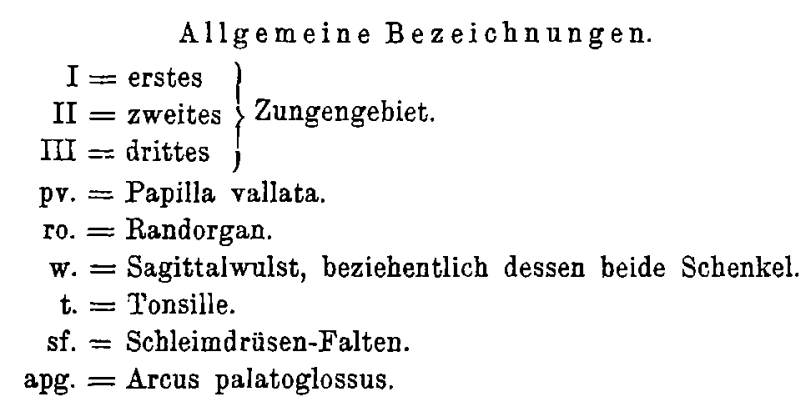

\section{Tafel XIX.}

Fig. 1. Sus scrofa. Hinterer Teil der rechten Zungenbälfte von oben.

Fig. 2. Su s scrofa. Eine grosse Wallpapille von oben.

Fig. 3. Mustela foina. Grenze zwischen drittem und viertem Zungengebiet ron oben. 
Fig 4. Mustela foina. Grosse Papillae fungiformes der Seitenreihe.

Fig. 5. Pteropus edulis (alter Fötus). Hinterer Zungenteil von oben.

Fig. 6. Schaf. Wallpapillen-Gruppe.

Fig 7. Schaff. Übergänge zwischen Pilz- und Wallpapillen.

Fig. 8. Macacus (spec.?). Auf dem Etikette der Sammlung: Simia macacus. Randorgan der linken Seite.

\section{Tafel XX.}

Fig. 9. Didelphys virginiana. Ganze Zunge von oben.

Fig. 10. Vesperugo noctua. Ebenso. Da die Pilzpapillen mit der Lupe nicht erkannt werden konnten, wurden sie schwarz nach Schnittserien eingetragen. Rot das Gebiet der serösen, blau das der Schleimdrüsen.

Fig. 11. Pteropus edulis (Fötus). Ebenso.

Fig. 12. Erinaceus europaeus. Ebenso. pf $=$ erste, pf $^{\prime}=$ zweite und $\mathrm{pf}^{\prime \prime}=$ dritte Pilzpapillenreihe.

Fig. 13. Mus musculus. Ebenso.

Fig. 14. Lepus timidus. Ebenso.

Fig. 15. Hystrix cristata. Hinteres Zungenende.

Fig. 16. Nasua socialis. Zunge von oben.

Fig. 17. Mustela foina. Zunge von oben und etwas rechts. $r=$ Rinne; Schleimdrüsengebiet blau, das der serösen Drüsen rot.

Fig. 18. Meles fossor. Hinteres Zungenende von oben.

\section{Tafel XXI.}

Fig. 19. Lutra vuIgaris. Ebenso.

Fig. 20. Hausschein. Zunge von oben.

rig. 21. Schaf (jung). Ebenso.

Fig. 22. Hepale penicillata. Hinteres Zungenende von oben.

Fig. 23. Lemur varius. Ebenso.

Fig. 24. Cercopithecus sabaeus. Ebenso.

Fig. 25. Semnopithecus entellus (Simia s. der Sammlung). Ganze Zunge ron oben.

Fig. 26. Satyrus orang. Ebenso.

Fig. 27. Homo. Ebenso. kp. = Koronalpapillen. 







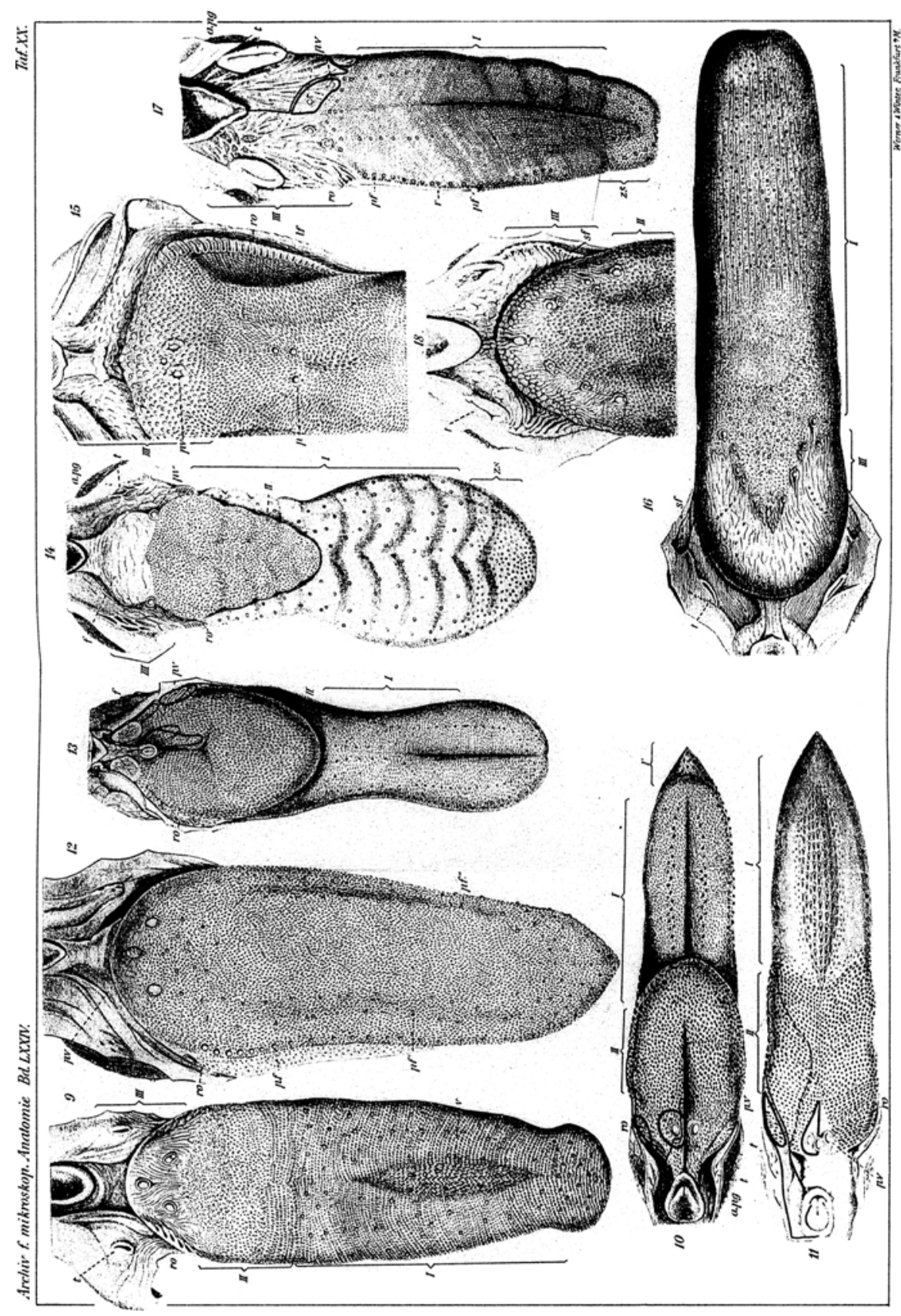




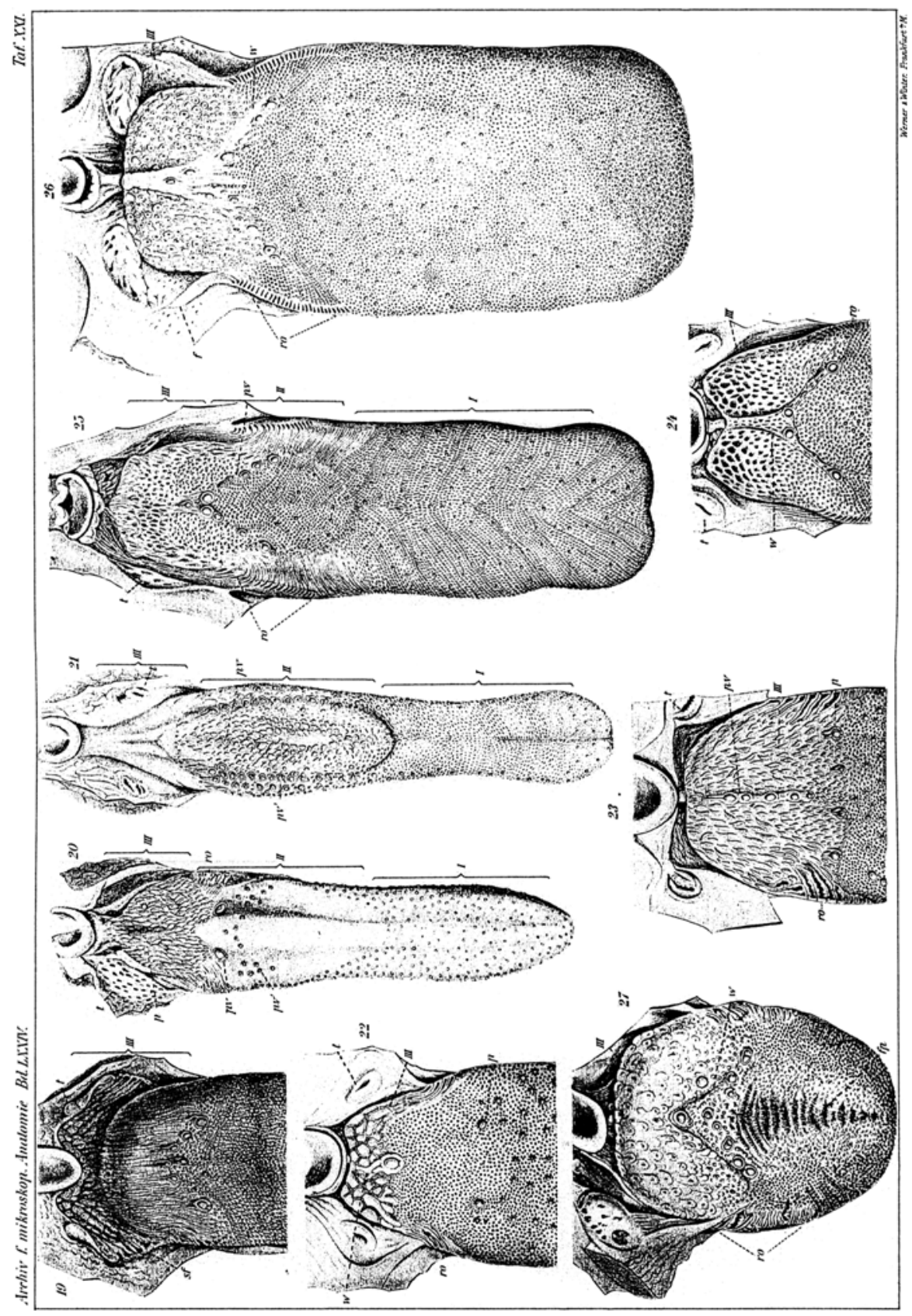

